RENATO PERES VIO

\title{
ALGORITMO IMUNE A VARIAÇÕES DE FREQÜÊNCIA APLICADO À PROTEÇÃO DIGITAL DE GERADORES
}

Dissertação apresentada à Escola Politécnica da Universidade de São Paulo para obtenção do Título de Mestre em Engenharia. 


\section{ALGORITMO IMUNE A VARIAÇÕES DE FREQÜÊNCIA APLICADO À PROTEÇÃO DIGITAL DE GERADORES}

Dissertação apresentada à Escola Politécnica da Universidade de São Paulo para obtenção do Título de Mestre em Engenharia.

Área de Concentração:

Sistemas de Potência

Orientador:

Prof. Dr. Eduardo César Senger 


\section{Vio, Renato Peres}

Algoritmo imune a variações de freqüência aplicado à proteção digital de geradores. São Paulo, 2005.

120p.

Dissertação (Mestrado) - Escola Politécnica da Universidade de São Paulo.

Departamento de Engenharia de Energia e Automação Elétricas.

1. Proteção de Geradores 2. Filtros digitais I.Universidade de São Paulo. Escola Politécnica.

Departamento de Engenharia de Energia e Automação Elétricas. II.t. 
A minha família que sempre me apoiou e incentivou em tudo que fiz. 


\section{AGRADECIMENTOS}

Ao meu orientador Prof. Dr. Eduardo César Senger, pelas diretrizes seguras e incentivo.

A minha esposa Jaqueline pelo incansável apoio.

A todos que direta ou indiretamente, colaboraram na execução deste trabalho. 


\section{RESUMO}

O objetivo deste trabalho é a investigação de um algoritmo adaptativo para compensação dos erros no cálculo dos fasores do sistema de potência quando há variações significativas na freqüência dos sinais de tensão e corrente.

O principal benefício desta técnica é permitir a compensação dos erros utilizando frequiência de amostragem e janela de dados constantes, possibilitando a construção de relés microprocessados para proteção de geradores com hardware mais simples.

O algoritmo adaptativo denominado AIVF (Algoritmo Inume a Variações de Freqüência) foi testado a partir de uma série de sinais com características como variação da freqüência da fundamental, componente exponencial amortecida e harmônicos, sendo os resultados apresentados no capítulo 4.4.

Além do AIVF, nos capítulos iniciais são apresentados aspectos inerentes à proteção de geradores como aterramento e uma descrição das principais proteções aplicáveis a geradores de até 50MVA. 


\begin{abstract}
The main pourpose of that work is inquire an adaptive algorithm to compensate the errors in the power system phasors calculation when occur significant changes in the frequency of the current and voltage signals.

The main benefit of that technique is to permit errors compensation with constant sampling frequency and constant data window, making possible construction of microcomputer relays for generator protection with simple hardware.

The adaptive algorithm named ANAFC (Algorithm Not Affected by Frequency Changes) was tested by some signals with characteristics like changes in the fundamental frequency, dc decaying and harmonics. The results are presented in the section 4.4.

Beyond ANAFC, in the initial sections are presented aspects regarding generator protection like earthing and a description of the main protection functions applied in generators till 50MVA.
\end{abstract}




\section{SUMÁRIO}

1. INTRODUÇÃO ................................................................................................... 13

2. PROTEÇÃO DE GERADORES .............................................................................. 15

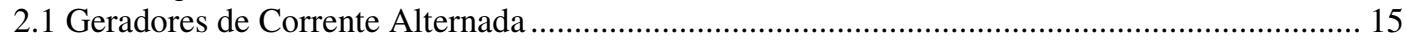

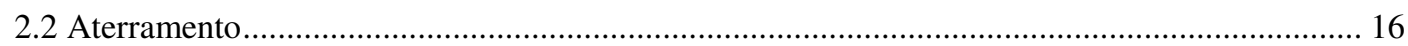

2.4 Principais Proteções Aplicáveis a Geradores ....................................................................... 25

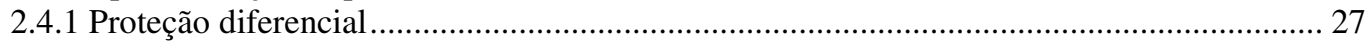

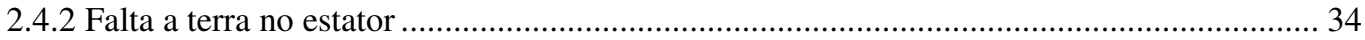

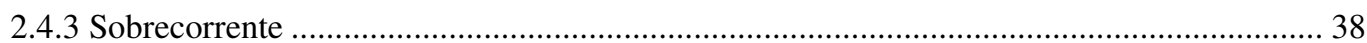

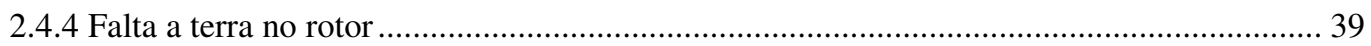

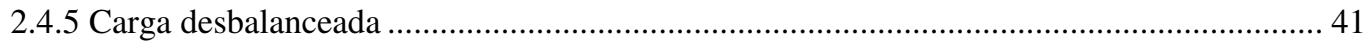

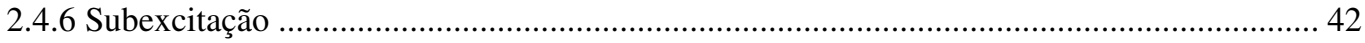

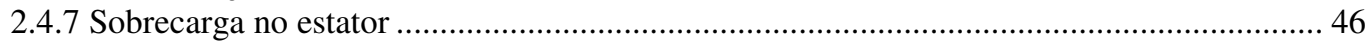

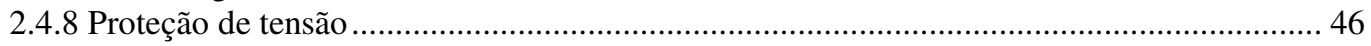

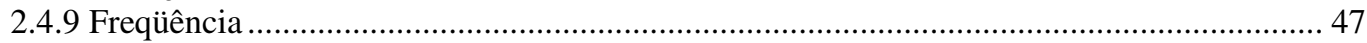

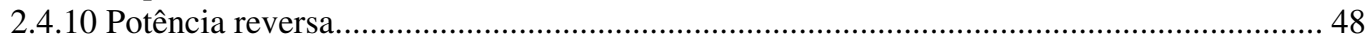

2.4.11 Funções Complementares..................................................................................... 48

3. PROTEÇÃO DIGITAL ............................................................................................ 51

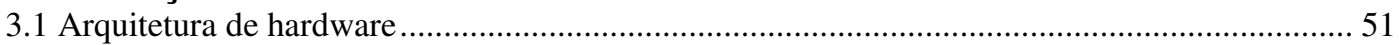

3.2 Processamento dos sinais do sistema de potência ................................................................... 53

4. ALGORITMOS DE PROTEÇÃO DIGITAL .......................................................... 55

4.1 Algoritmo de filtragem baseado no método de Fourier......................................................... 55

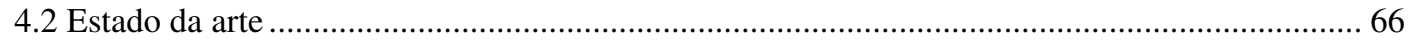

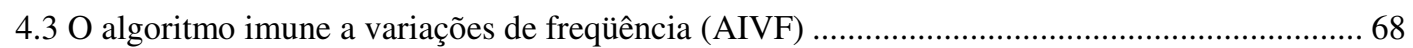

4.4 Simulações e Analise do Desempenho do AIVF.................................................................. 89

4.4.1 Comportamento frente a sinais não distorcidos........................................................ 89

4.4.2 Comportamento frente a componente exponencial amortecida e a harmônicos ................. 94

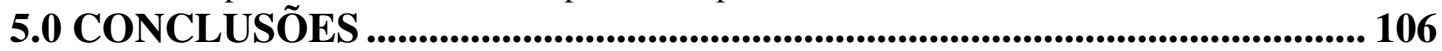

ANEXOS:

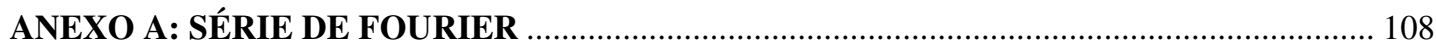

ANEXO B: MÉTODO DOS MÍNIMOS QUADRADOS ...................................................... 111

ANEXO C: COEFICIENTES DOS FILTROS UTILIZADOS............................................. 113 


\section{LISTA DE FIGURAS}

Fig. 1. Configurações típicas de plantas de geração (representadas intencionalmente sem aterramento): A) Unidade Transfomador-Gerador (UTG); B) Geradores em Barra Comum (GBC) e C) Geradores com alimentadores diretamente conectados a tensão do Gerador (GAG) .....

Fig. 2. Aterramento através de resistor: A) Aterramento através de transformador monofásico no neutro e resistor no secundário; B) Aterramento através de transformador de distribuição trifásico na configuração delta aberto no secundário com resistor e C) Aterramento através de resistor no neutro.

Fig. 3. Métodos de aterramento: A) Sistema isolado; B) Aterramento ressonante e C) Aterramento efetivo (sistema solidamente aterrado)...

Fig. 4. Proteção diferencial percentual: Princípio de funcionamento .......................................... 27

Fig. 5. Proteção diferencial percentual: Curto-circuitos internos ................................................ 28

Fig. 6. Característica de atuação da proteção diferencial percentual ............................................. 30

Fig. 7. Proteção diferencial de alta impedância: Princípio de funcionamento.................................. 32

Fig. 8. Proteção diferencial de neutro: Princípio de funcionamento ............................................. 33

Fig. 9. Proteção contra faltas a terra no estator para aterramento (d), (e) e (f): A) Aterramento através de transformador monofásico no neutro do gerador; B) Aterramento através de transformador trifásico nos terminais do gerador.

Fig. 10. Correntes para terra em uma planta GBC com aterramento através de transformador trifásico em conexão Y-Delta aberto.......................................................................................... 36

Fig. 11. Proteção contra faltas a terra no estator para aterramento (d), (e) e (f): A) Proteção diferencial de neutro; B) Proteção de sobrecorrente de neutro.

Fig. 12. Proteção contra faltas a terra no estator para sistemas isolados: A) Proteção de sobrecorrente com TC's em conexão residual; B) Proteção de sobrecorrente com TC de janela...................... 37

Fig. 13. Proteção de sobrecorrente com restrição de tensão (51V) ................................................ 38

Fig. 14. Dupla falta para a terra no enrolamento de campo......................................................... 39

Fig. 15. Proteção contra faltas no circuito do rotor (enrolamento de campo) ................................. 40

Fig. 16. Relés de distância utilizados para detectar perda de excitação .......................................... 43

Fig. 17. Proteção de subexcitação executada através da monitoração do fluxo de potência reativa .. 43

Fig. 18. Curva de Capabilidade de um gerador de 62MVA-14,4kV .......................................... 44

Fig. 19. Transformação da curva de capabilidade em diagrama de admitância ............................... 45

Fig. 20. Limites de operação, à plena carga ou carga parcial, em freqüências anormais (figura 6 de [15])...

Fig. 21. Representação de uma matriz de desligamento........................................................ 50

Fig. 22. Hardware típico de um relé digital para proteção de geradores ......................................... 51

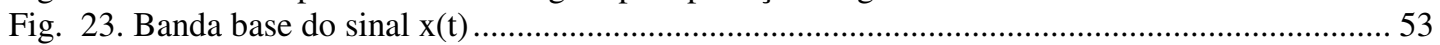

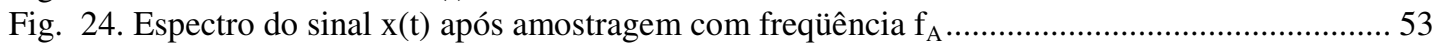

Fig. 25. Resposta em freqüência dos filtros Yc e Ys............................................................... 56

Fig. 26. Filtro analógico e seu efeito nos filtros Yc e Ys ........................................................... 57

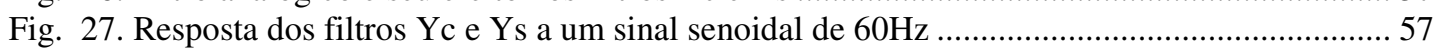

Fig. 28. Erro de amplitude para variação da freqüência do sinal entre 59 e $61 \mathrm{~Hz}$.......................... 59

Fig. 29. Erro de amplitude para variação da frequiência do sinal entre 59 e $61 \mathrm{~Hz}$ em função da freqüência

Fig. 30. Erro de amplitude para variação da freqüência do sinal entre 50 e $70 \mathrm{~Hz}$ em função da freqüência e fase do sinal .....

Fig. 31. Erro de amplitude para variação da freqüência do sinal entre 50 e 70 em função da freqüência do sinal

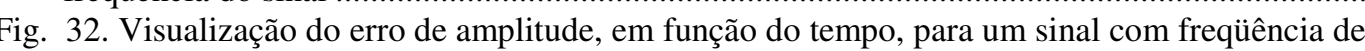
$50 \mathrm{~Hz}$.

Fig. 33. Erro de amplitude para variação da frequiência do sinal entre 20 e $70 \mathrm{~Hz}$ em função da freqüência e fase do sinal

Fig. 34. Erro de amplitude para variação da freqüência do sinal entre 20 e $70 \mathrm{~Hz}$, em função da freqüência do sinal

Fig. 35. Visualização do erro de amplitude, em função do tempo, para um sinal com freqüência de $30 \mathrm{~Hz}$.

Fig. 36. Visualização do erro de amplitude, em função do tempo, para um sinal com freqüência de $40 \mathrm{~Hz}$. 
Fig. 37. Estrutura geral do algoritmo

Fig. 38. Estimativa da freqüência de um sinal a partir da diferença angular de dois fasores consecutivos

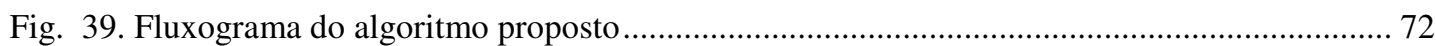

Fig. 40. Resposta em freqüência dos filtros Yc...................................................................... 77

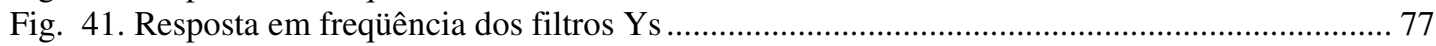

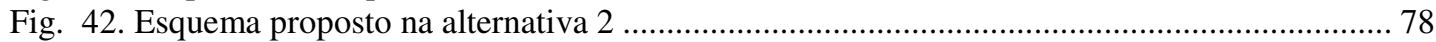

Fig. 43. Resposta em freqüência dos filtros Yc projetados para atenuar a componente exponencial, terceiro e quinto harmônicos ......................................................................................... 81

Fig. 44. Resposta em freqüência dos filtros Ys projetados para atenuar a componente exponencial, terceiro e quinto harmônicos

Fig. 45. Resposta em freqüência dos filtros Yc projetados para atenuar o terceiro e quinto harmônicos

Fig. 46. Resposta em frequiência dos filtros Ys projetados para atenuar o terceiro e quinto harmônicos

Fig. 47. Resposta em freqüência dos filtros projetados para atenuar a componente exponencial amortecida.....

Fig. 48. Resposta no domínio do tempo a um sinal característico de curto-circuito com fundamental de $40 \mathrm{~Hz}$ e componente exponencial amortecida. (a) Sem filtro para atenuar a componente exponencial amortecida; (b) Com filtro para atenuar a componente exponencial amortecida ..... 85

Fig. 49. Resposta em freqüência dos filtros Yc resultantes da utilização combinada do método dos mínimos quadrados e do filtro para atenuar a componente exponencial .................................. 86

Fig. 50. Resposta em freqüência dos filtros Ys resultantes da utilização combinada do método dos mínimos quadrados e do filtro para atenuar a componente exponencial ................................... 86

Fig. 51. Resposta em freqüência dos filtros Yc projetados para atenuar o segundo, terceiro e quinto harmônicos

Fig. 52. Resposta em frequiência dos filtros Ys projetados para atenuar o segundo, terceiro e quinto harmônicos

Fig. 53. Variação de freqüência nos utilizada para gerar os sinais de teste deste capítulo ................. 89

Fig. 54. Sinal de teste com variação linear de frequiência e amplitude constante.............................90

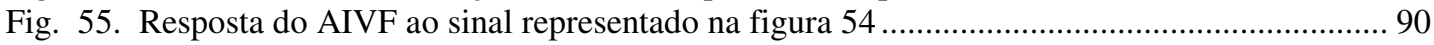

Fig. 56. Comportamento de filtros calculados somente para $60 \mathrm{~Hz}$ ao sinal da figura $54 . . . \ldots \ldots \ldots \ldots . . . . .91$

Fig. 57. Sinal de teste com variação linear de freqüência e variação da amplitude em degraus ........ 92

Fig. 58. Resposta do AIVF ao sinal representado na figura 57 ............................................... 92

Fig. 59. Comportamento de filtros calculados somente para $60 \mathrm{~Hz}$ ao sinal da figura $57 \ldots \ldots \ldots \ldots \ldots . . . . .93$

Fig. 60. Forma de onda teste com fundamental de $40 \mathrm{~Hz}$ e componente exponencial amortecida ..... 94

Fig. 61. Resposta do AIVF ao sinal representado na figura 60 .............................................. 95

Fig. 62. Resposta do AIVF ao sinal representado na figura 60 adicionado de $20 \%$ do terceiro e quinto

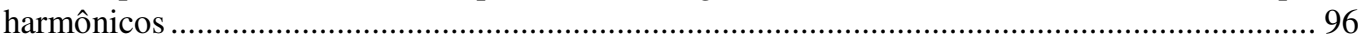

Fig. 63. Resposta do AIVF ao sinal representado na figura 58 adicionado de $5 \%$ do segundo harmônico

Fig. 64. Forma de onda teste com fundamental de $60 \mathrm{~Hz}$ e componente exponencial amortecida ..... 98

Fig. 65. Resposta do AIVF ao sinal representado na figura 64 .................................................. 98

Fig. 66. Resposta do AIVF ao sinal representado na figura 64 adicionado de $20 \%$ do terceiro e quinto harmônicos ....

Fig. 67. Resposta do AIVF ao sinal representado na figura 64 adicionado de $5 \%$ do segundo harmônico

Fig. 68. Forma de onda teste com fundamental de $70 \mathrm{~Hz}$ e componente exponencial amortecida ... 101

Fig. 69. Resposta do AIVF ao sinal representado na figura 68 ................................................... 101

Fig. 70. Resposta do AIVF ao sinal representado na figura 68 adicionado de $20 \%$ de terceiro e quinto

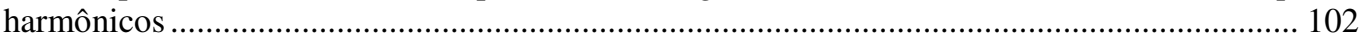

Fig. 71. Resposta do AIVF ao sinal representado na figura 68 adicionado de $5 \%$ de segundo harmônico.

Fig. 72. Reposta do AIVF a um curto-circuito nos terminais do gerador, com fundamental de $50 \mathrm{~Hz}$

Fig. 73. Reposta do AIVF a um curto-circuito nos terminais do gerador, com fundamental de $50 \mathrm{~Hz}$ e componente exponencial amortecida 


\section{LISTA DE TABELAS}

Tabela 1. Classificação das classes de aterramento (extrato de [10] ).

Tabela 2. Proteções recomendadas para geradores (o - opcional) ... 


\section{LISTA DE ABREVIATURAS E SIGLAS}

AIVF: Algoritmo Imune a Variações de Freqüência;

CC: Corrente Contínua;

CA: Corrente Alternada;

E2PROM: ROM regravável (Electrical Eraseble Programable ROM);

f: Freqüência;

fa: Freqüência de amostragem;

fo: Freqüência da onda fundamental;

GBC: Geradores em Barra Comum;

GAG: Geradores com Alimentadores diretamente conectados a tensão do Gerador;

L: Indutor;

n: amostra;

$\mathrm{N}$ : Número de amostras em um ciclo da fundamental;

P: Potência ativa;

p.u. : valores por unidade;

Q: Potência reativa;

R: Resistor;

ROM: Memória somente de leitura (Read Only Memory);

RAM: Memória de acesso aleatório (Random Acess Memory);

S: Potência aparente;

S/H : Circuito "Sample-Hold";

T: Período de certo sinal;

Ta: Período de amostragem;

TC: Transformador de Corrente;

TP: Transformador de Potencial;

To: Período da onda fundamental;

UTG: Unidade Transformador-Gerador;

Yc: Filtro digital baseado no método de Fourier (utiliza cosseno), ortogonal a Ys;

Ys: Filtro digital baseado no método de Fourier (utiliza seno), ortogonal a Yc. 


\section{LISTA DE SÍMBOLOS}

Ro: Resistência de seqüência zero;

Xo: Reatância de seqüência zero;

$\mathrm{R}_{1}$ : Resistência de seqüência positiva

$\mathrm{X}_{1}$ : Reatância de sequiência positiva;

Xd: Reatância síncrona;

Xd': Reatância transitória;

Xd": Reatância subtransitória;

Td': Constante de tempo transitória;

Td": Constante de tempo subtransitória;

Tg: Constante de tempo para decaimento da componente exponencial amortecida

Iestab: Corrente de estabilização (proteção diferencial);

Idif: Corrente diferencial;

$\mathrm{I}_{\mathrm{N}}$ : Corrente nominal;

$\mathrm{I}_{1}$ : Corrente de seqüência positiva;

$\mathrm{I}_{2}$ : Corrente de seqüência negativa;

Io: Corrente de seqüência zero;

$\mathrm{V}_{1}$ : Tensão de seqüência positiva;

$\mathrm{V}_{2}$ : Tensão de seqüência negativa;

Vo: Tensão de seqüência zero;

$\Delta \phi$ : Diferença angular entre dois fasores calculados a partir de amostras consecutivas; 


\section{INTRODUÇÃO}

Geradores podem operar fora da frequiência nominal em diversas situações e por tempos consideráveis. Durante a partida alguns tipos de geradores podem demorar vários minutos até atingir sua condição de freqüência nominal. Da mesma forma durante o desligamento (já desconectado da rede), a condição de operação fora da frequiência nominal é comum. Mesmo quando conectados ao sistema de potência, a operação fora da frequiência nominal pode ocorrer devido à instabilidades decorrentes da desigualdade entre potência gerada, cargas consumidoras e perdas, corrigidas freqüentemente por operações de rejeição de cargas e geração.

Embora a característica principal dos geradores seja fornecer energia a partir da tensão em $60 \mathrm{~Hz}$ a operação fora da frequiência nominal é comum e não deve ser desconsiderada.

Portanto é necessário que a proteção do gerador mantenha-se precisa e confiável mesmo que o gerador encontre-se operando fora da freqüência nominal.

Relés microprocessados utilizam técnicas de processamento digital para medição das grandezas do sistema elétrico de potência. Um dos elementos principais desse processamento são os filtros digitais.

A classe de filtros digitais comumente utilizados nos algoritmos de relés digitais para determinação de fasores é baseada no método de Fourier, o qual caracteriza-se por ser bastante afetado por variações na frequiência da forma de onda analisada, pois são projetados considerando um número constante e inteiro de amostras por ciclo. Quando há variações na freqüência do sinal, erros consideráveis são introduzidos nos resultados.

Relés digitais multifunção com grande penetração no mercado como dos fabricantes Siemens [1], GE [2], SEL [3] e Alstom [4] utilizam freqüência de amostragem variável de forma a manter constante o número de amostras por ciclo para toda sua faixa de atuação (geralmente de $20 \mathrm{~Hz}$ a $70 \mathrm{~Hz}$ ). Esta solução utiliza uma estimativa da frequiência do sinal através de software e a partir daí varia a frequiência de amostragem do sinal mantendo, assim, constante o número de amostras por ciclo $[5,6]$. 
Estes relés necessitam de hardware especialmente desenvolvido para comportar mudanças na frequiência de amostragem do sinal exclusivamente para aplicações em geradores, aumentando seu custo.

O desenvolvimento de um filtro adaptativo (software) que possa compensar os erros causados pela variação da freqüência do sinal é desejável, pois permite o emprego de um hardware mais simples (freqüência de amostragem constante) na fabricação de relés para geradores.

Neste trabalho serão apresentados os fundamentos desta técnica, bem como uma descrição das principais funções de proteção recomendadas para geradores de até 50MVA. Além disso, serão discutidos os principais sistemas de aterramento aplicados à plantas de geração de energia elétrica. 


\section{PROTEÇÃO DE GERADORES}

\subsection{Geradores de Corrente Alternada}

A maior parte da energia elétrica consumida mundialmente é produzida por geradores síncronos. Para grandes centrais geradoras, a opção por máquinas síncronas é quase que direta devido à algumas de suas características que são:

- A frequiência da tensão induzida é determinada pela velocidade de rotação do rotor, imposta pela turbina (máquina primária);

- O sistema de excitação permite o controle da tensão e da potência reativa do gerador.

Com isto tem-se flexibilidade e controle do sistema de geração.

Em sistemas alternativos de geração de energia, como fazendas de vento [7], energia das ondas marítimas [8] e pequenas centrais hidrelétricas [9], quando operam em paralelo com o sistema de potência, a utilização de geradores assíncronos (máquinas de indução) vem ganhando espaço devido a algumas das características destas máquinas, que são:

- Esquema simples de excitação (não necessidade de fontes externas);

- Sem escovas (rotor gaiola);

- Robusto (baixa manutenção);

- Relação W/kg alta;

- Proteção intrínseca contra curto-circuitos (colapso da excitação).

Os reativos necessários à produção do campo estatórico podem ser fornecidos pelo sistema de potência ou por capacitores instalados na planta de geração, a frequiência e módulo da tensão gerada são ditados pelo sistema de potência (rede interconectada). Esta é uma opção extremamente interessante para trabalhar com turbinas ou sistemas com velocidade variável, pois estas variações se refletem apenas no montante de energia gerada, desde que a velocidade se mantenha acima da velocidade síncrona da máquina.

Neste trabalho maior atenção será dada à proteção de geradores síncronos por ser mais completa (abranger um maior número de funções de proteção).

Daqui pra frente, quanto não mencionado contrário, a expressão gerador refere-se a um gerador síncrono. 


\subsection{Aterramento}

A escolha do aterramento para determinada planta de geração de energia elétrica é de suma importância pois, como visto a seguir, o método de aterramento interfere nas características das faltas para terra, isto é, alguns sistemas de aterramento impõem sobretensões severas, outros altas correntes de falta para a terra. Logo a escolha das funções de proteção deve ser feita considerando o método de aterramento escolhido para a planta de geração.

O objetivo principal do aterramento de geradores é a proteção do gerador e equipamentos associados, contra danos causados por condições elétricas anormais. Os objetivos específicos de proteção são:

- Minimizar os danos devido a faltas internas para terra (antes do disjuntor do gerador);

- Limitar fadigas mecânicas no gerador devido à faltas externas;

- Limitar sobretensões temporárias e transitórias que comprometam a isolação do gerador;

- Permitir que o sistema de proteção contra faltas para terra detecte a condição anormal.

A um aterramento são designados dois atributos que são Classe e Método de aterramento. A classe de aterramento é definida, principalmente, através de relações entre as componentes simétricas do sistema; já o método de aterramento pode ser definido como a maneira com que se atinge a classe em questão, por exemplo:

- Aterramento através de resistor de baixa resistência

Método: Aterramento através de resistor (diretamente no neutro ou no secundário de um transformador);

Classe: Baixa resistência, definida conforme tabela 1. 
A escolha do método e classe de aterramento deve ser associada à configuração da planta de geração. Plantas de geração, por sua vez, podem ser divididas em três categorias que são:

- Unidade Transformador-Gerador (UTG): quando um único gerador é conectado diretamente a um transformador elevador delta-estrela com o enrolamento delta na tensão do gerador.

- Geradores em Barra Comum (GBC): quando dois ou mais geradores (não associados com a mesma máquina primária) são conectados à mesma barra através de seus respectivos disjuntores. A principal preocupação nesta configuração é estabelecer uma seletividade no desligamento, muitas vezes conseguida em detrimento à limitação da corrente de falta para terra.

- Geradores com Alimentadores diretamente conectados à tensão do Gerador $\underline{(\mathrm{GAG}):}$ nesta configuração alimentadores (de distribuição, subtransmissão, auxiliares etc) captam energia na barra do(s) gerador(es) à tensão do(s) gerador(es).
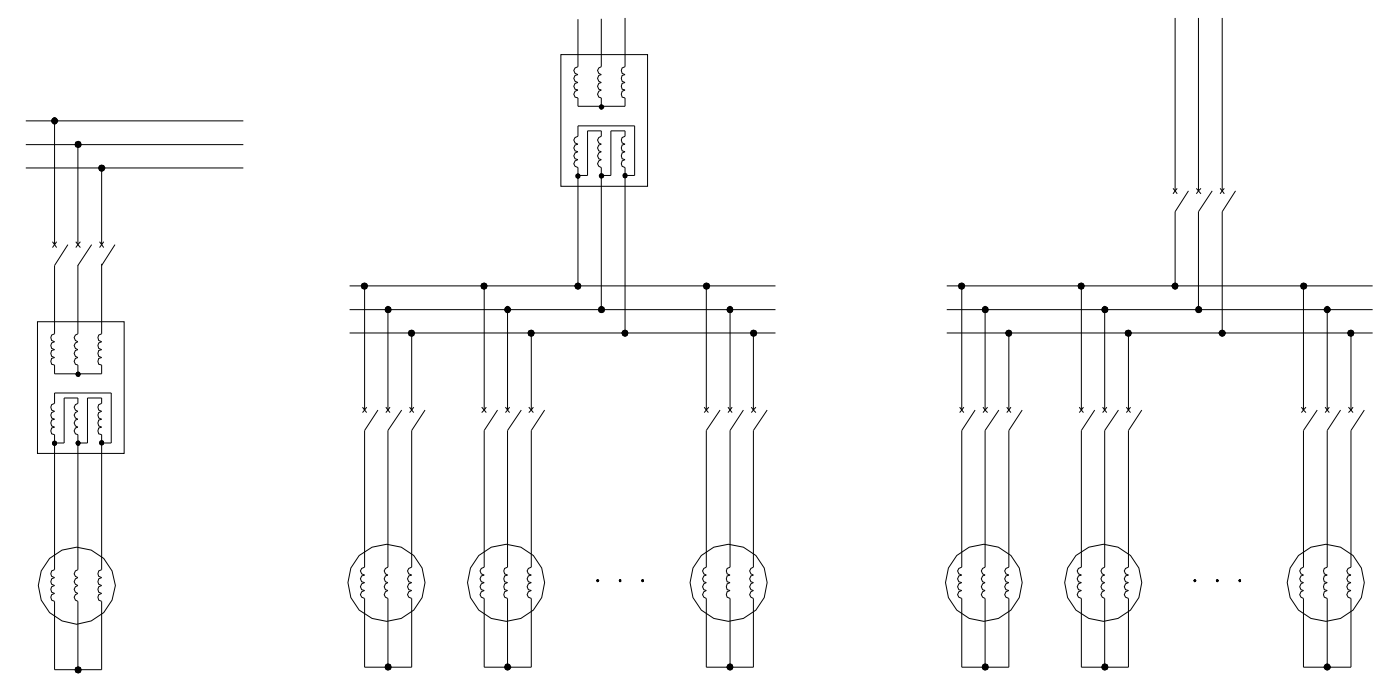

Fig. 1. Configurações típicas de plantas de geração (representadas intencionalmente sem aterramento): A) Unidade Transfomador-Gerador (UTG); B) Geradores em Barra Comum (GBC) e C) Geradores com alimentadores diretamente conectados a tensão do Gerador (GAG) 
Os principais métodos e classes de aterramento utilizados em geradores são:

- Aterramento efetivo (sistema solidamente aterrado);

- Aterramento através de reator de baixa reatância;

- Aterramento através de resistor de baixa resistência;

- Aterramento ressonante;

- Aterramento através de resistor de alta resistência;

- Sistema isolado.

Listados acima da menor para a maior sobretensão transitória durante faltas para terra.

Uma classificação mais rigorosa das classes de aterramento é baseada em relações entres os parâmetros das componentes simétricas, conforme tabela 1 [10].

\begin{tabular}{|c|c|c|c|c|c|}
\hline \multirow[t]{2}{*}{$\begin{array}{l}\text { Métodos e Classes } \\
\text { de aterramento }\end{array}$} & \multicolumn{3}{|c|}{$\begin{array}{l}\text { Relação entre os parâmentros } \\
\text { das componentes simétricas }\end{array}$} & \multirow[t]{2}{*}{$\begin{array}{c}\text { \% da corrente de } \\
\text { curto-circuito trifásica }\end{array}$} & \multirow[t]{2}{*}{$\begin{array}{l}\text { Tensão transitória em } \\
\text { valores por unidade }\left(^{\star}\right)\end{array}$} \\
\hline & $\mathrm{X}_{0} / \mathrm{X}_{1}$ & $\mathrm{R}_{0} / \mathrm{X}_{1}$ & $\mathrm{R}_{0} / \mathrm{X}_{0}$ & & \\
\hline \multicolumn{6}{|l|}{ a) Aterramento efetivo } \\
\hline 1. Aterrado & 0 a 3 & 0 a 1 & - & $>60$ & $\leq 2$ \\
\hline 2. Solidamente aterrado & 0 a 1 & 0 a 0,1 & - & $>95$ & $<1,5$ \\
\hline \multicolumn{6}{|l|}{ b) Aterramento não efetivo } \\
\hline \multicolumn{6}{|l|}{ 1. Através de reator } \\
\hline baixa reatância & 3 a 10 & $0 \mathrm{a} 1$ & - & $>25$ & $<2,3$ \\
\hline alta reatância & $>10$ & & $<2$ & $<25$ & $\leq 2,73$ \\
\hline \multicolumn{6}{|l|}{ 2. Através de resistor } \\
\hline baixa resistência & 0 a 10 & & $\geq 2$ & $<50$ & $<2,5$ \\
\hline alta resistência & & $>100$ & $\leq(-1)$ & $<1$ & $\leq 2,73$ \\
\hline 3. Ressonante & & & - & $<1$ & $\leq 2,73$ \\
\hline \multicolumn{6}{|l|}{ 4. Sistema isolado } \\
\hline faixa $A$ & $-\infty$ a -40 & & - & $<8$ & $\leq 3$ \\
\hline faixa $B$ & -40 a 0 & & - & $>8$ & $>3$ \\
\hline
\end{tabular}

Tabela 1. Classificação das classes de aterramento (extrato de [10] )

* Tensão transitória fase-terra, após aplicação repentina de uma falta, em p.u. tendo como valor base a tensão de pico fase-terra pré-falta. 
Para plantas de geração denominadas UTG, os seguintes métodos e classes de aterramento são geralmente utilizados:

1) Aterramento através de resistor de alta resistência: se caracteriza pela relação $\mathrm{R}_{0} / \mathrm{X}_{1}>100$ onde geralmente se limita a corrente de falta para a terra (estator para terra) numa faixa de $5 \mathrm{~A}$ a $15 \mathrm{~A}$. Basicamente três métodos de aterramento são aplicáveis a esta classe, que são:

- Aterramento através de transformador monofásico no neutro do gerador e resistor no secundário (fig. 2A);

- Aterramento através de transformador de distribuição trifásico na configuração delta aberto no secundário com resistor (fig. 2B);

- Aterramento através de resistor no neutro do gerador (fig. 2C).

O dimensionamento adequado do resistor é imperativo para reduzir sobretensões temporárias durante faltas para terra. O principal critério é permitir que durante faltas para a terra as perdas através do resistor sejam iguais à potencia capacitiva para a terra do sistema, compreendido entre o gerador e os enrolamentos de baixa tensão do transformador elevador.

Métodos empregando transformadores no neutro ou transformadores trifásicos com delta aberto são mais empregados, pois permitem a utilização de resistores de menor potência e isolação quando comparados à resistores aplicados diretamente no neutro de geradores.

Entretanto cuidados devem ser tomados em ambos os casos para evitar saturação no núcleo destes transformadores [11].

Como pontos positivos inerentes a esta classe e métodos de aterramento pode-se destacar:

- Fadigas mecânicas e danos devidos a faltas para terra são limitados devido à baixa corrente imposta;

- Sobretensões temporárias são limitadas a níveis toleráveis; 
Como pontos negativos pode-se destacar:

- Equipamentos de proteção contra surtos de tensão (pára-raios) devem ser dimensionados considerando a maior sobretensão temporária durante faltas para terra;

- Tempos para o desligamento podem aumentar significantemente.

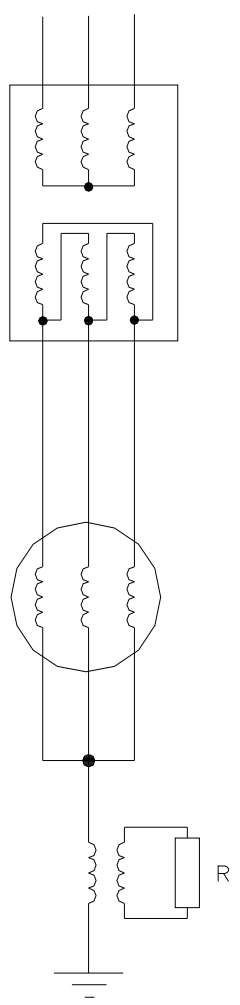

A)

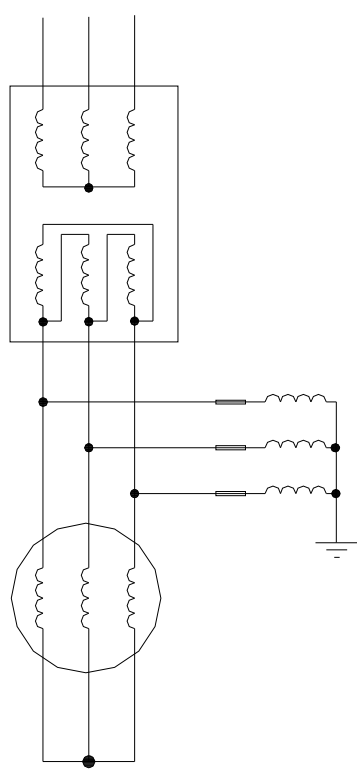

B)
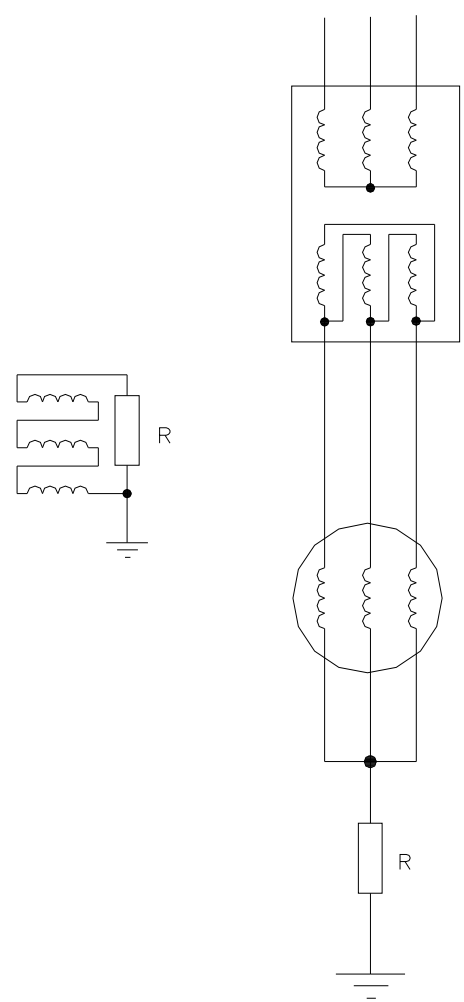

C)

Fig. 2. Aterramento através de resistor: A) Aterramento através de transformador monofásico no neutro e resistor no secundário; B) Aterramento através de transformador de distribuição trifásico na configuração delta aberto no secundário com resistor e C) Aterramento através de resistor no neutro. 
2) Sistema isolado: caracterizado por nenhuma conexão intencional para terra, exceto transformadores de potencial e pára-raios (fig. 3A); neste caso $\mathrm{X}_{0}$ é geralmente capacitivo e aproximadamente da mesma ordem de $Z_{0}$, enquanto $R_{0} / X_{0}$ é relativamente pequeno. As vantagens deste método são essencialmente as mesmas apontadas para o aterramento por alta resistência exceto o fato de que as sobretensões temporárias não são controladas ou limitadas. A desvantagem é a elevada sobretensão causada durante operações de chaveamento e faltas para terra, principalmente intermitentes.

3) Aterramento ressonante: caracterizado pelo aterramento através de um reator dimensionado para que, durante faltas para a terra, a corrente de falta que circula pelo reator e a corrente que circula através da capacitância para a terra do sistema (fases sãs) sejam aproximadamente iguais em amplitude mas defasadas de 180 graus elétricos, praticamente se cancelando. Este tipo de reator é geralmente chamado de "ground fault neutralizer", "arc-supression coil" ou bobina de Peterson ("Perterson Coil").

O método de aterramento geralmente empregado neste caso é a utilização de transformador monofásico instalado no neutro do gerador associado a um reator no secundário (fig. 3B) e como mencionado, o reator é selecionado para que quando referido à valores primários, sua reatância indutiva seja aproximadamente igual ao total da reatância capacitiva do sistema (compreendido entre o gerador e os enrolamentos de baixa tensão do transformador elevador).

Como pontos positivos inerentes à esta classe e métodos de aterramento pode-se destacar:

- Possibilidade de limitar a corrente de falta para a terra a praticamente zero, minimizando a fadiga mecânica no gerador durante faltas para terra;

- Permite a possibilidade de continuar a operação com uma falta para terra até que o desligamento possa ser efetuado sem prejuízo ao processo em questão (aplicações na industria);

- Limitar sobretensões à níveis toleráveis durante faltas para a terra, principalmente no caso de faltas intermitentes. 
Como pontos negativos pode-se destacar:

- Faltas no secundário dos transformadores de potencial quando conectados em estrela aterrado - estrela aterrado podem sensibilizar a proteção de faltas para terra;

- Equipamentos de proteção contra surtos de tensão (pára-raios) devem ser dimensionados considerando a maior sobretensão temporária durante faltas para terra;

- Altas tensões e correntes de seqüência zero podem ocorrer (principalmente $3^{\mathrm{a}}$ harmônica) devido a possibilidade de ressonância paralela (ferroressonância), sendo minimizadas através da "retirada de sintonia" do sistema (reator com taps) e da escolha de um fator de qualidade $(\mathrm{Q}=\mathrm{X} / \mathrm{R})$ conveniente para o reator.

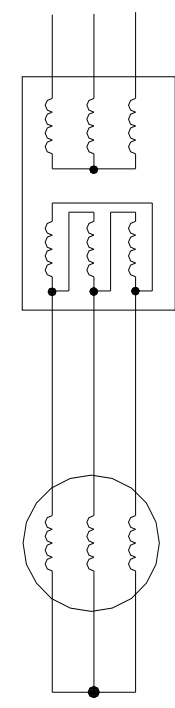

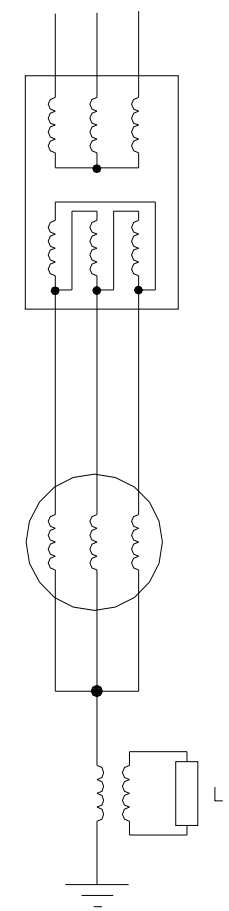

B)

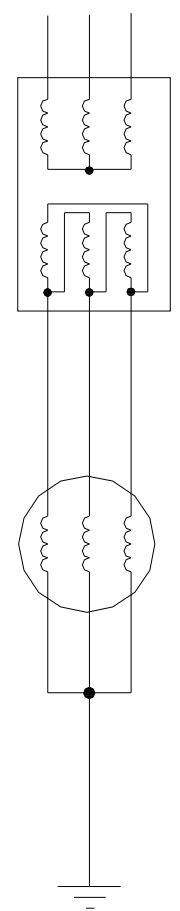

c)

Fig. 3. Métodos de aterramento: A) Sistema isolado; B) Aterramento ressonante e C) Aterramento efetivo (sistema solidamente aterrado) 
Para plantas de geração denominadas GBC (geradores em barra comum), os seguintes métodos e classes de aterramento são geralmente utilizados:

1) Aterramento através de resistor de baixa resistência: se caracteriza pela relação $\mathrm{X}_{0} / \mathrm{X}_{1}$ entre 0 e 10 onde geralmente se limita a corrente de falta para a terra a 1,5 vezes a corrente nominal do gerador (algumas centenas de amperes). O método de aterramento empregado pode ser a inserção de um resistor diretamente no neutro do gerador ou através de um transformador monofásico no neutro associado a um resistor (fig. 2A e fig. 2C).

A principal vantagem deste tipo de aterramento é limitar a corrente de falta para a terra à valores moderados, sem a ocorrência de grandes sobretensões. A principal desvantagem é o custo do resistor de aterramento, pois limitando a corrente de falta para a terra a 1,5 vezes a corrente nominal tem-se a uma perda no resistor de 50 porcento da potência do gerador em kVA.

2) Aterramento através de reator de baixa reatância: se caracteriza pela relação $X_{0} / X_{1}$ entre 3 e 10 onde geralmente se limita a corrente de falta para a terra a valores inferiores à corrente de curto-circuito trifásico do gerador. O método de aterramento é similar ao do aterramento por resistor de baixa resistência, exceto na substituição do resistor pelo reator, reator este com reatância indutiva menor do que a requerida ao aterramento ressonante.

Como pontos positivos inerentes à esta classe e método de aterramento pode-se destacar:

- Sobretensões são limitadas a valores toleráveis;

- Admite a aplicação de pára-raios de tensões disruptivas menores, permitindo uma proteção mais abrangente.

A maior desvantagem deste tipo de aterramento é que a relativa alta corrente de falta para a terra aumenta a possibilidade de fadiga mecânica no caso de faltas internas (antes do disjuntor do gerador). 
3) Aterramento efetivo (sistema solidamente aterrado): se caracteriza pela relação $\mathrm{X}_{0} / \mathrm{X}_{1}$ entre 0 e 3 . O método empregado é o aterramento do neutro do gerador diretamente sem a inserção intencional de qualquer impedância (fig. 3C). Esta classe e método de aterramento possuem vantagens e desvantagens similares às indicadas para o aterramento através de indutor de baixa reatância com duas diferenças significativas que são:

- Alta corrente na ocorrência de faltas para terra, visto que a reatância de seqüência zero do gerador $\left(\mathrm{X}_{0}\right)$ é menor do que sua reatância subtransitória, com isto tem-se a ocorrência de correntes de faltas para a terra maiores que as correntes de curtocircuito trifásico.

- Ocorrência de sobretensões temporárias pequenas devido a baixa relação $X_{0} / X_{1}$. A principal desvantagem deste método, e o que o leva a não ser recomendado para geradores que atendem grandes centros consumidores, é o risco de dano no gerador devido à faltas para a terra internas, pois estas geralmente apresentam correntes maiores do que as correntes de curto-circuito trifásicas.

Em algumas plantas na configuração GBC (geradores em barra comum), principalmente na Europa, o aterramento de alta impedância, através de transformador trifásico (conexão Y-Delta aberto) é amplamente utilizado. Nestes casos, uma desvantagem imposta pela configuração da planta é a difícil identificação do gerador em falta devido a limitação da corrente de falta para terra.

Para plantas de geração denominadas GAG (geradores com alimentadores diretamente conectados à tensão do gerador), a escolha do método e classes de aterramento deve seguir às necessidades do alimentador. Caso o alimentador não tenha uma necessidade específica para o aterramento, os métodos e classes preferíveis são o aterramento através de resistor de baixa resistência ou através de reator de baixa reatância, pois apresentam um bom compromisso entre baixas correntes não danificando o gerador e correntes altas o suficiente para sensibilização da proteção com operação seletiva, além de apresentarem sobretensões reduzidas no evento de faltas para a terra. 


\subsection{Principais Proteções Aplicáveis a Geradores}

Além do sistema de aterramento, a determinação das funções de proteção para um gerador deve levar em consideração o custo da proteção em relação ao objeto protegido e sua importância (disponibilidade necessária, tempo para substituição, para reparo entre outros), logo não há um padrão universal para a escolha das proteções para um gerador.

$\mathrm{Na}$ tabela 2 tem-se um exemplo de proteções recomendadas de acordo com a potência do gerador [12]. A tendência, como visto na tabela 2, é utilizar mais funções de proteção com o aumento da potência do gerador.

\begin{tabular}{|c|c|c|c|c|c|}
\hline \multirow[b]{2}{*}{ Proteção } & \multirow[b]{2}{*}{ No ANSI (*) } & \multicolumn{4}{|c|}{ Potência do Gerador [MVA] } \\
\hline & & $<5$ & $5-50$ & $50-200$ & $>200$ \\
\hline Falta a terra no Estator $90 \%$ & $\begin{array}{l}64,59 \mathrm{~N}, \\
67 \mathrm{~N}(* *)\end{array}$ & $\mathrm{x}$ & $\mathrm{x}$ & $\mathrm{X}$ & $\mathrm{X}$ \\
\hline Falta a terra no Estator $100 \%$ & $64(100 \%)$ & & & $\mathrm{X}$ & $\mathrm{X}$ \\
\hline Diferencial & $87,87 \mathrm{~N}$ & O & $\mathrm{X}$ & $\mathrm{X}$ & $\mathrm{X}$ \\
\hline Sobrecorrente & $50 / 51,51 \mathrm{~V}$ & $\mathrm{x}$ & $\mathrm{x}$ & $\mathrm{O}$ & $\mathrm{O}$ \\
\hline Impedância & 21 & & & $\mathrm{X}$ & $\mathrm{X}$ \\
\hline Curto entre espiras "interturn" & & & & $\mathrm{x}$ & \\
\hline Falta a terra no rotor & 64R & o & $\mathrm{x}$ & $\mathrm{x}$ & $\mathrm{X}$ \\
\hline Carga desbalanceada & 46 & & $\mathrm{x}$ & $\mathrm{X}$ & $\mathrm{X}$ \\
\hline Subexcitação & 40 & $\mathrm{O}$ & $\mathrm{X}$ & $\mathrm{X}$ & $\mathrm{X}$ \\
\hline Fora de sincronismo & 78 & & & & $\mathrm{X}$ \\
\hline Sobrecarga no estator & 49 & $\mathrm{X}$ & $\mathrm{X}$ & $\mathrm{X}$ & $\mathrm{X}$ \\
\hline Sobrecarga no rotor & $49 \mathrm{R}$ & & & & $\mathrm{X}$ \\
\hline Sobretensão & 59 & $\mathrm{X}$ & $\mathrm{X}$ & $\mathrm{X}$ & $\mathrm{X}$ \\
\hline Sobre - freqüência & 81 & $\mathrm{X}$ & $\mathrm{X}$ & $\mathrm{X}$ & $\mathrm{X}$ \\
\hline Sub - freqüência & 81 & & $\mathrm{X}$ & $\mathrm{X}$ & $\mathrm{X}$ \\
\hline Potência reversa & 32 & $\mathrm{x}$ & $\mathrm{X}$ & $\mathrm{X}$ & $\mathrm{X}$ \\
\hline Sobre - excitação $(\mathrm{V} / \mathrm{Hz})$ & 24 & & o & $\mathrm{x}$ & $\mathrm{X}$ \\
\hline
\end{tabular}

Tabela 2. Proteções recomendadas para geradores (o - opcional)

\section{(*) ANSI/IEEE C37.2}

(**) Utilizado em casos especiais como plantas GBC (Geradores em Barra Comum) ou GAG (Geradores com Alimentadores diretamente conectados à tensão do Gerador) com aterramento através de transformador trifásico na barra (conexão YDelta aberto). 
Como descrito no capítulo 1. (Introdução), serão apresentadas a seguir as principais funções de proteção recomendadas para geradores de até 50 MVA que são:

- Proteção diferencial;

- Falta a terra no estator (90\%);

- Sobrecorrente;

- Falta a terra no rotor;

- Carga desbalanceada;

- Subexcitação;

- Sobrecarga no estator;

- Sobretensão;

- Freqüência;

- Potência reversa.

Além destas proteções, as funções de subtensão, monitoração dos fusíveis do transformador de potencial ("fuse failure") e a matriz de desligamentos também serão apresentadas como complemento às principais proteções aplicadas ao controle e monitoramento da planta de geração. 


\subsubsection{Proteção diferencial}

O princípio de funcionamento da proteção diferencial é baseado na comparação das correntes que chegam e saem do sistema (ou objeto) protegido. Assim, no caso de um gerador protegido diferencialmente, deve-se ter que as correntes que circulam entre os terminais de entrada e saída de uma bobina de uma dada fase do gerador devem ser exatamente iguais, caso contrário existe algum desvio interno, o qual deverá ser detectado pela proteção diferencial.

Basicamente dois tipos de proteção diferencial são utilizados em geradores; a proteção diferencial percentual e a proteção diferencial de alta impedância.

a) Proteção diferencial percentual:

Este princípio de proteção tem a finalidade de permitir uma proteção sensível para curto-circuitos dentro da área protegida apresentando, também, estabilidade para curto-circuitos externos. A fig. 4 pode ilustrar o princípio de funcionamento desta proteção.

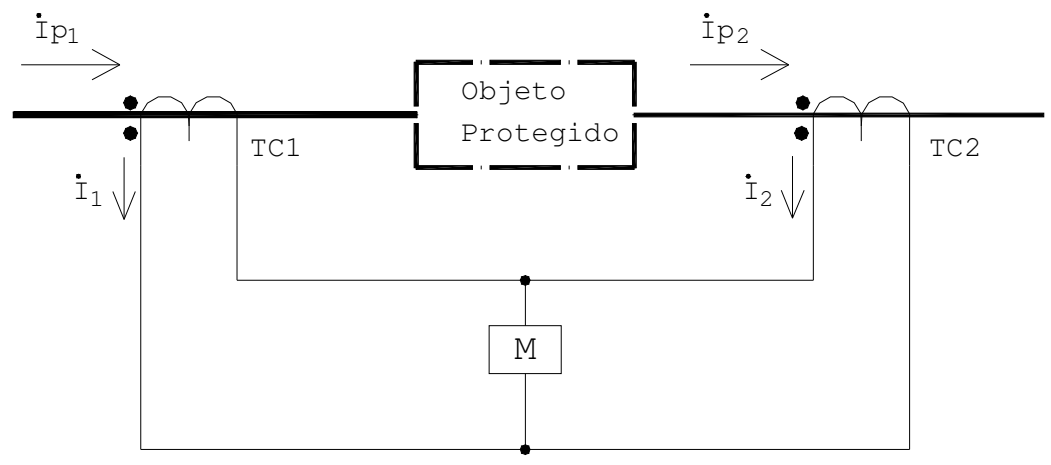

Fig. 4. Proteção diferencial percentual: Princípio de funcionamento

Considerando que os TC's 1 e 2 (fig. 4) possuem a mesma relação de transformação, estes são conectados de forma a se estabelecer um circuito fechado. Conectando-se o elemento de medição M no ponto de balanço elétrico, pode-se detectar a diferença 
entre as correntes $\dot{I}_{1} e \dot{I}_{2}$. Em condições normais (operação em carga), não há corrente fluindo no elemento M. Caso ocorra uma falta dentro da área protegida (entre TC's), fluirá no circuito primário a corrente $\dot{I}_{P 1}+\dot{I}_{P 2}$ e no circuito secundário, circulam pelo elemento de medição, as correntes $I_{1} e I_{2}$, como representado na figura 5 .

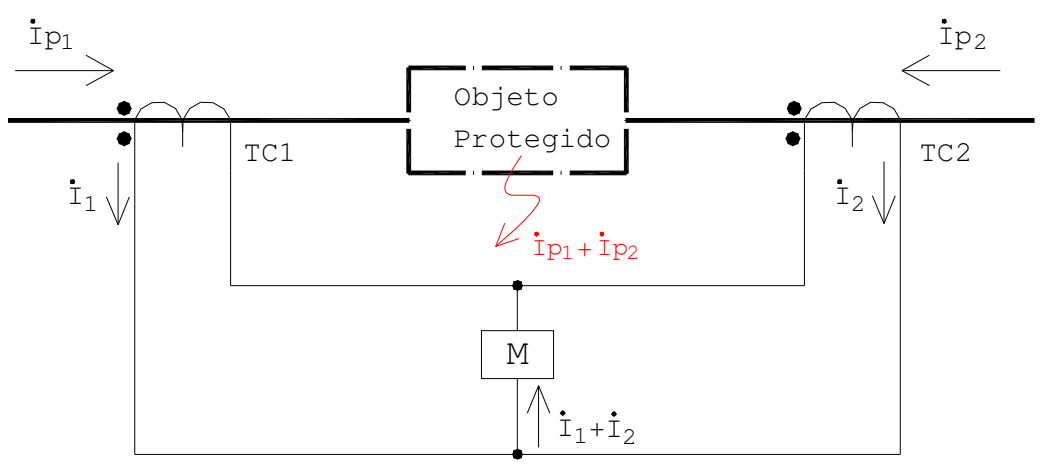

Fig. 5. Proteção diferencial percentual: Curto-circuitos internos

Estabilização

Faltas externas (fora da área protegida) causam correntes elevadas circulando no circuito primário. Diferenças nas características magnéticas dos TC's podem levar a uma condição de saturação diferenciada nos TC's causando uma circulação, significativa, de corrente no elemento $\mathrm{M}$.

Caso o valor desta corrente supere o ajuste do elemento de medição, um sinal de desligamento é enviado ao respectivo elemento de manobra (disjuntor do gerador). Para prevenir este tipo de erro de operação, defini-se a corrente de estabilização como sendo a soma aritmética dos valores absolutos de $\mathrm{I}_{1}$ e $\mathrm{I}_{2}$, isto é:

$$
I_{\text {estab }}=\left|I_{1}\right|+\left|I_{2}\right|
$$


Alguns fabricantes de relés definem a corrente de estabilização de outra forma, como segue:

$$
I_{\text {estab }}=\frac{\left|\dot{I_{1} \mid}+\right| \dot{I}_{2} \mid}{2}
$$

Já, por sua vez, a corrente diferencial é definida como segue:

$$
I_{d i f}=\left|\dot{I_{1}}+\dot{I}_{2}\right|
$$

Para exemplificar, três condições operacionais importantes podem ser analisadas.

Nos casos descritos a seguir, considera-se que os TC's possuem a mesma característica magnética e relação de transfomação.

1) Sistema íntegro em carga ou curto-circuito externo:

Neste caso as correntes $I_{1}$ e $I_{2}$ tem sentidos opostos $\left(\dot{I_{1}}=-\dot{I_{2}}\right)$, resultando em:

$$
\begin{aligned}
& I_{\text {dif }}=\left|\dot{I}_{1}+\dot{I}_{2}\right|=0 \\
& I_{\text {estab }}=\left|\dot{I}_{1}\right|+\left|\dot{I}_{2}\right|=2\left|\dot{I}_{1}\right|
\end{aligned}
$$

Logo, não é enviado sinal de trip.

2) Curto-circuito dentro da área protegida, alimentado por correntes iguais nos dois lados.

Neste caso $\dot{I}_{1}=\dot{I}_{2}$, resultando em:

$$
\begin{aligned}
& I_{\text {dif }}=\left|\dot{I}_{1}+\dot{I}_{2}\right|=2\left|\dot{I}_{1}\right| \\
& I_{\text {estab }}=\left|\dot{I}_{1}\right|+\left|\dot{I}_{2}\right|=2\left|\dot{I}_{1}\right|
\end{aligned}
$$


Nesta situação Idif e Istab tem o mesmo valor, correspondendo a corrente total de falta e o sinal de trip é enviado.

3) Curto-circuito dentro da área protegida alimentado somente por um lado

Neste caso $\dot{I}_{2}=0$, resultando em:

$$
\begin{aligned}
& I_{\text {dif }}=\left|\dot{I}_{1}+\dot{I}_{2}\right|=\left|\dot{I}_{1}\right| \\
& I_{\text {estab }}=\left|\dot{I}_{1}\right|+\left|\dot{I}_{2}\right|=\left|\dot{I}_{1}\right|
\end{aligned}
$$

Nesta situação Idif e Istab tem o mesmo valor, correspondendo a corrente total de falta e o sinal de trip é enviado.

Conclui-se, portanto, que para faltas internas em condições ideais Idif = Istab.

Logo a característica de faltas internas é uma reta com ângulo de $45^{\circ}$ positivos a partir da origem.

Do exposto resulta a característica representada na fig. 6 .

PROTEÇÃO DIFERENCIAL PERCENTUAL

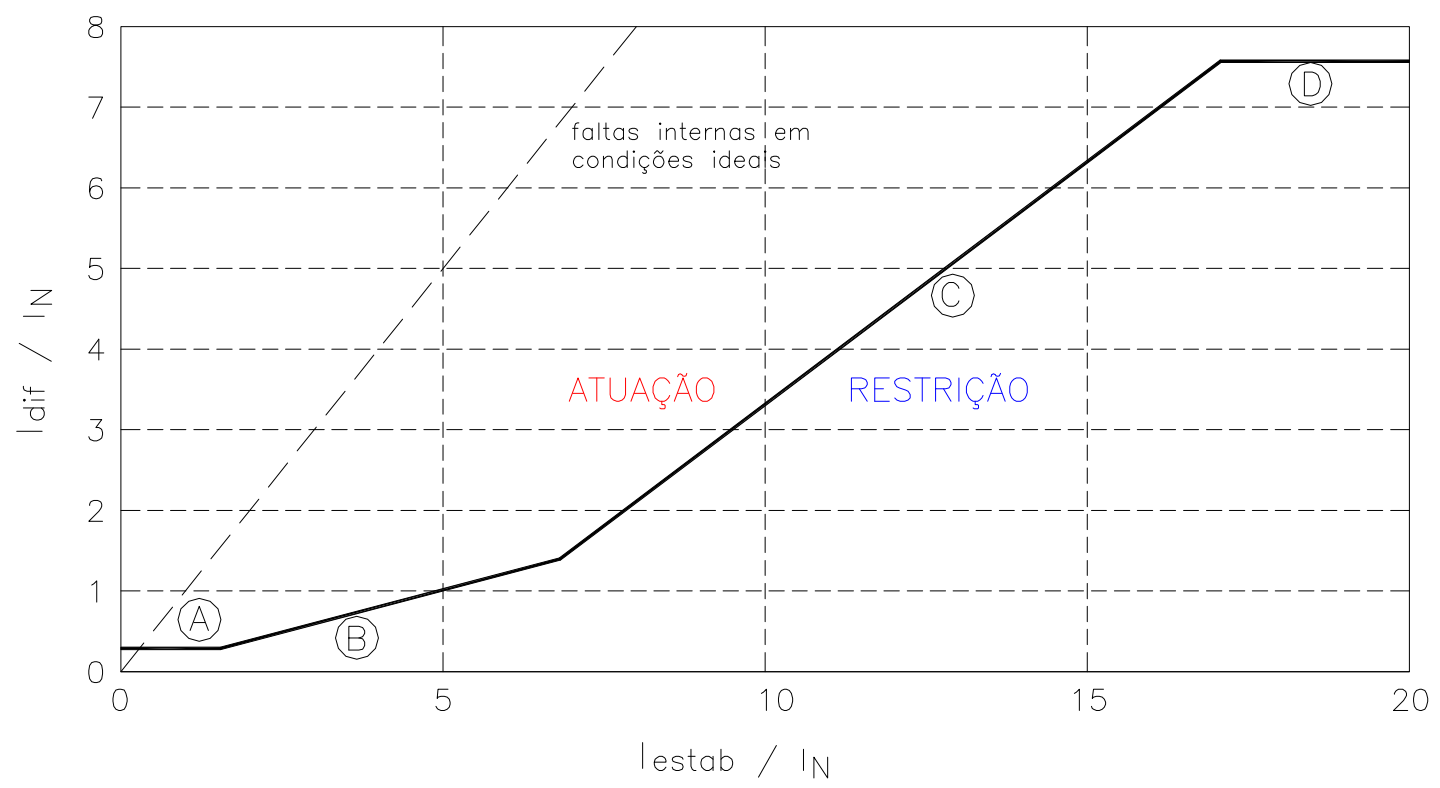

Fig. 6. Característica de atuação da proteção diferencial percentual 
Esta característica é composta de dois patamares Idif $>$ (A) e Idif $>>$ (D) e duas retas inclinadas B e C.

O primeiro patamar Idif > representa a tolerância a erros constantes como das correntes de magnetização do objeto protegido.

O segundo patamar Idif $>>$ representa a zona de alta velocidade, na qual a corrente diferencial apresenta altos valores percentuais (ou em valores por unidade).

A reta com inclinação $\mathrm{B}$, considera erros proporcionais a corrente circulante, como os devido a relações de transformação diferentes entre TC's nos extremos do objeto protegido.

E a reta com inclinação $\mathrm{C}$, considera os erros devido a características magnéticas diferentes dos TC's em altas correntes promovendo uma certa estabilização em condições de saturação.

b) Proteção diferencial de alta impedância

Este princípio de proteção é utilizado, com mais frequiência, para proteção de barras em situações em que a saturação de TC's pode não ser evitada devido às altas correntes circulantes.

Colocando os TC's de cada fase em paralelo, as correntes secundárias são somadas e a resultante é conduzida a resistores de valor conhecido, causando uma queda de tensão proporcional a corrente circulante. A função do relé de proteção é monitorar a tensão resultante neste circuito.

O ajuste da tensão de operação deve considerar que pode haver saturação de TC's para curto-circuitos externos. 


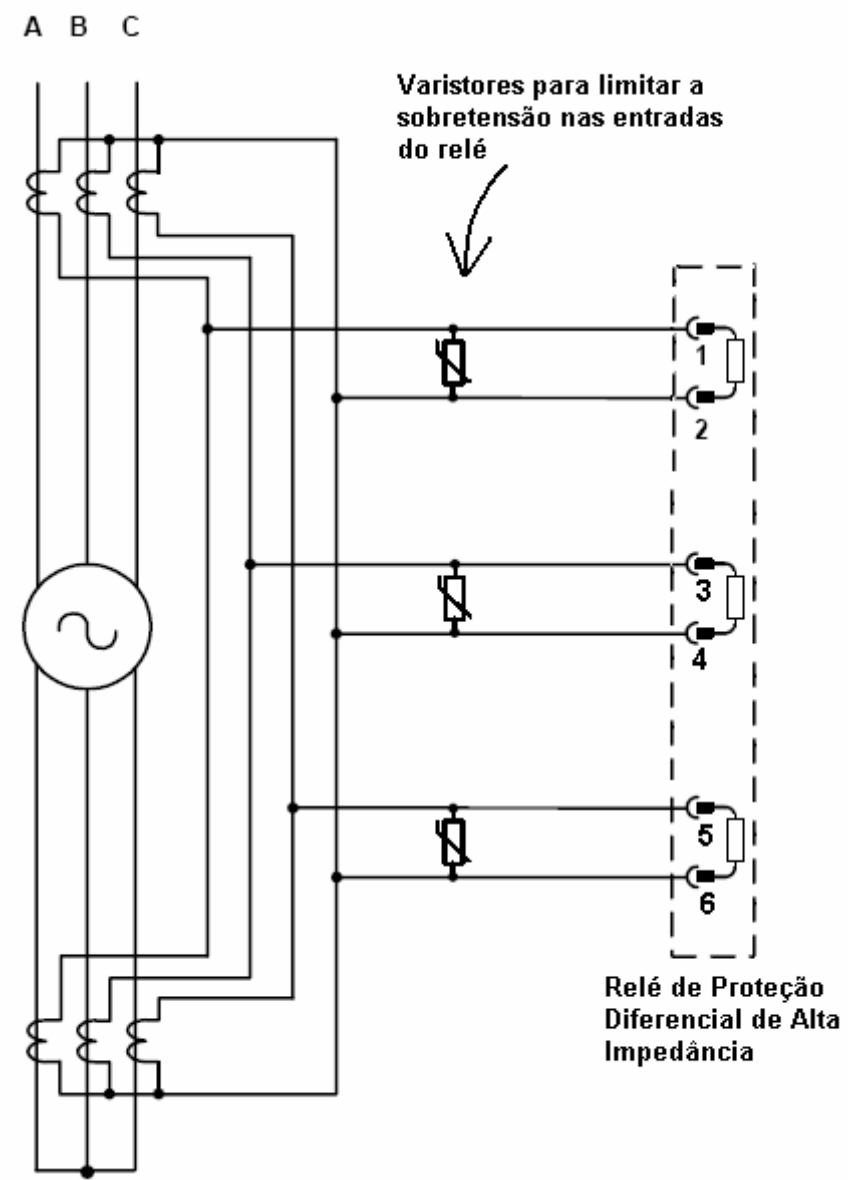

Fig. 7. Proteção diferencial de alta impedância: Princípio de funcionamento

Há uma variante da proteção diferencial no que diz respeito à faltas para terra em sistemas com neutro aterrado.

Esta é chamada proteção diferencial de neutro (87N), como representado na fig. 8 . 


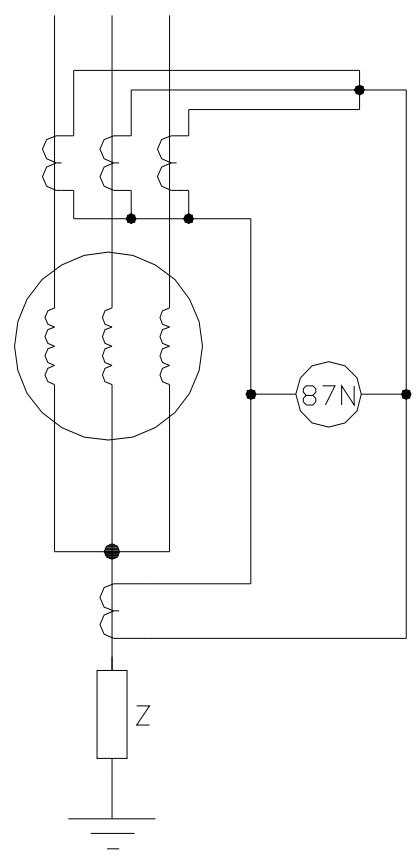

Fig. 8. Proteção diferencial de neutro: Princípio de funcionamento

Tanto o princípio de alta impedância quanto o percentual, podem ser utilizados na proteção diferencial de neutro. 


\subsubsection{Falta a terra no estator}

A proteção principal contra sobrecorrentes, tanto de fase quanto de neutro, é a proteção diferencial $(87,87 \mathrm{~N})$. Para alguns esquemas de aterramento, devido a limitação da corrente de falta para a terra, outros tipos de proteção devem ser aplicados, visando a integridade do sistema.

Conforme descrito no item 2.2, os principais métodos e classes de aterramento utilizados em geradores são:

(a) Sistema solidamente aterrado;

(b) Aterramento através de resistor de baixa resistência;

(c) Aterramento através de reator de baixa reatância;

(d) Aterramento através de reator de alta reatância;

(e) Aterramento através de resistor de alta resistência;

(f) Aterramento ressonante;

(g) Sistema isolado.

Para plantas de geração empregando os métodos e classes de aterramento descritos nos itens (a), (b) e (c) deste capítulo, a proteção diferencial de corrente (87), tendo como proteção de retaguarda a proteção de sobrecorrente de neutro $(50 / 51 \mathrm{~N})$ é capaz de detectar e isolar o defeito para terra.

Para os outros métodos e classes de aterramento, onde a corrente de falta para terra é limitada, existem dificuldades para as proteções diferencial e de sobrecorrente detectarem estas faltas. Logo se faz necessário o emprego de outros esquemas de proteção visando à integridade do sistema.

Para plantas das classes de aterramento descritos nos itens (d), (e) e (f) deste capítulo, utilizam-se transformadores em basicamente duas configurações como método de aterramento, transformador monofásico no neutro ou transformador trifásico nos terminais do estator. Independente do tipo de transformador empregado, a medição da tensão de seqüência zero, no resistor ou reator de aterramento (59N) é o tipo de proteção empregado. Em complemento ou como proteção de retaguarda, a medição da corrente circulante no resistor ou reator, também é utilizada $(51 \mathrm{~N})$. 


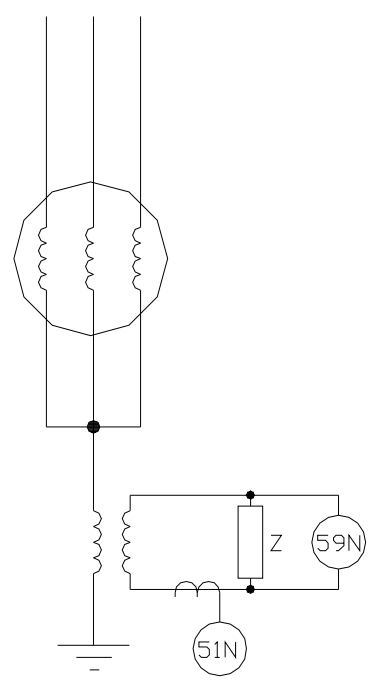

A)
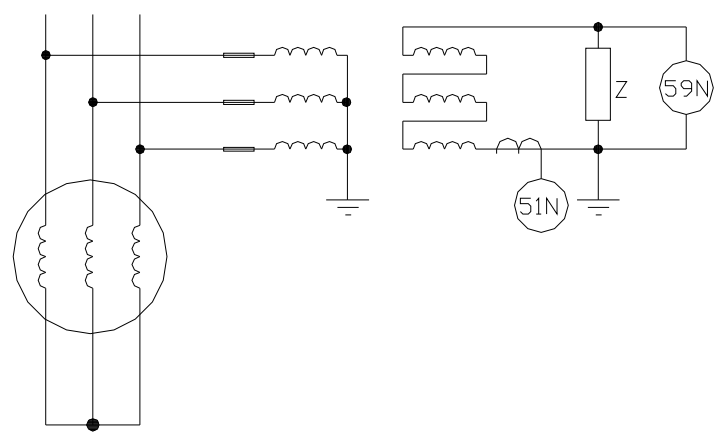

Fig. 9. Proteção contra faltas a terra no estator para aterramento (d), (e) e (f): A) Aterramento através de transformador monofásico no neutro do gerador; B) Aterramento através de transformador trifásico nos terminais do gerador.

Para plantas GBC e GAG com aterramento de alta impedância (principalmente através de transformador de aterramento na barra), torna-se difícil diferenciar em qual gerador existe uma falta para terra ou mesmo, diferenciar entre uma falta na rede externa e nos geradores a partir, apenas, da tensão de seqüência zero e da ocorrência de sobrecorrentes. Nestes casos a utilização da proteção de sobrecorrente direcional de neutro $(67 \mathrm{~N})$ é o meio mais eficaz e confiável para correta isolação do defeito para terra. 


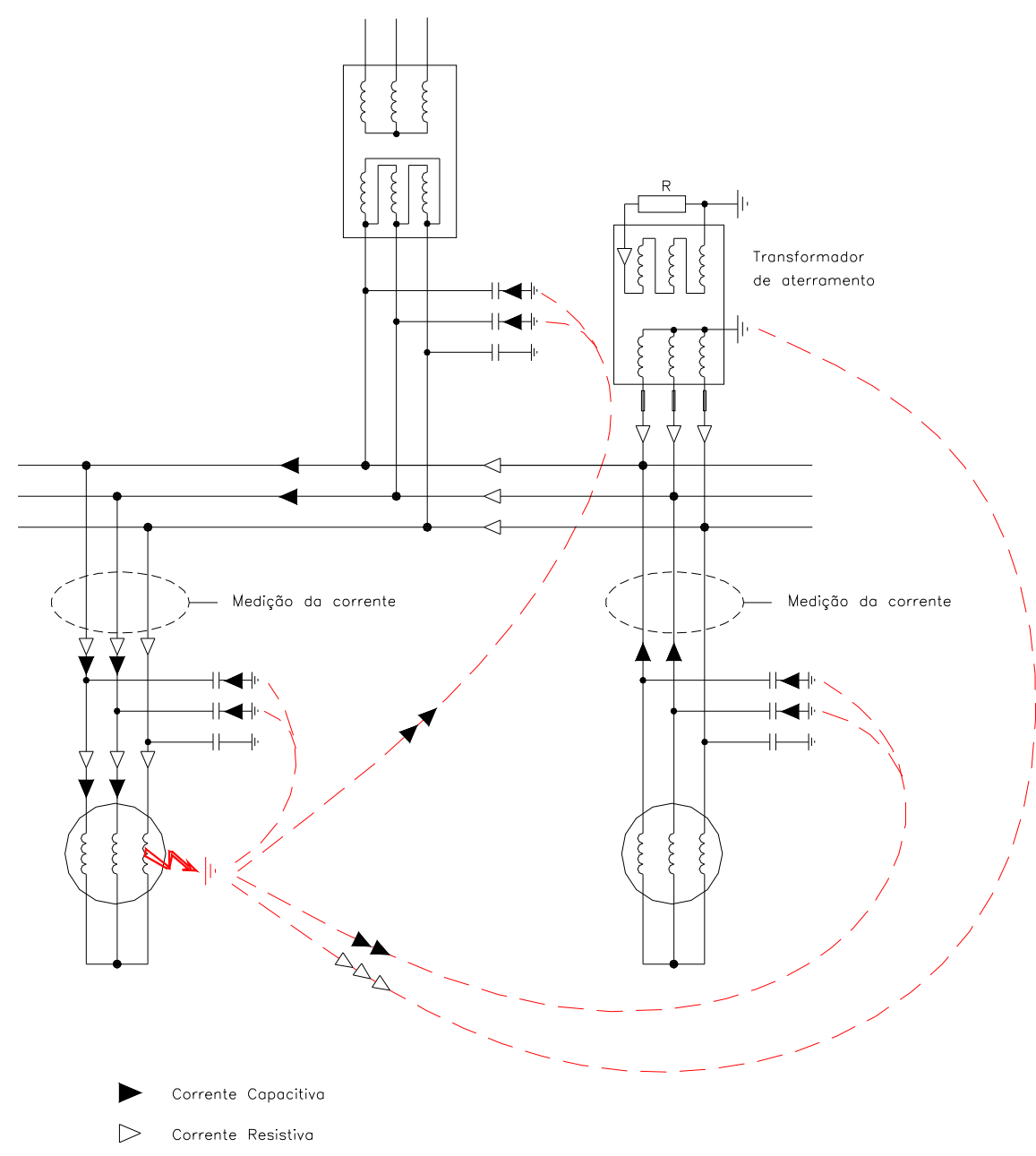

Fig. 10. Correntes para terra em uma planta GBC com aterramento através de transformador trifásico em conexão Y-Delta aberto.

Para o aterramento através de resistor ou reator diretamente no neutro do gerador, um transformador de corrente no neutro, associado a uma proteção de sobrecorrente de alta sensibilidade $(50 / 51 \mathrm{~N})$, em conjunto ou não com a proteção diferencial de neutro $(87 \mathrm{~N})$ provê uma proteção segura e eficaz contra faltas para a terra. 


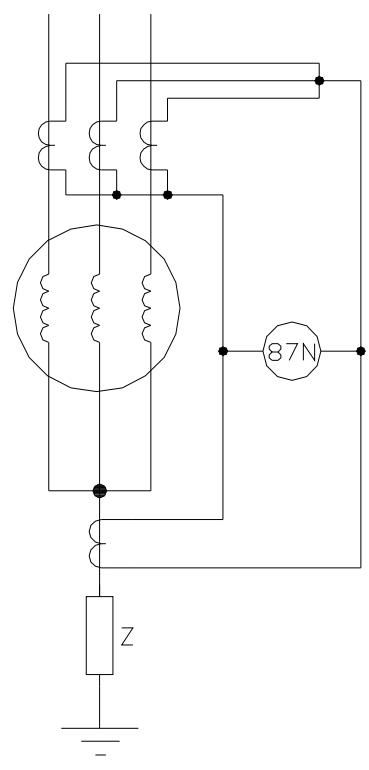

A)

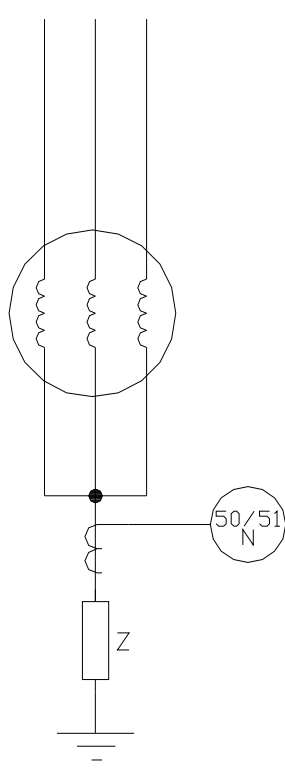

B)

Fig. 11. Proteção contra faltas a terra no estator para aterramento (d), (e) e (f): A) Proteção diferencial de neutro; B) Proteção de sobrecorrente de neutro.

Para sistemas isolados, um transformador de potencial na configuração estrela-delta aberto, onde a tensão residual (seqüência zero) é medida (59N ou 64) provê uma proteção segura e eficaz. A utilização de transformadores de corrente tipo janela (ou três transformadores em ligação residual) também é utilizada como complemento.

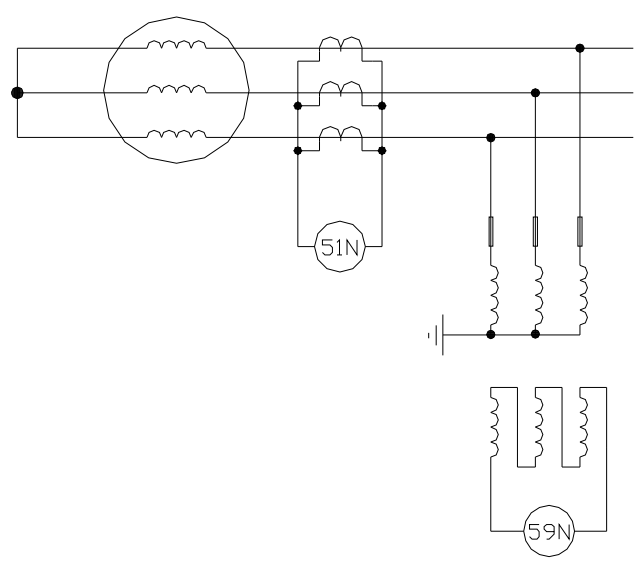

A)
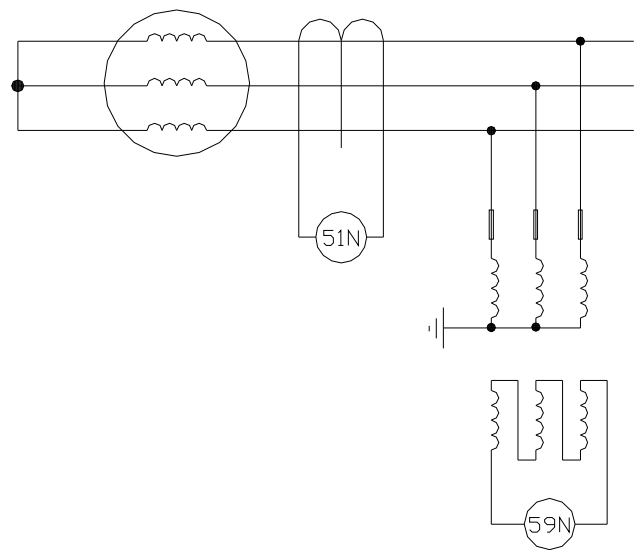

B)

Fig. 12. Proteção contra faltas a terra no estator para sistemas isolados: A) Proteção de sobrecorrente com TC's em conexão residual; B) Proteção de sobrecorrente com TC de janela. 
A proteção de faltas para a terra no estator, descrita como $90 \%$ ou efetiva em $90 \%$ do estator são as indicadas acima, sendo baseadas na medição da tensão e corrente residual fundamental (sequiência zero). Para a detecção de faltas próximas ao neutro do gerador (proteção de faltas para a terra 100\%), esquemas com injeção de tensão subharmônica [1] ou baseados na tensão de terceira harmônica [3] são utilizados.

\subsubsection{Sobrecorrente}

A proteção de sobrecorrente é geralmente utilizada como proteção de retaguarda da proteção diferencial, tanto de fase quanto de neutro.

No caso de faltas nos terminais do gerador, quando a energia de excitação é obtida destes através de um transformador (sistema de excitação estática), a corrente de curto circuito não é mantida e cai abruptamente abaixo do valor de ajuste da proteção de sobrecorrente antes do desligamento ser assegurado (devido ao colapso do sistema de excitação), fazendo com que a proteção não reconheça a situação anormal. Devido a esta situação, a proteção de sobrecorrente deve possuir um estágio de subtensão que reduz o ajuste da proteção de sobrecorrente proporcionalmente a tensão do sistema; conseqüentemente, para a mesma corrente o tempo é diminuído (proteção 51V).

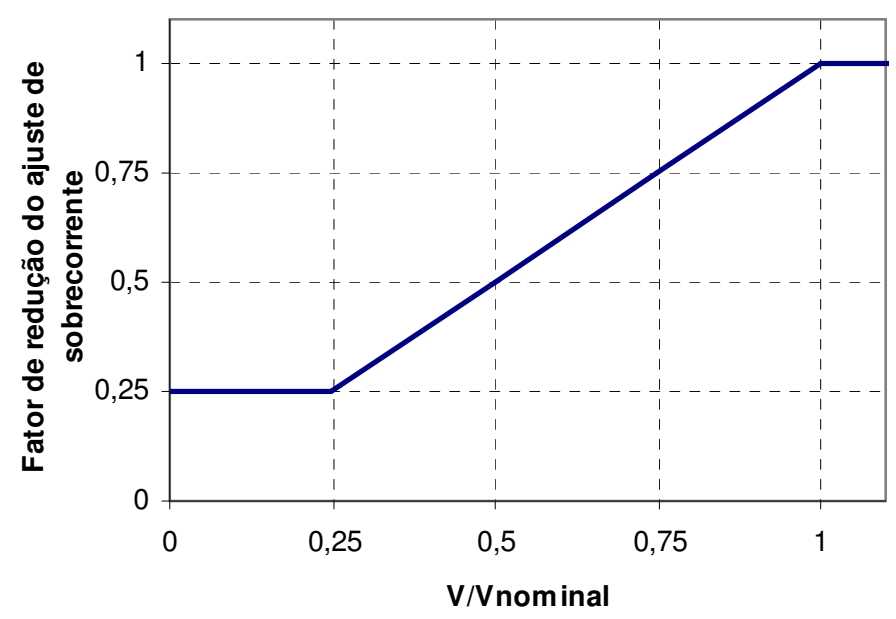

Fig. 13. Proteção de sobrecorrente com restrição de tensão (51V) 


\subsubsection{Falta a terra no rotor}

Esta proteção visa detectar faltas para terra no enrolamento de campo do gerador. O enrolamento de campo de geradores não é aterrado. Uma falta para terra neste enrolamento, não afeta a operação do gerador e não causará danos mecânicos. Entretanto após a primeira falta, há uma referência para a terra as custas do deterioramento da isolação do circuito do rotor, facilitando a ocorrência de uma segunda falta. Quando uma segunda falta ocorre, parte do enrolamento de campo é curto-circuitado produzindo fluxo não balanceado no entreferro da máquina. Este fluxo não balanceado produzirá forças não balanceadas resultando em vibrações que podem causar falhas mecânicas severas. Além da possibilidade de falhas mecânicas ocorre aquecimento do circuito do rotor devido à alta corrente.

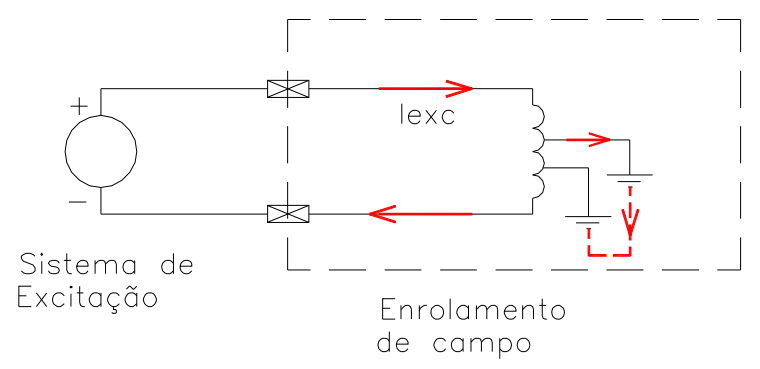

Fig. 14. Dupla falta para a terra no enrolamento de campo

Métodos tradicionalmente utilizados como relé de sobretensão em série com fonte de corrente contínua ou divisor de tensão associado com relé de sobretensão levam a atuação indevida, principalmente durante a partida do gerador [13].

Um método mais seguro, baseado na aplicação de uma tensão de baixa frequiência no circuito do rotor (enrolamento de campo) foi então desenvolvido e, hoje em dia, é amplamente utilizado. 

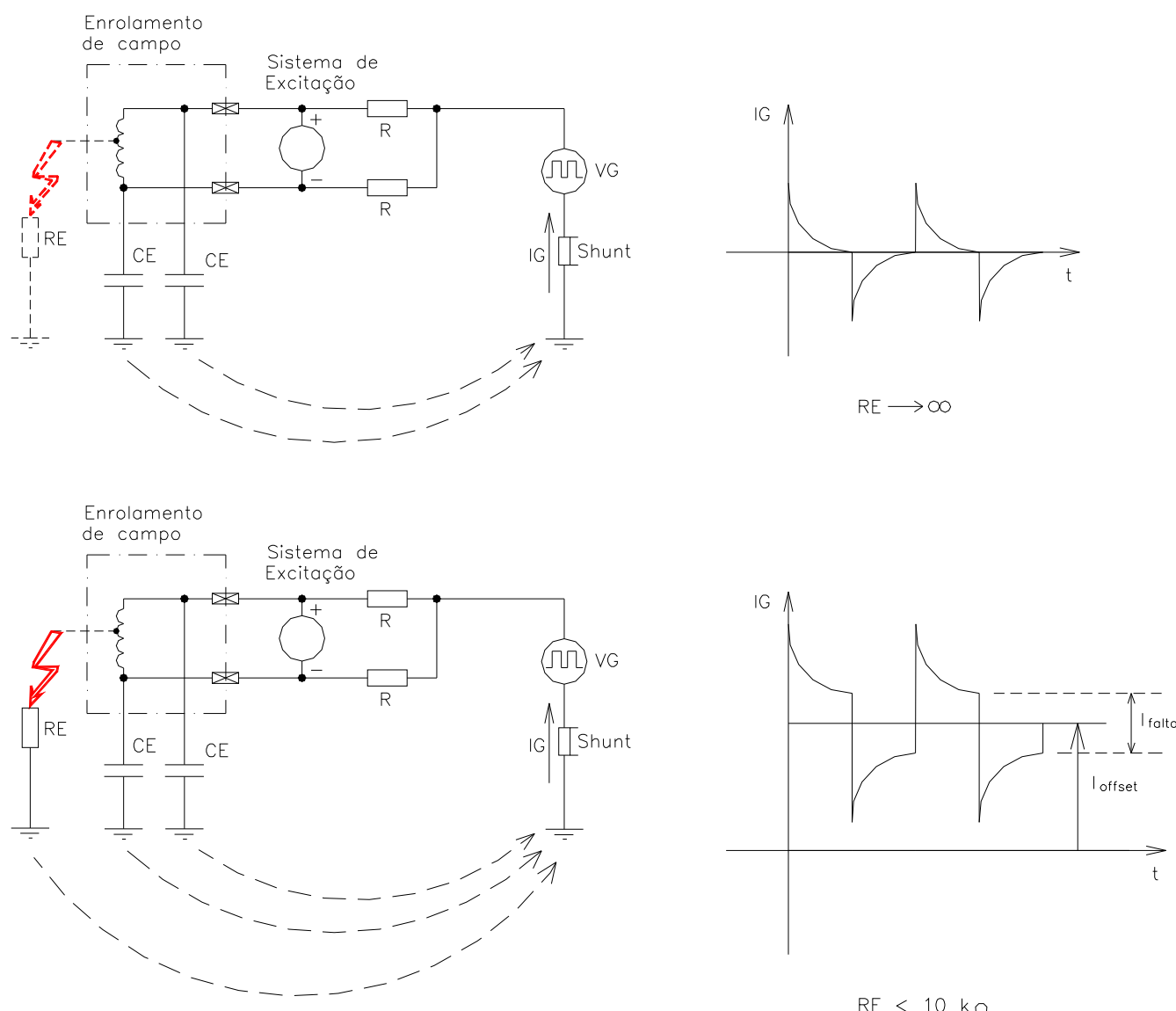

Fig. 15. Proteção contra faltas no circuito do rotor (enrolamento de campo)

Onde:

VG: Tensão de referência;

IG: Corrente do circuito do rotor para terra;

CE: Capacitância do circuito do rotor para terra;

R: Resistor

RE: Resistência de falta;

Ioffset: Interferência devido ao sistema de excitação

Uma onda quadrada, cuja freqüência é ajustada em função da capacitância para a terra do circuito de excitação $(0,1 \mathrm{~Hz}$ a $1 \mathrm{~Hz})$, é aplicada no enrolamento de campo resultando na circulação de uma corrente (com o sistema íntegro somente corrente de carga para as capacitâncias, caso haja falta uma corrente é sobreposta à corrente de carga das capacitâncias). A partir da tensão aplicada e da corrente medida, o relé de proteção avalia a resistência para a terra. Valores típicos são $40 \mathrm{k} \Omega$ ou $20 \mathrm{k} \Omega$ para alarme e $5 \mathrm{k} \Omega$ para desligamento [1]. 
O mesmo princípio também pode ser aplicado a geradores com sistema de excitação sem escovas ("brusless") onde, instalando o sistema eletrônico para formação da tensão de referência e medição da corrente, próximo do eixo do rotor (visando minimizar os efeitos centrífugos) e, sendo a energia necessária à formação da tensão de referência (onda quadrada) fornecida através de um acoplamento indutivo de média freqüência (baixa eficiência) tem-se os elementos necessários para avaliação da resistência de isolamento do rotor. Estes sinais (tensão de referência e corrente circulante) são transmitidos via modulação em freqüência e divisão no tempo para o módulo que, a partir de filtros, avalia a resistência de isolação do rotor [14].

\subsubsection{Carga desbalanceada}

Há várias causas para corrente desbalanceada em sistemas trifásicos, que podem ser faltas assimétricas, circuitos abertos e carga não balanceada.

A corrente de seqüência negativa $I_{2}$ (associada a esta situação), no estator do gerador, cria um fluxo magnético do entreferro que, girando em sentido oposto ao fluxo do rotor (a velocidade síncrona) induz correntes na superfície deste com o dobro da freqüência do sistema. Estas correntes induzidas (correntes parasitas) levam ao aquecimento do corpo do rotor, enrolamento de campo, enrolamento de amortecimento e outros componentes metálicos.

A capacidade do gerador suportar o aquecimento provocado pela corrente de seqüência negativa, é expressa pela constante $\mathrm{I}_{2}{ }^{2} \mathrm{t}$ (característica informada pelo fabricante da máquina). Ajustes são, portanto, baseados na eq.(4)

$$
t=\frac{k}{\left(I_{2} / \text { In }\right)^{2}}
$$

Onde k é um parâmetro que deve ser informado pelo fabricante do gerador.

Esta função é particularmente eficaz para detecção de faltas assimétricas com corrente menor que a de carga da máquina. 


\subsubsection{Subexcitação}

A excitação do gerador pode ser perdida pelo desligamento do disjuntor de campo, curto-circuito no circuito de excitação, falha do sistema de controle da excitação ou falha da excitatriz piloto.

Quando o gerador perde a excitação, este tenderá a se comportar como um gerador de indução. Sua velocidade aumentará acima de sua velocidade síncrona, operará fornecendo potência ativa reduzida e consumirá energia reativa do sistema sendo excitado a partir deste.

Nesta situação, correntes são induzidas no circuito do rotor (excitação através do sistema de potência), estas correntes podem causar aquecimento danificando este circuito. Além de altas correntes no circuito do rotor, sobretensões podem ocorrer danificando sua isolação.

Em virtude dos efeitos causados na operação do gerador devido a falha de excitação, basicamente, dois métodos são utilizados para detectar esta condição anormal que são:

- Utilização de relés de distância para sentir variações na impedância vista nos terminais do gerador, já que a impedância é função da potencia entregue pelo gerador;

- Monitoração do fluxo de potência reativa.

Quando relés de distância são utilizados para sentir a perda de excitação, a zona de desligamento, tipicamente, é marcada por círculos MHO centralizados no eixo da reatância e deslocados de $\mathrm{X}_{\mathrm{d}}{ }^{\prime} / 2$ no eixo da resistência.

Duas zonas são geralmente utilizadas, uma instantânea e outra temporizada. 


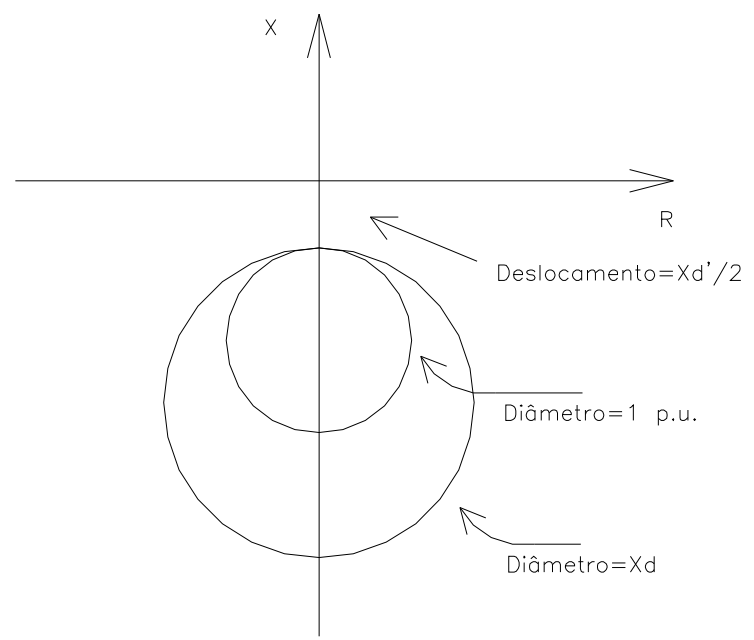

Fig. 16. Relés de distância utilizados para detectar perda de excitação

Veja que este método para detectar perda de excitação não permite uma visualização simples do ajuste, pois não apresenta correlação direta com os limites de projeto do gerador (curva de capabilidade).

Quando a monitoração do fluxo de potência reativa é utilizada para detectar perda de excitação o ajuste é facilmente visualizado em função da curva de capabilidade do gerador.

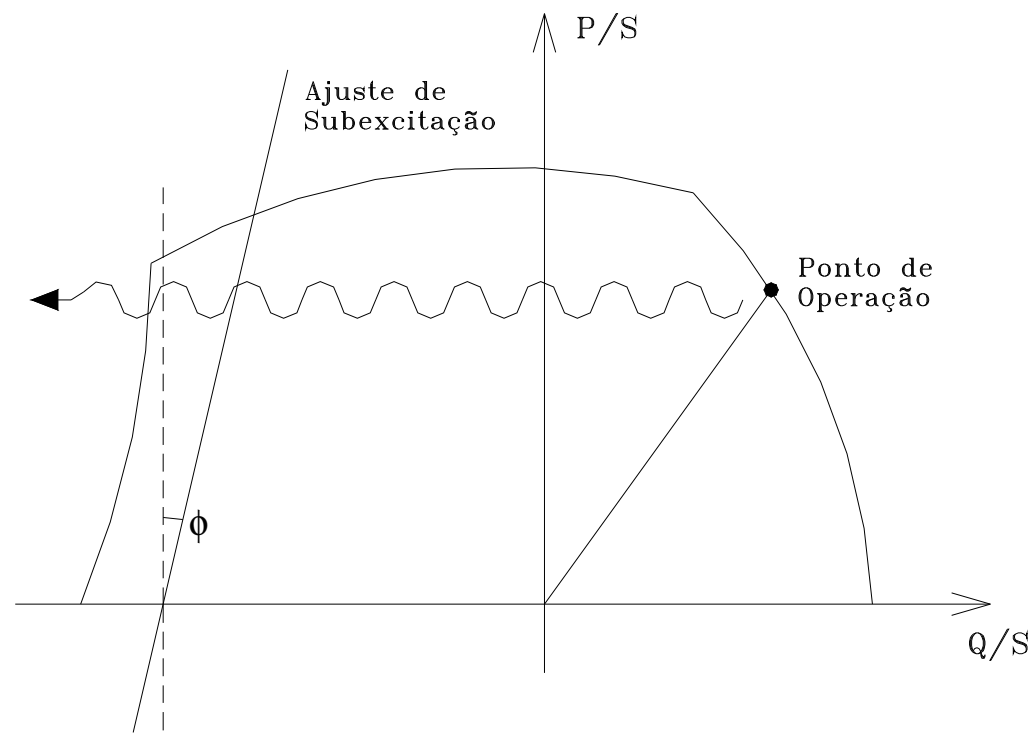

Fig. 17. Proteção de subexcitação executada através da monitoração do fluxo de potência reativa 
A curva de capabilidade varia em função da tensão do gerador. Como a simples monitoração do fluxo de potência reativa não leva em consideração esta característica, o gerador em condições de subtensão pode não estar devidamente protegido ou sendo sub-utilizado.

Na fig. 18 pode-se verificar a variação da curva de capabilidade de um gerador de 62MVA-14,4kV em condições de subtensão e sobretensão.
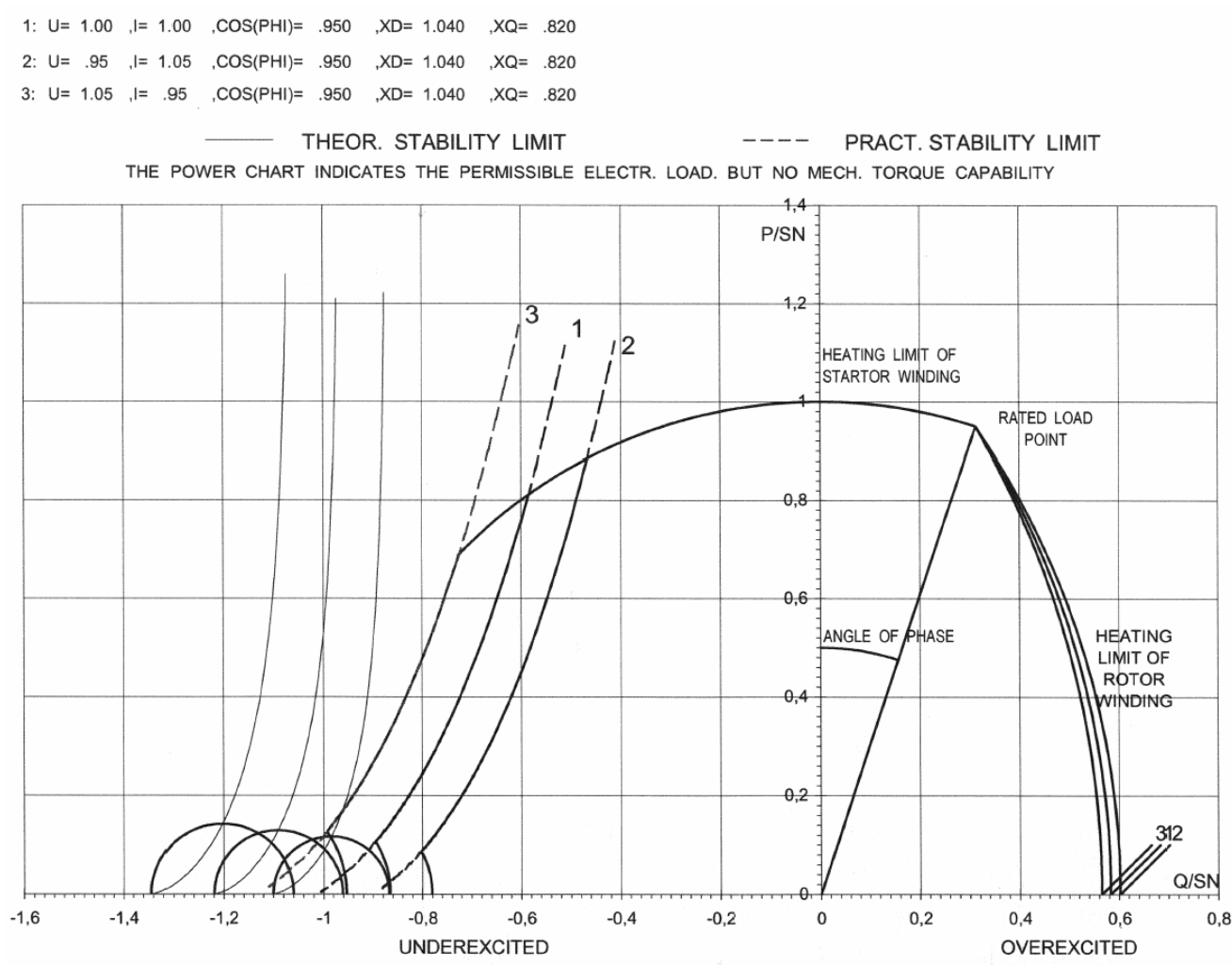

Fig. 18. Curva de Capabilidade de um gerador de 62MVA-14,4kV

Devido a esta característica desfavorável, um método baseado no cálculo da admitância vista nos terminais do gerador apresenta-se como a solução ideal, pois além considerar o efeito da variação da tensão, permite um ajuste otimizado (e de fácil vizualização) em função da curva de capabilidade do gerador.

Para tal, a curva de capabilidade deve ser "transformada" em diagrama de admitância como demonstrado na fig. 19. 
Potência complexa:

$\dot{S}=\dot{V} \dot{I}$

$\dot{S}=P+j Q$

Admitância:

$\dot{Y}=\frac{\dot{I}}{\dot{V}}$

$\dot{Y}=G+j B$

Onde G e B representam a condutância e a susceptância

Transformação

$\dot{Y}=\frac{\dot{I}}{\dot{V}} x \frac{V^{*}}{V^{*}}=\frac{\dot{S}}{V^{2}}=\frac{P+j Q}{V^{2}}=\frac{P}{V^{2}}+\frac{Q}{V^{2}}$
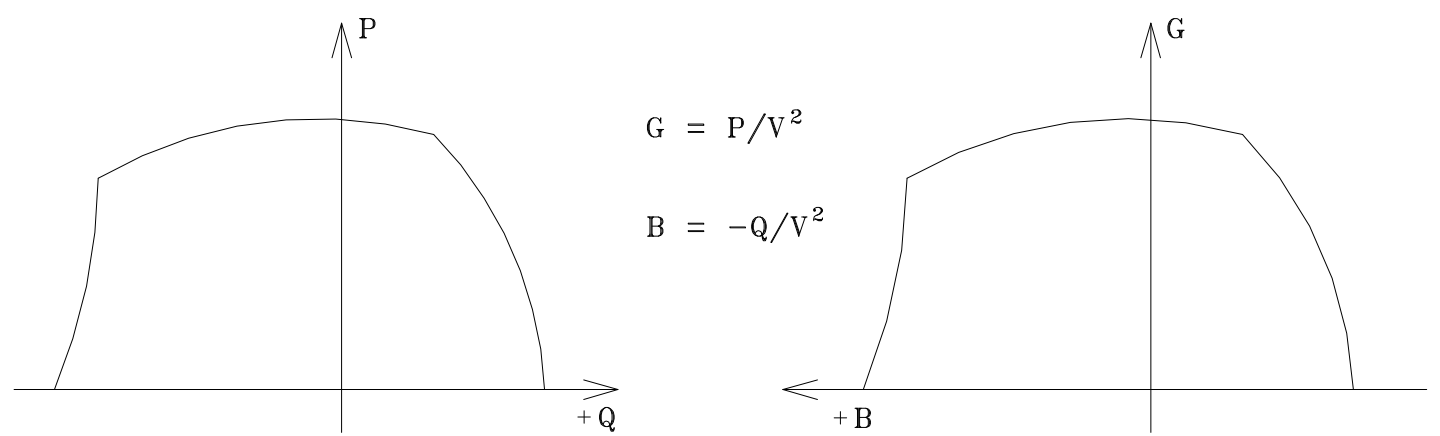

Fig. 19. Transformação da curva de capabilidade em diagrama de admitância

Veja que o diagrama de admitância resultante é diretamente proporcional a curva de capabilidade do gerador (em valores por unidade), somente o eixo da potência reativa deve ser multiplicado por -1 (menos um). 


\subsubsection{Sobrecarga no estator}

A utilização dos equipamentos do sistema elétrico até seus limites operacionais tem se tornado uma prática cada vez mais comum, com isto a proteção contra sobrecargas vem ganhando mais importância.

Geralmente, geradores são equipados com sensores de temperatura em pontos considerados críticos pelo fabricante. Estes sensores, para medir temperatura, aproveitam o efeito da variação da resistência elétrica em função da temperatura e são genericamente chamados de RTD's ("Resistance Temperature Devices”).

Alguns relés de proteção possuem entradas compatíveis com certos tipos de RTD's como o Pt100, NI100 e o NI120.

Independente do uso de RTD's uma proteção baseada na chamada “imagem térmica" onde a temperatura do objeto protegido é calculada a partir da corrente circulante, é interessante como proteção de retaguarda ou, como proteção principal no caso de geradores não equipados com sensores de temperatura.

\subsubsection{Proteção de tensão}

A proteção de tensão é tratada em duas faixas, sobretensão e subtensão.

Sobretensão visa proteger o gerador e equipamentos associados contra os efeitos de tensões impermissíveis.

Os ajustes de tempo para esta função devem ser coordenados com a atuação do regulador de tensão do gerador. A proteção não deve intervir no processo de regulação de tensão numa condição em que não haja nenhuma anomalia no sistema. Para tal, os ajustes de tempo desta função, devem ser superiores às características do regulador de tensão.

Por sua vez, a função de subtensão é útil para detectar condições anormais, principalmente relacionadas à estabilidade do sistema.

Curto-circuitos monofásicos e bifásicos causam assimetria no sistema trifásico de tensões, logo esta proteção deve ser baseada no sistema de seqüência positiva pois este não é influenciado por estes defeitos. 


\subsubsection{Freqüência}

A condição de operação em freqüências que não a nominal podem atingir, basicamente, três subsistemas que são o gerador, a turbina e o sistema interligado.

Para o gerador, o principal efeito é o aquecimento devido à operação em subfreqüência. Nesta condição o fluxo de ar diminuirá causando o aquecimento do gerador ou imporá uma operação abaixo da potência nominal.

Para a turbina, principalmente em turbinas a vapor, a operação fora da freqüência (rotação) nominal pode resultar em uma condição de ressonância com a freqüência natural das pás da turbina, gerando vibração excessiva e conseqüentemente esforços não permissíveis na turbina, danificando-a.

Especialmente no caso de turbinas a vapor, a fadiga causada nas pás, devido à operação fora da frequiência (velocidade) nominal é cumulativa. Para cada faixa de frequiência estabelecida pelo fabricante da turbina, o tempo de operação deve ser acumulado (somente após os 10 primeiros ciclos) e comparado com os limites estabelecidos. Após alcançado o tempo limite de, pelo menos, uma faixa de frequiências, atividades de manutenção nas pás são altamente recomendadas [15].

Para o sistema interligado, a freqüência é um indicador do balanço entre as cargas e a capacidade de geração do sistema. Visando manter este balanço constante, operações de rejeição de carga (ou geração) são indispensáveis, mantendo a operação estável do sistema. 


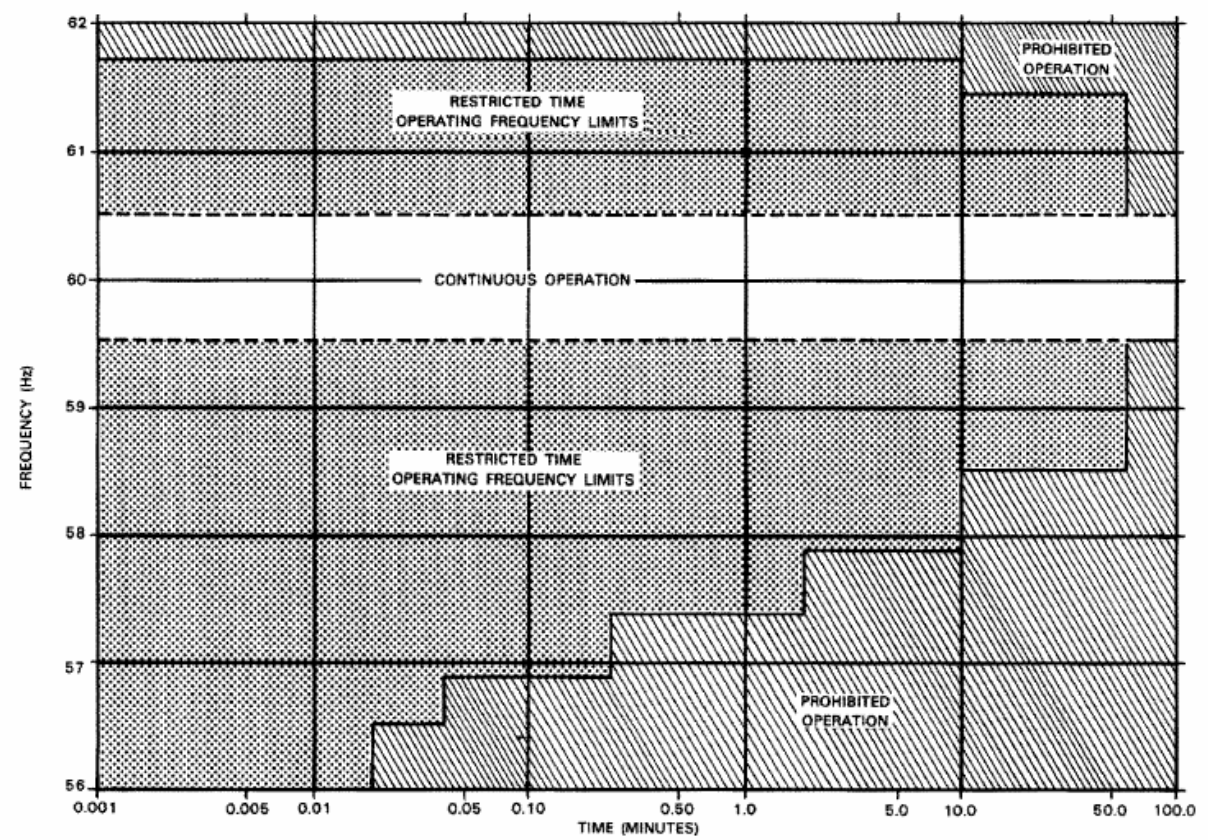

Fig. 20. Limites de operação, à plena carga ou carga parcial, em freqüências anormais (figura 6 de [15])

\subsubsection{Potência reversa}

Esta é utilizada para proteger o gerador (gerador e turbina) em caso de falha de sua máquina primária. Nesta situação o gerador funciona como um motor, girando sua turbina através de energia captada da rede. Isto conduz a danos, principalmente na turbina.

Ajustes típicos são da ordem de $1 \%$ a $3 \%$ da potencia nominal para turbinas à vapor , a gás e hidráulicas; e de $5 \%$ para motores diesel.

\subsubsection{Funções Complementares}

a) Detecção de defeitos no secundário do transformador de potencial (TP): No caso de falhas na medição da tensão do sistema, causada por curto-circuitos no secundário do TP, as funções de proteção que são dependentes da tensão atuarão erroneamente. Para evitar este efeito, contatos auxiliares do disjuntor (ou fusível) instalado no secundário do TP podem ser usados para bloquear as funções dependentes da tensão. 
Adicionalmente, a avaliação das correntes e tensão do sistema também é um meio confiável e eficaz para detectar defeitos no secundário do TP.

Esta função baseia-se no seguinte princípio:

$\underline{\text { Sistema íntegro: }}$

$\frac{V_{2}}{V_{1}}=0 \quad e \quad \frac{I_{2}}{I_{1}}=0$

Curto-circuito monofásico no secundário do TP:

$\frac{V_{2}}{V_{1}}=\frac{0,33}{0,66}=0,5 \quad e \quad \frac{I_{2}}{I_{1}}=0 \quad\left(\frac{V_{2}}{V_{1}}>\frac{I_{2}}{I_{1}}\right)$

Curto-circuito bifásico no secundário do TP:

$\frac{V_{2}}{V_{1}}=\frac{0,33}{0,33}=1 \quad e \quad \frac{I_{2}}{I_{1}}=0 \quad\left(\frac{V_{2}}{V_{1}}>\frac{I_{2}}{I_{1}}\right)$

O índice 2 refere-se ao sistema de seqüência negativa e o índice 1 ao sistema de sequiência positiva.

Curto-circuito trifásico no secundário do TP:

Este defeito não é detectado através da avaliação da razão entre tensões e correntes dos sistemas de seqüência positiva e negativa; mas sim da avaliação temporal (em função do tempo) do comportamento da tensão e corrente.

Caso a tensão caia a aproximadamente zero e a corrente, neste intervalo de tempo, se mantiver constante, (ou aproximadamente constante, isto é, sem características de curto-circuito) configura-se um forte indicativo de curto-circuito no secundário do TP.

Ajustes típicos são:

$\mathrm{V}_{2} / \mathrm{V}_{1}>0,4$ e $\mathrm{I}_{2} / \mathrm{I}_{1}<0,2$ (para curtos monofásicos e bifásicos)

b) Matriz de desligamento:

A um sistema de geração de energia elétrica são associados diversos disjuntores (dependendo da configuração e natureza da planta) como disjuntor do gerador, do sistema de excitação, do sistema de serviços auxiliares, da turbina entre outros. 
O sistema de proteção deve atuar nos diferentes disjuntores, dependendo da natureza da falta, visando minimizar os danos sobre a unidade geradora, além de permitir o pronto restabelecimento da unidade no caso de faltas transitórias. Par tal, utiliza-se a matriz de desligamento.

O princípio de operação está representado na fig. 21. Os disjuntores são representados nas colunas e as funções de proteção nas linhas. A programação desta matriz depende de vários fatores, dentre eles recomendações dos fabricantes do gerador e da turbina, experiência dos projetistas e critérios operacionais.

A implementação da matriz de desligamento pode ser feita através de software no próprio relé de proteção ou convencionalmente via relés eletromecânicos.

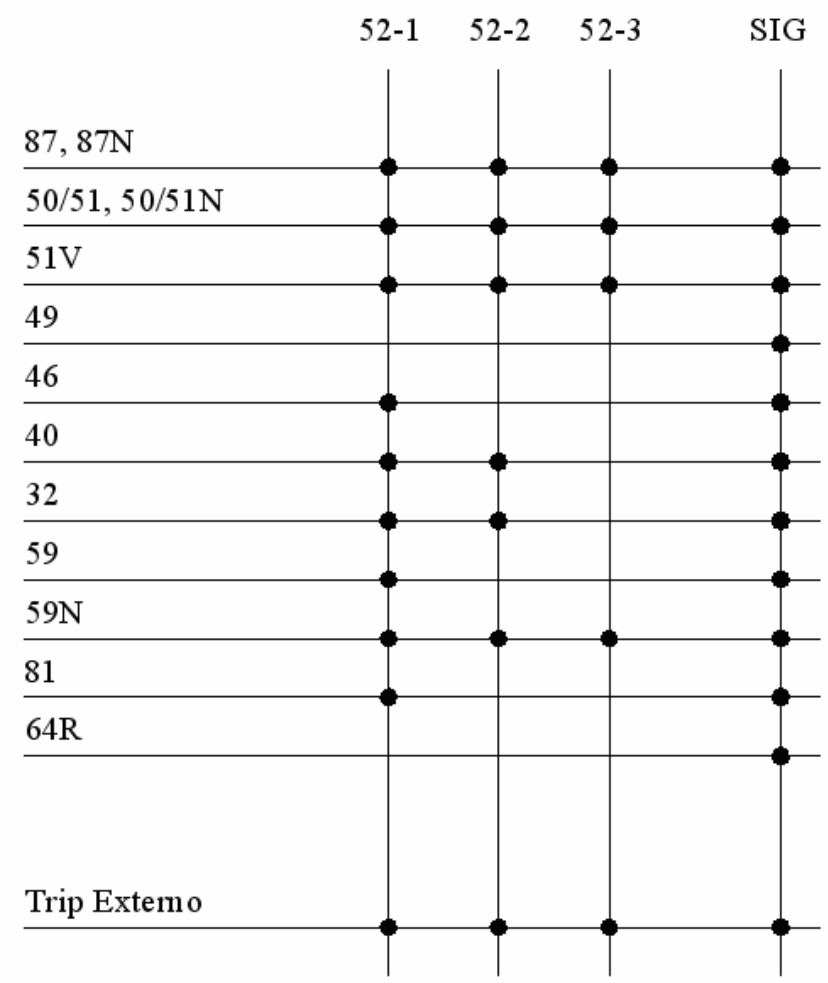

52-1: Disjuntor Principal

52-2: Disjuntor Principal com bloqueio de religamento

52-3: Disjuntor do Sistema de Excitação

SIG: Alarme e sinalização

Fig. 21. Representação de uma matriz de desligamento 


\section{PROTEÇÃO DIGITAL}

\subsection{Arquitetura de hardware}

Neste capítulo serão apresentados os principais componentes do hardware normalmente utilizado em relés de proteção digitais (microprocessados). Detalhes relacionados a este hardware não serão discutidos neste trabalho.

Na fig. 22 está representado o hardware normalmente utilizado em relés digitais de proteção.

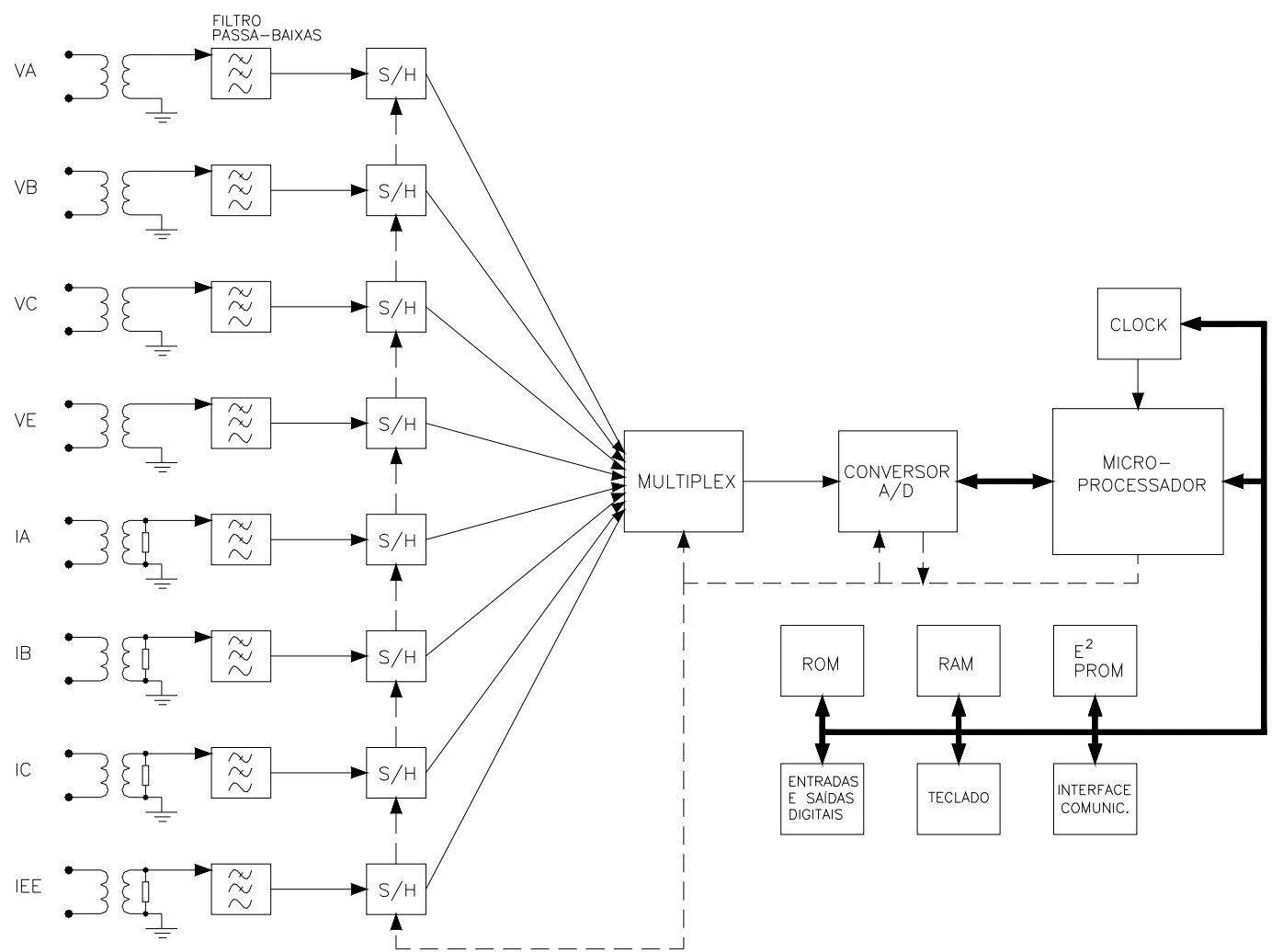

Fig. 22. Hardware típico de um relé digital para proteção de geradores 
A conversão analógica-digital (A/D) é usualmente executada a partir de sinais de tensão $( \pm 5 \mathrm{~V}$ ou $\pm 10 \mathrm{~V})$. Para tal, as tensões provenientes dos transformadores de potencial são convertidas e isoladas por transformadores auxiliares aos níveis de conversão A/D. Já para as correntes, provenientes dos transformadores de corrente, além do transformador auxiliar, um resistor com resistência conhecida (shunt) é geralmente utilizado para conversão do sinal de corrente para tensão.

Após isolação galvânica e adequação às características e níveis de conversão A/D, os sinais são submetidos a filtros passa-baixas que tem por função eliminar os erros de “aliasing" provocados pelo processo de amostragem. Após filtragem anti-aliasing, esses sinais são amostrados utilizando circuitos sample-hold $(\mathrm{S} / \mathrm{H})$ que tem por função manter a magnitude das amostras constantes durante o intervalo de conversão, além de permitir que todos os sinais de tensão e corrente tenham a mesma referência de tempo (importante para proteções onde mais de um sinal é analisado em conjunto, como nas funções direcional de potência, sobrecorrente com restrição de tensão entre outros).

No hardware apresentado, percebe-se que cada canal possui seu próprio sample-hold. Um multiplexador analógico controlado pelo microprocessador é utilizado em série com estes circuitos, permitindo que a digitalização seja feita por apenas um conversor $\mathrm{A} / \mathrm{D}$. Com a diminuição dos custos dos conversores $\mathrm{A} / \mathrm{D}$, a tendência é a utilização de um conversor por sinal.

Após passagem pelo conversor $\mathrm{A} / \mathrm{D}$, os sinais digitalizados são então manipulados pelo microprocessador que executa o algoritmo pré-programado.

$\mathrm{O}$ algoritmo de proteção se encontra gravado na memória ROM e seus ajustes são armazenados na $E^{2}$ PROM. A memória RAM armazena apenas valores digitalizados de amostras e cálculos intermediários executados pelo algoritmo de proteção. 


\subsection{Processamento dos sinais do sistema de potência}

Como mencionado no capítulo 3.1, o processo de amostragem introduz erros de aliasing nos sinais medidos pelo relé. Isso pode ser evitado caso a frequiência de amostragem seja escolhida de modo a obedecer ao teorema da amostragem, como segue:

Supondo um sinal $\mathrm{x}(\mathrm{t})$ com espectro $|\mathrm{X}(\mathrm{f})|$, denominado banda base.

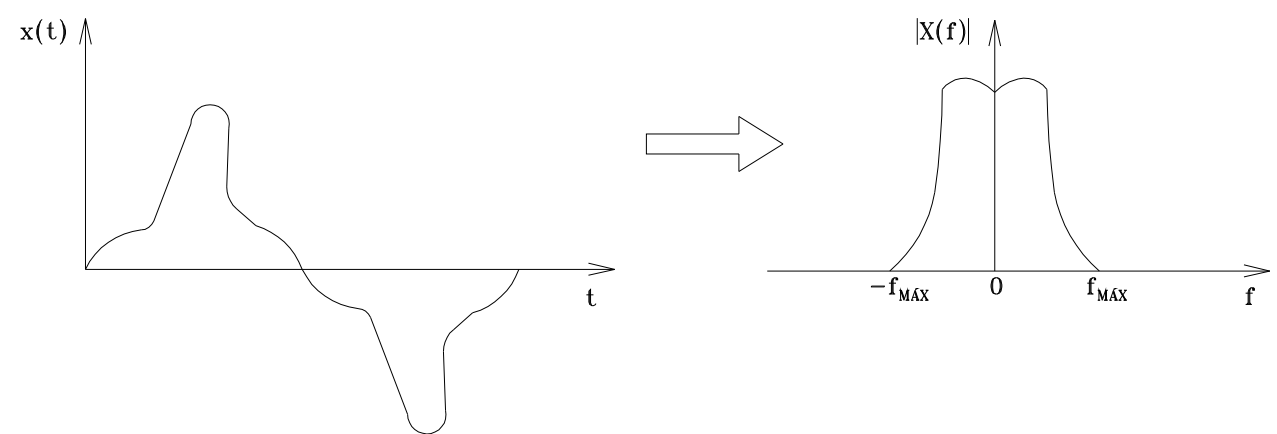

Fig. 23. Banda base do sinal $\mathrm{x}(\mathrm{t})$

Após o processo de amostragem, o espectro deste sinal conterá, além da banda base, infinitas bandas secundárias originárias da replicação da banda base em torno de freqüências múltiplas inteiras da freqüência de amostragem, conforme ilustrado na fig. 24.
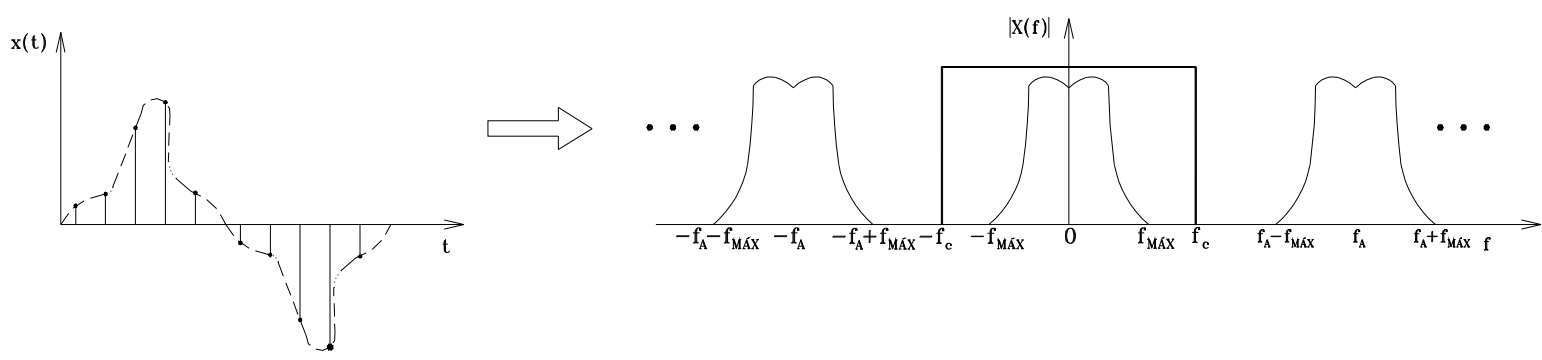

Fig. 24. Espectro do sinal $\mathrm{x}(\mathrm{t})$ após amostragem com freqüência $\mathrm{f}_{\mathrm{A}}$

Percebe-se que para evitar o erro de aliasing, a freqüência de amostragem deve ser escolhida de modo a satisfazer o critério de Nyquist, eq. 8 [16].

$f_{A}>2 \cdot f_{\text {MÁX }}$ 
Assim, o espectro do sinal original poderá ser recuperado utilizando um filtro passabaixas com freqüência de corte satisfazendo o estabelecido na eq. 9.

$f_{C}=\frac{f_{A}}{2}$

Eventualmente, em relés de proteção pode-se admitir uma pequena sobreposição de espectro, pois vias de regra, além da frequiência fundamental, apenas o $3^{\circ}$ e $5^{\circ}$ harmônicos são considerados. Portanto, certo grau de aliasing é tolerado desde que não interfira nas componentes do sinal a serem processadas.

Depois de filtrados analogicamente, os sinais de entrada passam por uma etapa de digitalização antes de serem processados pelo algoritmo do relé. Por se tratar de um assunto relevante à implementação em hardware, esta etapa do processamento dos sinais não será abordada neste trabalho. 


\section{ALGORITMOS DE PROTEÇÃO DIGITAL}

\subsection{Algoritmo de filtragem baseado no método de Fourier}

A grande maioria das funções de proteção utilizadas em geradores, descritas no item 2.4, baseiam-se em algoritmos que empregam fasores referentes aos sinais de tensão e corrente. Desta forma, o primeiro objetivo dos algoritmos de filtragem aplicados a proteção de geradores é obter uma estimativa precisa desses fasores a partir das amostras instantâneas dos sinais de tensão e corrente.

Os algoritmos mais comumente utilizados para esta finalidade (cálculo de fasores) são baseados no método de Fourier. Esse método tem como uma de suas características a necessidade de se tomar um número inteiro e constante de amostras por ciclo da componente fundamental do sinal. Particularmente na proteção de geradores, onde a freqüência do sinal pode excursionar em uma faixa bastante ampla, caso o hardware do relé utilize uma freqüência de amostragem constante, essa exigência do método de Fourier não será atendida e erros significativos poderão ser observados no cálculo dos fasores. O desenvolvimento apresentado a seguir neste item visa quantificar estes erros.

No método baseado em Fourier (anexo A), o fasor correspondente à componente fundamental de um sinal pode ser obtido através da utilização de dois filtros ortogonais como indicado pelas equações 10 a 13 a seguir:

$$
\begin{aligned}
& Y_{C}=\frac{2}{N} \sum_{l=0}^{N-1} s(n-(N-1)+l) \cos \left(\frac{2 \pi}{N} l\right) \\
& Y_{S}=\frac{2}{N} \sum_{l=0}^{N-1} s(n-(N-1)+l) \operatorname{sen}\left(\frac{2 \pi}{N} l\right)
\end{aligned}
$$

Fasor na forma retangular:

$$
A_{1} \angle \phi_{1}=Y_{C}-j Y_{S}
$$

Fasor na forma polar:

$$
A_{1}=\sqrt{Y_{C}^{2}+Y_{S}^{2}} \quad \text { e } \quad \phi_{1}=\operatorname{tg}^{-1}\left(\frac{-Y_{S}}{Y_{C}}\right)
$$


A título de ilustração, a fig. 25 apresenta a resposta em freqüência dos filtros Yc e Ys projetados quando se utiliza uma taxa de amostragem de 16 amostras por ciclo.

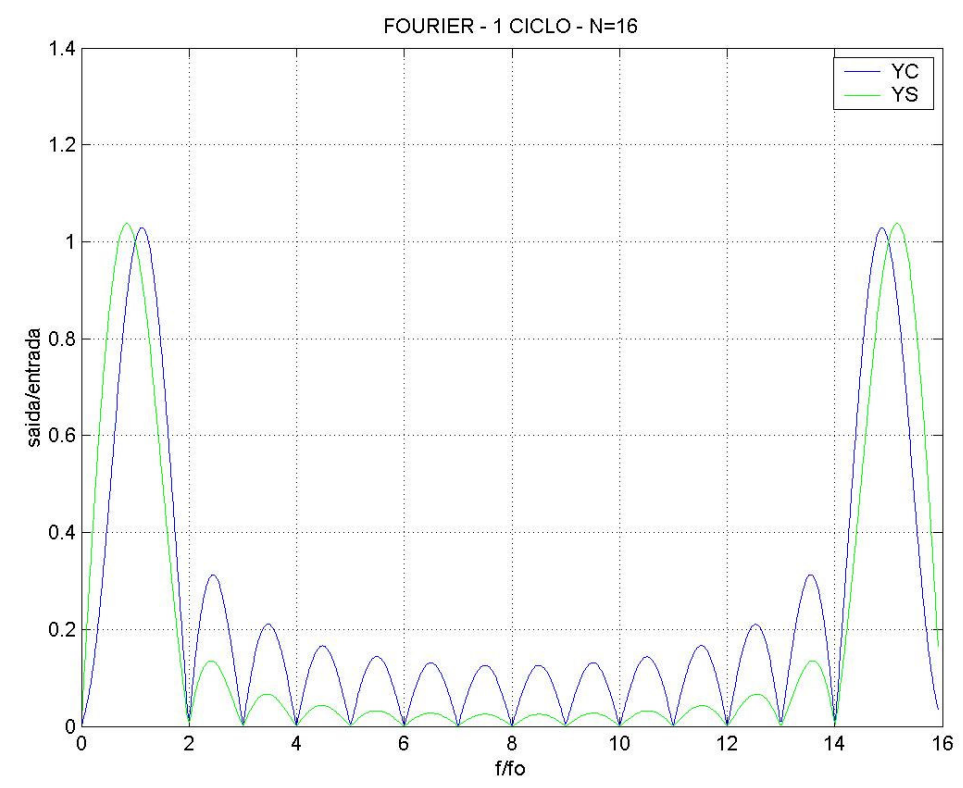

Fig. 25. Resposta em freqüência dos filtros Yc e Ys

Observa-se na fig. 25 a atenuação de todos os harmônicos, com exceção do $15^{\circ}$ harmônico (N-1), o qual deve ser eliminado pela filtragem analógica.

Utilizando um filtro analógico classe Butterworth, de terceira ordem e frequiência de corte de $180 \mathrm{~Hz}$, consegue-se atenuação deste harmônico. A resposta em freqüência do filtro analógico e seu efeito nos filtros Yc e Ys estão apresentados na figura 26. 

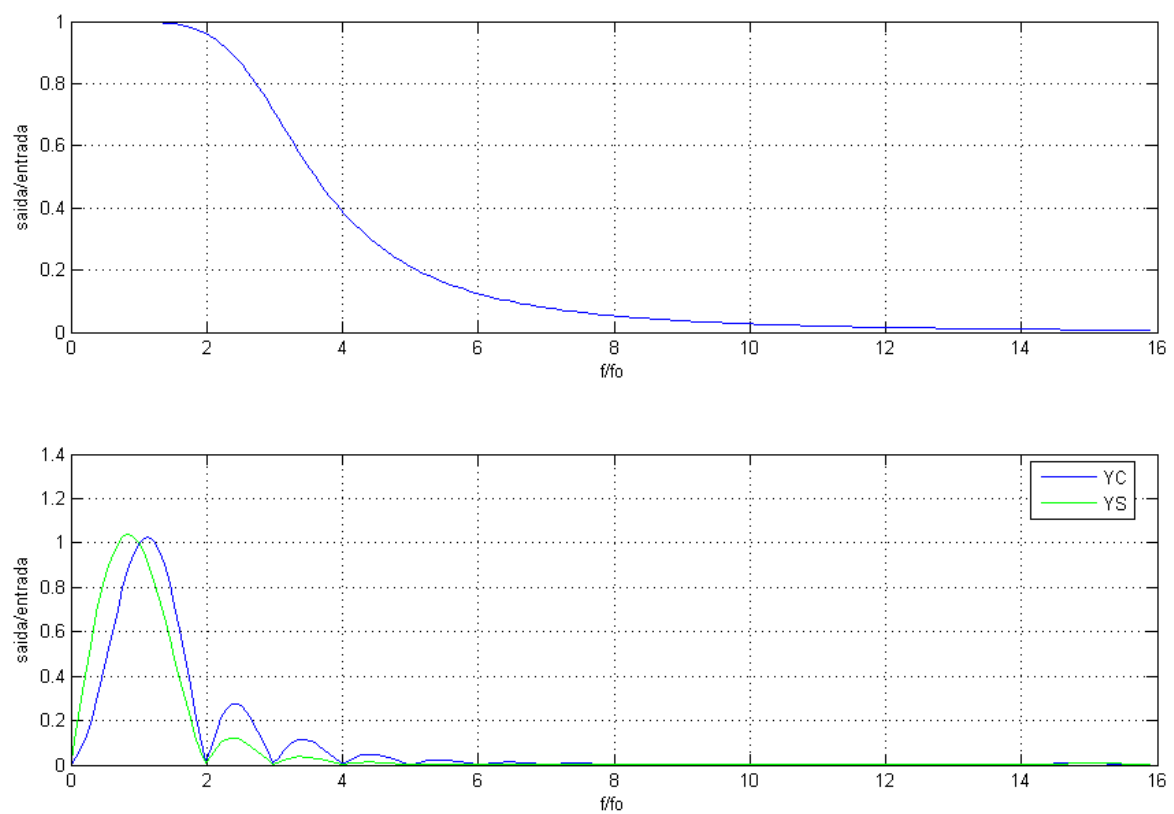

Fig. 26. Filtro analógico e seu efeito nos filtros Yc e Ys

Aplicando-se os filtros Yc e Ys em um sinal senoidal de $60 \mathrm{~Hz}$, amostrado a taxa de 16 amostras por ciclo tem-se a resposta representada na fig. 27.

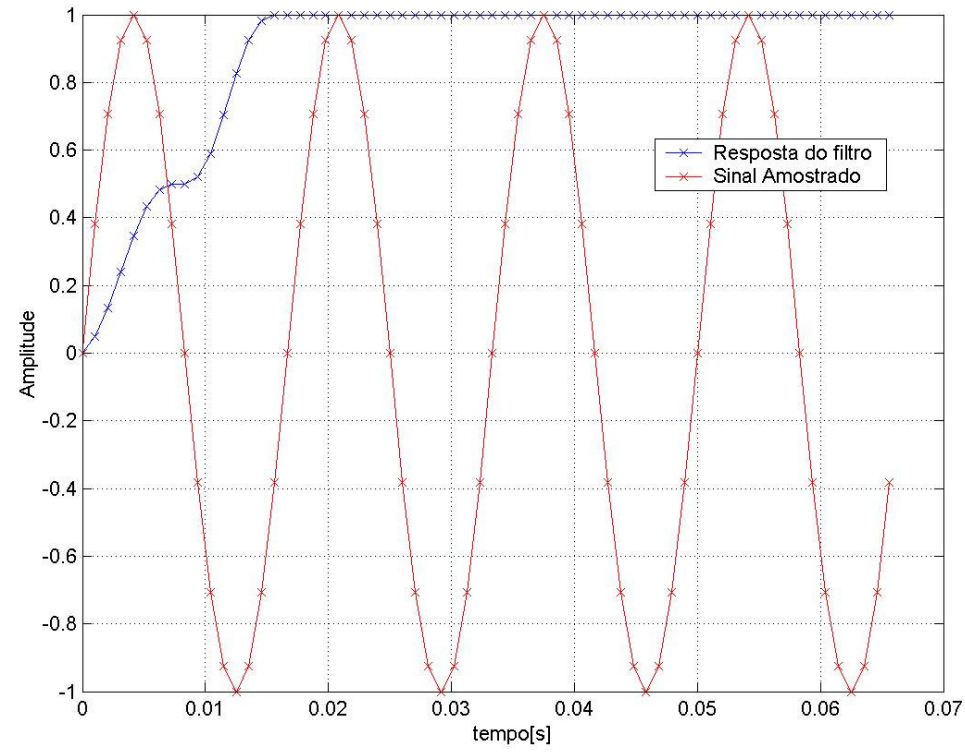

Fig. 27. Resposta dos filtros Yc e Ys a um sinal senoidal de $60 \mathrm{~Hz}$ 
A definição da série discreta de Fourier (eq. 14, demonstrada no anexo A), exige um número inteiro de amostras por ciclo, isto é, a relação $\mathrm{N}=\mathrm{To} / \mathrm{T}_{\mathrm{A}}$ (relação período do sinal pelo período de amostragem) deve resultar em um número inteiro. Caso a freqüência do sinal do sistema de potência varie, a relação $\mathrm{To} / \mathrm{T}_{\mathrm{A}}$ não será constante e erros serão introduzidos na estimativa da amplitude. A seguir é apresentada uma análise deste tipo de erro, para estimativa da amplitude da fundamental [21].

Do anexo A, tem-se o coeficiente da série discreta de Fourier dado pela eq. 14:

$C_{k} \cong \frac{1}{N} \sum_{l=0}^{N-1} s(n) e^{-j k \frac{2 \pi}{N} l}$

Consideremos que o sinal $\mathrm{s}(\mathrm{t})$ é composto somente pela fundamental com amplitude unitária, tem-se:

$$
s(t)=\cos (2 \pi f t+\phi)
$$

Sendo amostrada a uma frequiência fa, totalizando $N=$ fa/60 amostras/ciclo. As amostras podem ser escritas como:

$$
s(n)=\cos \left(2 \pi \frac{f}{f a} n+\phi\right)=\frac{1}{2}\left[e^{j \phi} e^{j 2 \pi \frac{f}{f a} n}+e^{-j \phi} e^{-j 2 \pi \frac{f}{f a} n}\right], \mathrm{n}=0,1, \ldots, \mathrm{N}-1
$$

O fasor pode ser estimado aplicando-se a eq. 16 na eq. 14 , como segue.

$$
\begin{aligned}
& \text { Sendo } c_{k}=\frac{c_{L}}{N} \text {, tem-se: } \\
& c_{L}=\sum_{n=0}^{N-1} s(n) e^{-j \frac{2 \pi}{N} n}=\sum_{n=0}^{N-1} s(n) e^{-j 2 \pi \frac{60}{f a} n}
\end{aligned}
$$


Que pode ser escrito como:

$c_{L}=\frac{1}{2}\left[c_{L, 1}+c_{L, 2}\right]$

Sendo:

$c_{L, 1}=e^{j \phi} \sum_{n=0}^{N-1} e^{j \frac{2 \pi}{f a}(f-60) n}=e^{j \phi} \frac{1-e^{j \frac{2 \pi}{f a}(f-60) N}}{1-e^{j \frac{2 \pi}{f a}(f-60)}}$
$c_{L, 2}=e^{-j \phi} \sum_{n=0}^{N-1} e^{-j \frac{2 \pi}{f a}(f+60) n}=e^{j \phi} \frac{1-e^{-j \frac{2 \pi}{f a}(f+60) N}}{1-e^{-j \frac{2 \pi}{f a}(f+60)}}$

A estimativa da amplitude da fundamental é o módulo de $c_{L} / \mathrm{N}$.

A seguir será apresentado o erro percentual na estimativa da amplitude para freqüência de amostragem de $960 \mathrm{~Hz}$ (16 amostras por ciclo), em função da freqüência do sinal e de sua fase.

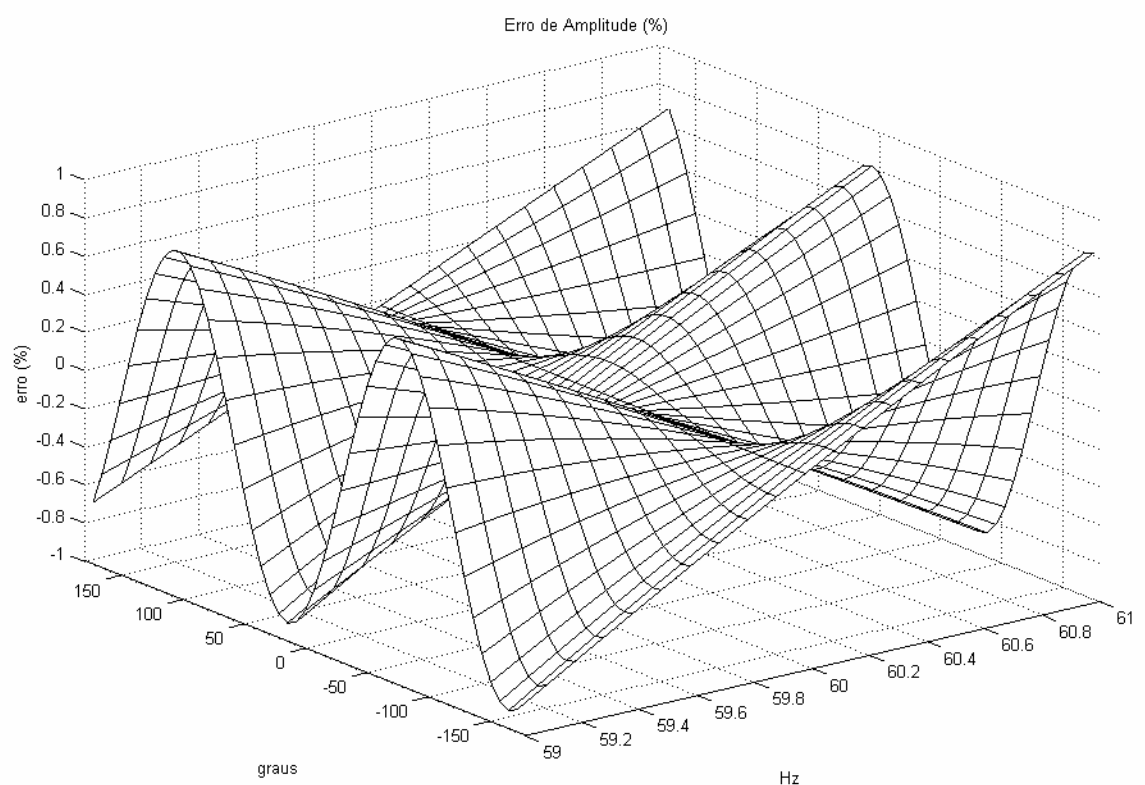

Fig. 28. Erro de amplitude para variação da freqüência do sinal entre 59 e $61 \mathrm{~Hz}$ 
O erro pode ser visualizado apenas em função da freqüência do sinal (considerando a variação de fase), como segue:

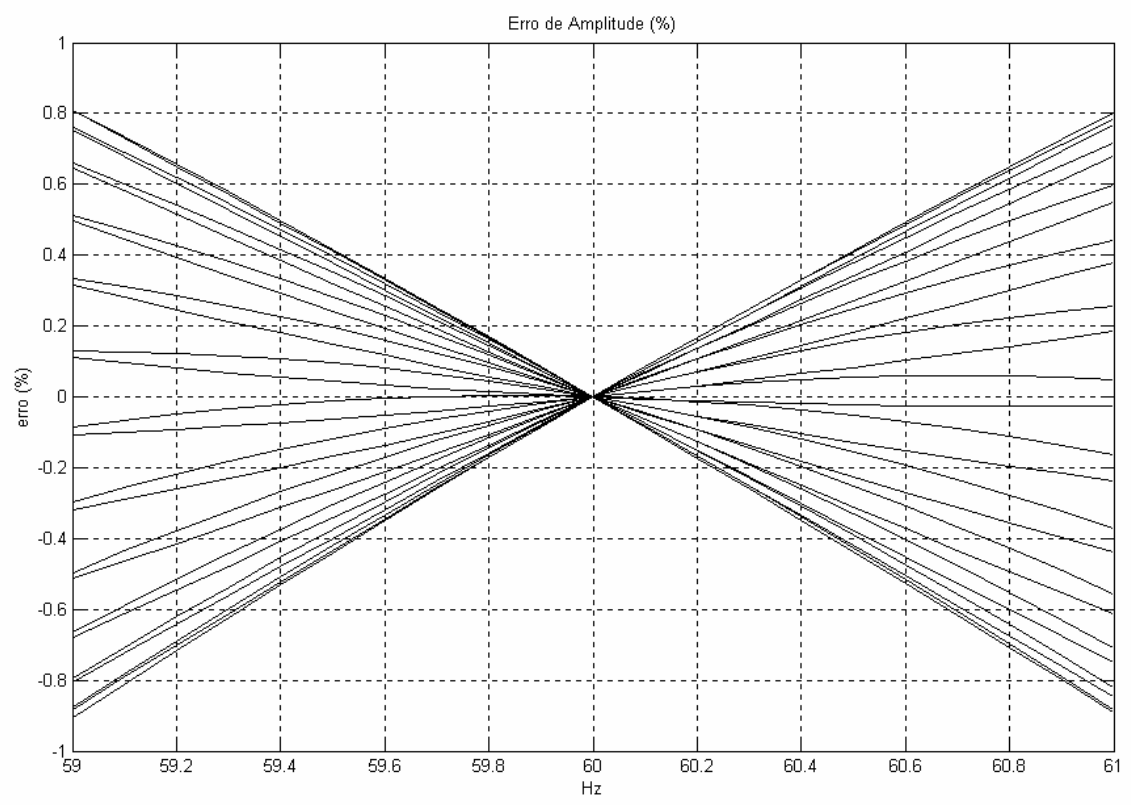

Fig. 29. Erro de amplitude para variação da freqüência do sinal entre 59 e $61 \mathrm{~Hz}$ em função da freqüência

Observa-se que o erro permanece menor do que $1 \%$ para frequiências entre 59 e $60 \mathrm{~Hz}$.

Os erros aumentam conforme a freqüência do sinal se afasta da frequiência para o qual o filtro foi projetado $(60 \mathrm{~Hz}$ neste caso), como demonstrado nas figs. 30 e 31 . 


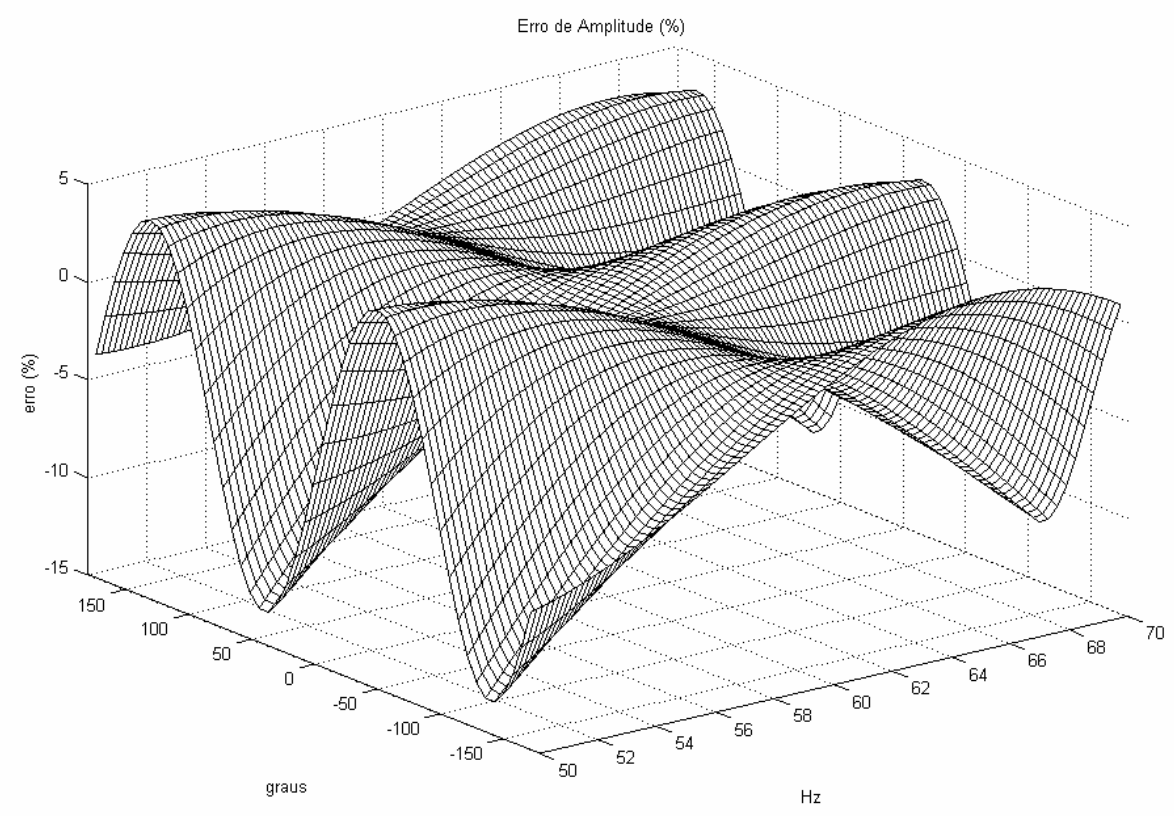

Fig. 30. Erro de amplitude para variação da freqüência do sinal entre 50 e $70 \mathrm{~Hz}$ em função da frequiência e fase do sinal

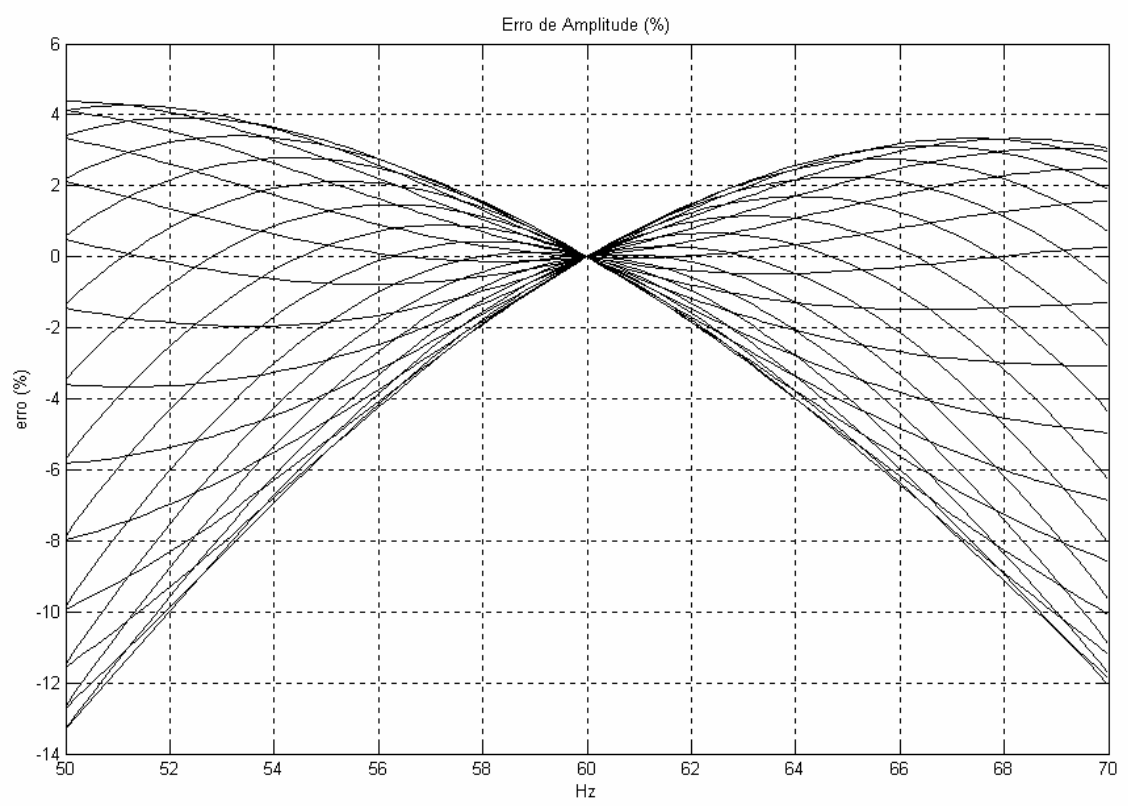

Fig. 31. Erro de amplitude para variação da frequiência do sinal entre 50 e 70 em função da frequiência do sinal

Observa-se que para um sinal com freqüência de $50 \mathrm{~Hz}$, os erros se aproximam de 14\%, causando oscilação na estimativa da amplitude, em função do tempo, como representado na fig. 32. 


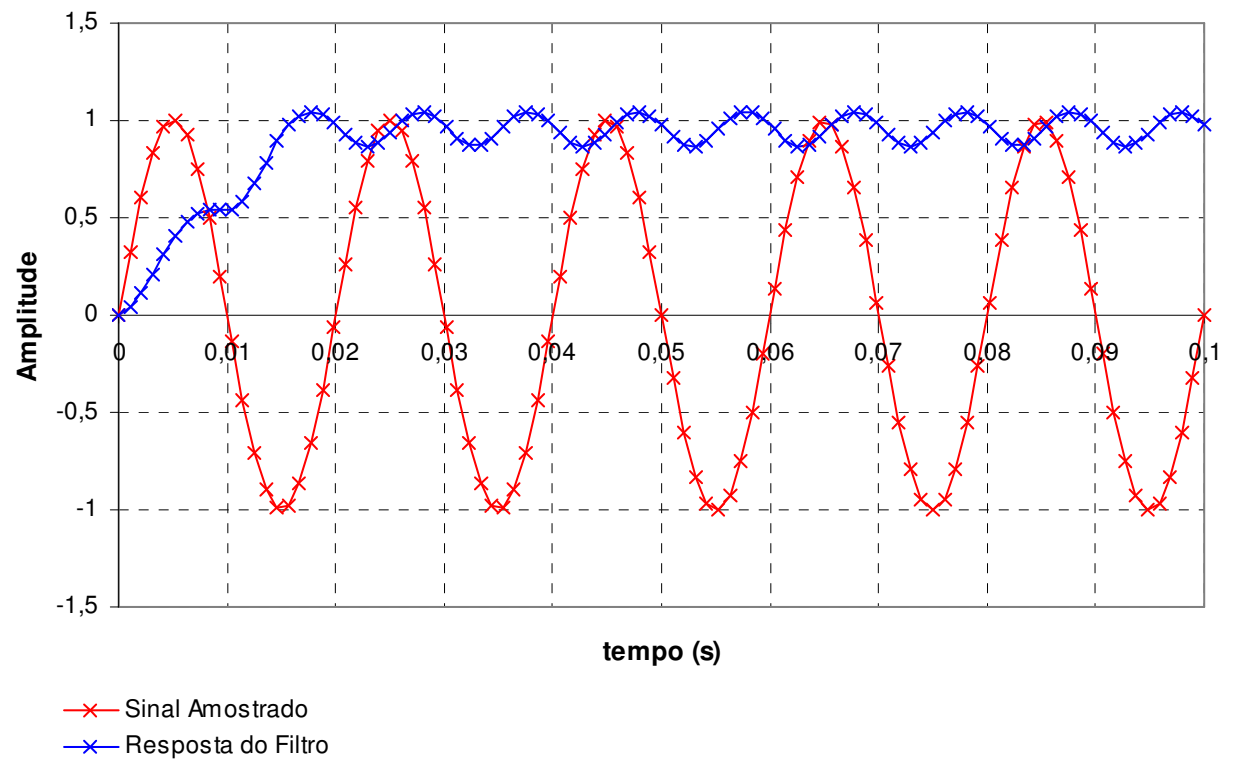

Fig. 32. Visualização do erro de amplitude, em função do tempo, para um sinal com frequiência de $50 \mathrm{~Hz}$

A oscilação observada pode ser explicada pelo fato da fase do sinal em relação a janela de dados variar ao longo do tempo e que, como já mostrado o erro depende da fase.

Considerando freqüências entre $20 \mathrm{~Hz}$ e $70 \mathrm{~Hz}$, os erros podem ser visualizados nas figs. 33 e 34 . 


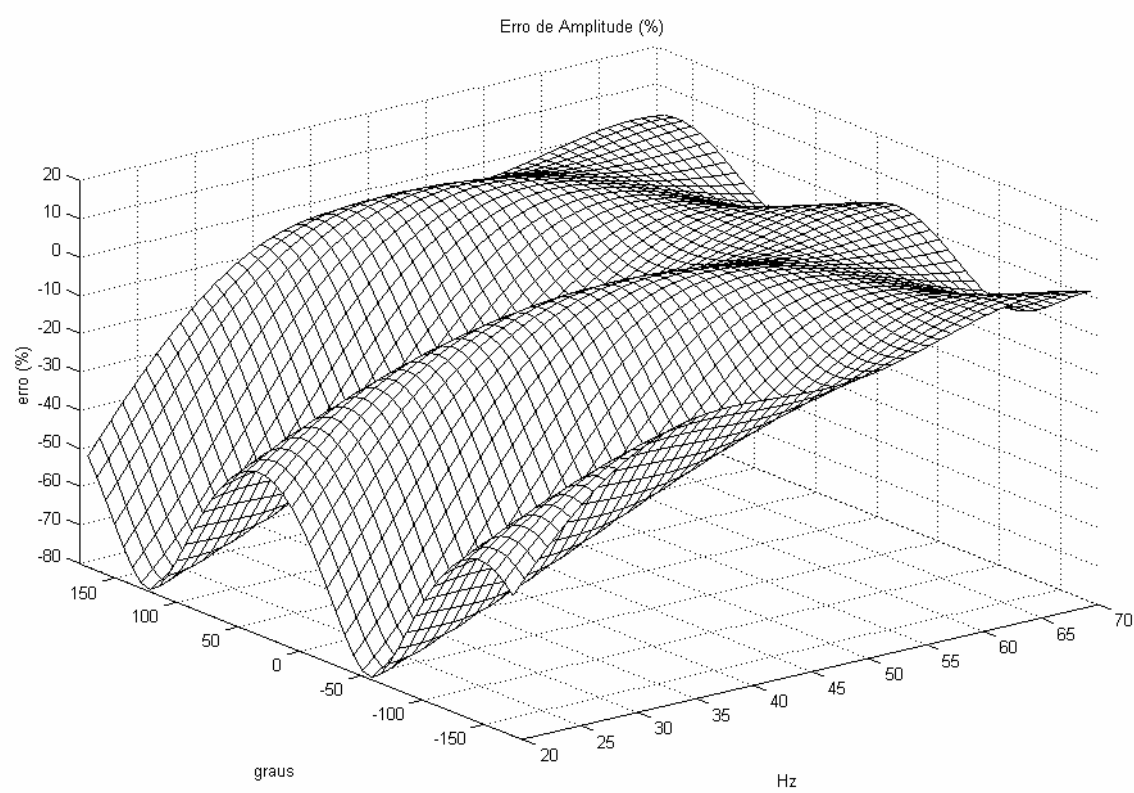

Fig. 33. Erro de amplitude para variação da freqüência do sinal entre 20 e $70 \mathrm{~Hz}$ em função da frequiência e fase do sinal

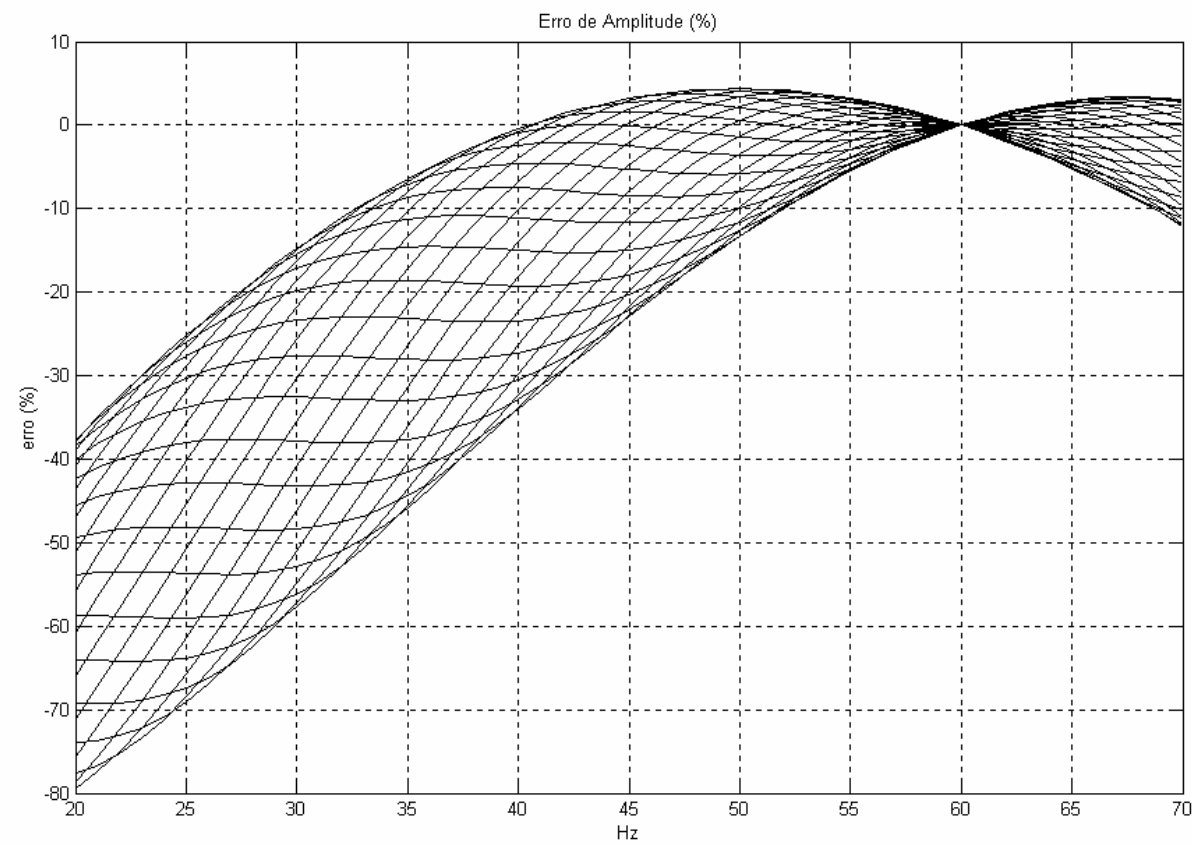

Fig. 34. Erro de amplitude para variação da freqüência do sinal entre 20 e $70 \mathrm{~Hz}$, em função da freqüência do sinal

A estimativa da amplitude, em função do tempo para sinais com freqüência de 30 e $40 \mathrm{~Hz}$ pode ser visualizada nas figuras. 35 e 36 . 


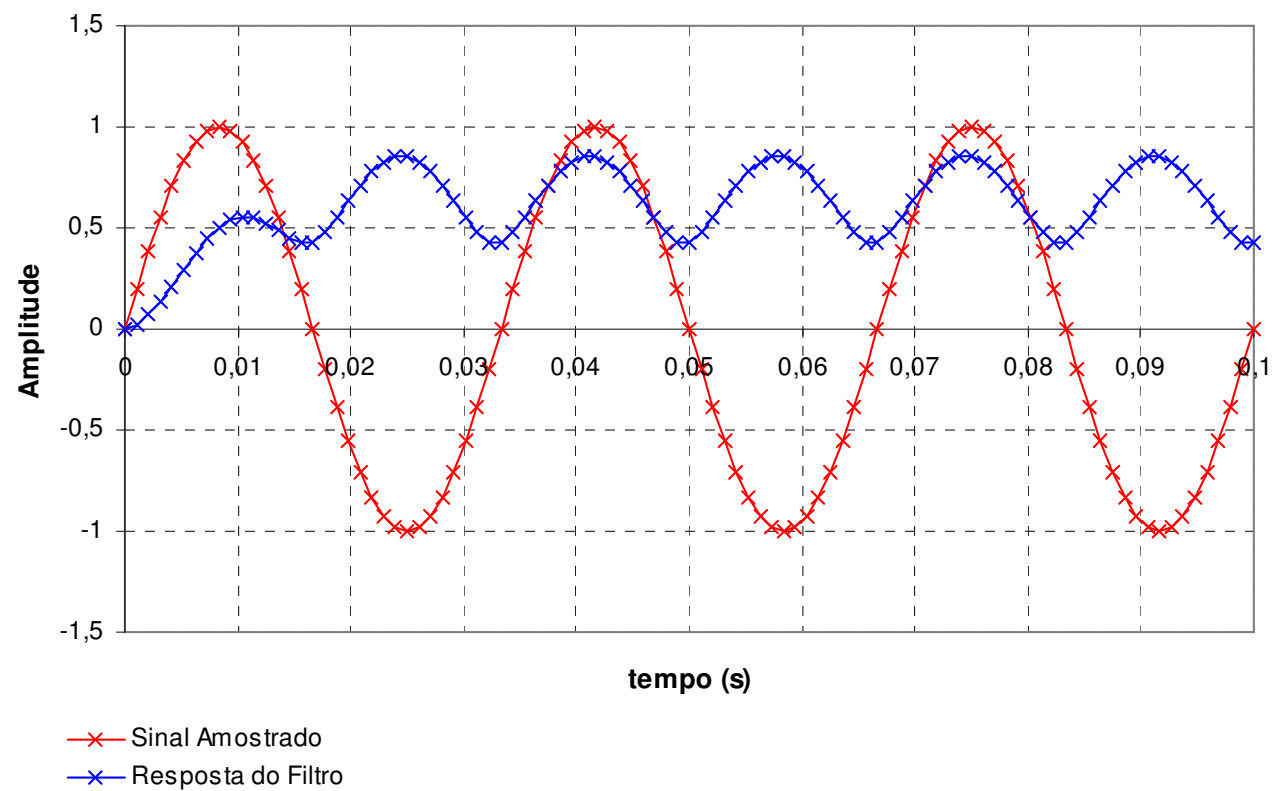

Fig. 35. Visualização do erro de amplitude, em função do tempo, para um sinal com frequiência de $30 \mathrm{~Hz}$

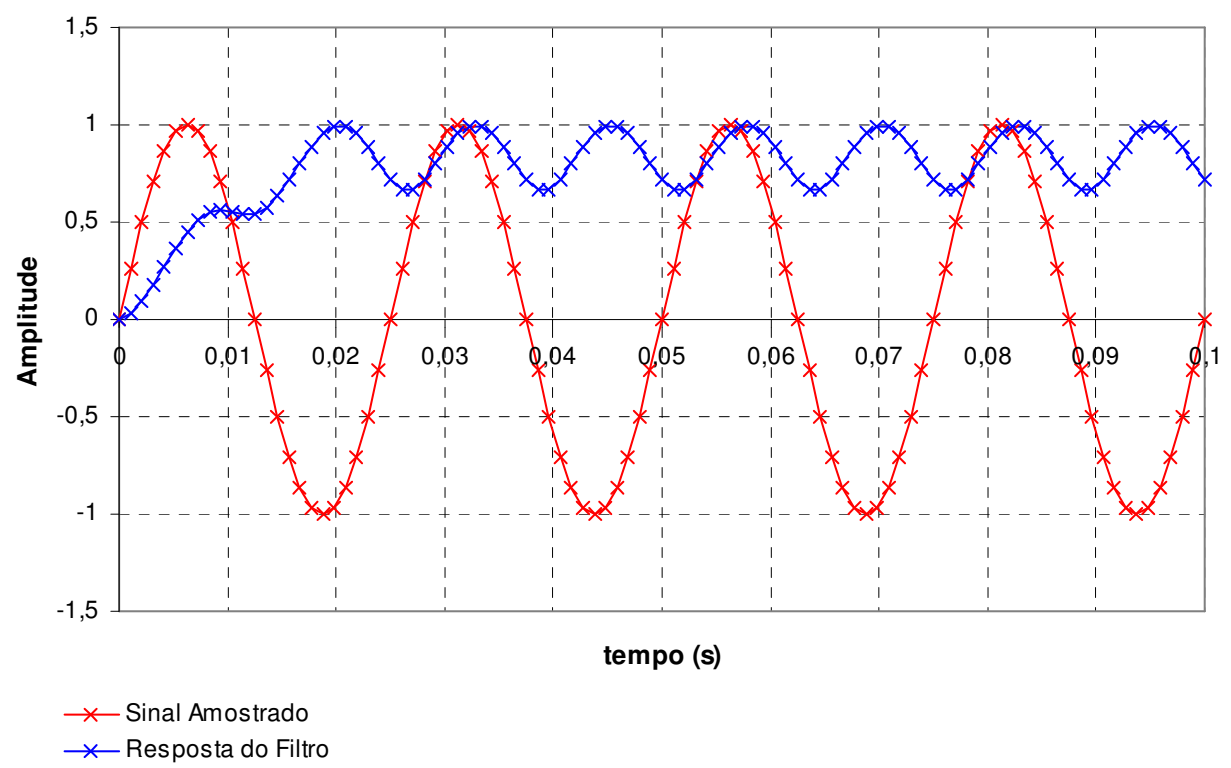

Fig. 36. Visualização do erro de amplitude, em função do tempo, para um sinal com frequiência de $40 \mathrm{~Hz}$ 
Considerando esta característica desfavorável dos filtros digitais baseados no método de Fourier, relés microprocessados para proteção de geradores com grande penetração no mercado, como dos fabricantes Siemens [1], GE [2], SEL [3] e Alstom [4] utilizam freqüência de amostragem variável de forma a manter constante o número de amostras por ciclo $(\mathrm{N})$ para toda sua faixa de atuação (geralmente de $20 \mathrm{~Hz}$ a $70 \mathrm{~Hz}$ ) obtendo, desta forma, uma estimativa precisa dos sinais do sistema de potência. 


\subsection{Estado da arte}

Como visto no item anterior, erros são introduzidos na avaliação dos fasores quando há variação na frequiência do sinal. Portanto detectar rapidamente variações de freqüência nos sinais do sistema de potência torna-se imprescindível para os algoritmos utilizados na proteção de geradores.

Vários métodos para avaliação da freqüência têm sido propostos e registrados na literatura. Estes podem ser classificados, a grosso modo, em três categorias que são:

- Estimativa da frequiência através da medição de um período (ou $1 / 2$ período) do sinal (passagem por zero) [22];

- Estimativa da frequiência através de métodos numéricos baseados no método dos mínimos quadrados e interpolação linear [23];

- Estimativa da frequiência através do método de Fourier (DFT), processando o incremento de fase em duas amostras consecutivas [24].

A última categoria permite a avaliação simultânea da freqüência e amplitude do sinal em frequiências que não a nominal, possibilitando medidas corretivas mais rápidas e com carga computacional menor. Dentro desta, outras três categorias podem ser identificadas, como segue:

- Amostragem adaptativa (freqüência de amostragem variável) que mantém constante o número de amostras por ciclo $[5,6]$;

- Janela de dados variável, ajustando o comprimento da janela de acordo com a freqüência atual do sinal, permitindo que a janela cubra exatamente um ciclo [19];

- Técnica que mantém constante a janela de dados, mas varia os coeficientes dos filtros de acordo com a frequiência atual através de um processo iterativo [17, $18]$. 
Visando permitir a utilização de um hardware mais simples para relés de proteção em aplicações para proteção de geradores, optou-se por uma técnica que permite estimativa dos fasores (para uma faixa ampla de frequiências) a partir de uma freqüência de amostragem constante.

Os trabalhos de Sachdev e Sidhu $[17,18]$ descrevem uma técnica simples em que, a partir de uma amostragem constante, a freqüência é calculada processando o incremento de fase em duas amostras consecutivas. Descreve, ainda, que os fasores do sistema de potência podem ser estimados através de um processo iterativo de recalculo dos coeficientes dos filtros ortogonais em função da frequiência medida em cada iteração. Entretanto as citadas referências não descrevem o processo de recálculo dos filtros ortogonais.

Tomando-os como referência, neste trabalho, propõe-se o método dos mínimos quadrados para recalculo dos coeficientes dos filtros ortogonais e a utilização de filtros de média (amplitude e freqüência) para estabilização do processo.

O processo para recálculo dos filtros será descrito em detalhes permitindo verificar peculiaridades em sua aplicação.

O processo de cálculo será chamado de AIVF, Algoritmo Imune a Variações de Freqüência, sendo descrito no próximo capítulo (4.3). 


\subsection{O algoritmo imune a variações de freqüiência (AIVF)}

O desenvolvimento de um algoritmo que possa compensar os erros causados pela variação da freqüência do sinal do sistema de potência é interessante, pois permite a utilização de um hardware comum (freqüência de amostragem constante) no desenvolvimento de relés de proteção para geradores.

O princípio de funcionamento deste algoritmo consiste na rápida avaliação da freqüência do sinal. Caso seja detectada variação de freqüência, os coeficientes dos filtros Yc e Ys (vide equações 10 e 11) devem ser recalculados, minimizando os erros na estimativa dos fasores.

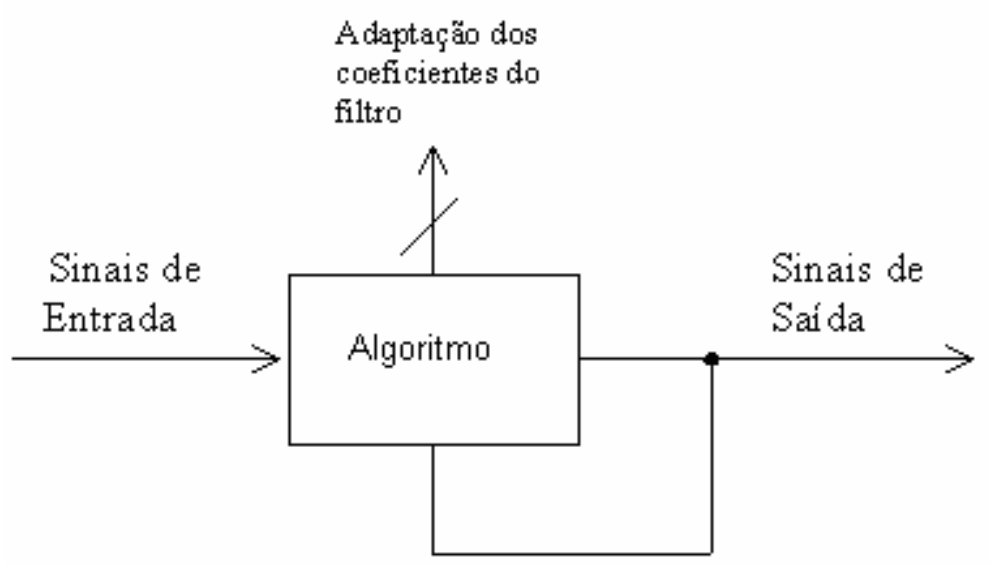

Fig. 37. Estrutura geral do algoritmo 
Uma rápida avaliação da freqüência do sinal pode ser conseguida a partir da diferença angular de dois fasores $(\Delta \phi)$ calculados a partir de duas amostras de duas janelas consecutivas [17 e 18]. A diferença angular representa a rotação do fasor do sinal, para um intervalo de amostragem, como segue:
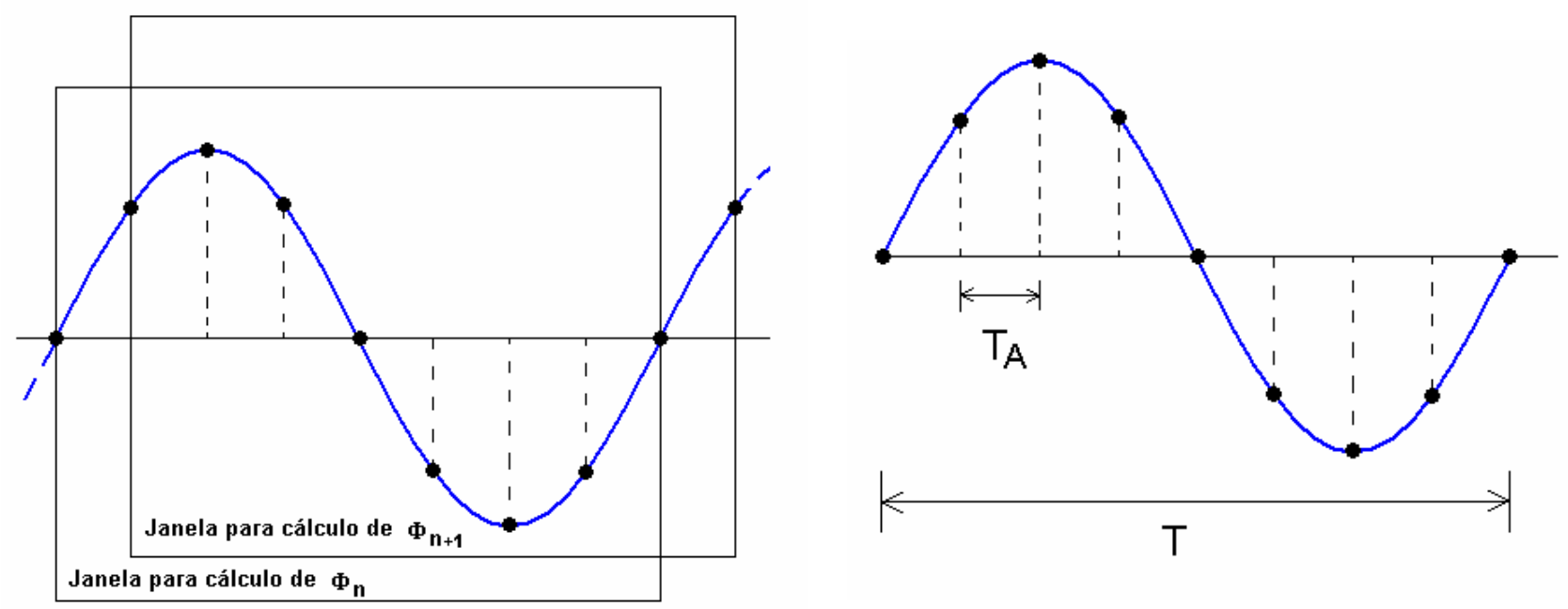

Fig. 38. Estimativa da frequiência de um sinal a partir da diferença angular de dois fasores consecutivos

Da fig. 38, tem-se:

$\mathrm{N}=$ número de amostras por ciclo

$\mathrm{T}=\mathrm{N} \mathrm{T}_{\mathrm{A}}$

$\Delta \phi=\frac{2 \pi}{N}=\frac{2 \pi \mathrm{T}_{\mathrm{A}}}{T}=2 \pi \mathrm{T}_{\mathrm{A}} f$

$f=\frac{\Delta \phi}{2 \pi \mathrm{T}_{\mathrm{A}}}$ 
A seguir apresenta-se uma descrição básica do AIVF:

Considerando o sinal do sistema de potência com freqüência supostamente igual à nominal (fo), amostrado a uma freqüência fa, pode-se projetar filtros ortogonais para extrair a componente real e imaginária e a partir destas calcular o fasor $(A \angle \phi)$.

A freqüência do sinal pode ser calculada como sugerido por Phadke, et al. [24] e utilizada por Sidhu e Sachdev [17 e 18], a partir de fasores calculados por duas janelas de dados consecutivas (eq. 21).

A partir daqui, duas situações podem ocorrer:

1) A freqüência calculada é igual à freqüência utilizada no projeto dos filtros ortogonais.

2) A freqüência calculada é diferente da freqüência utilizada no projeto dos filtros ortogonais.

Para o caso de 1) ser verdadeira, sugere-se para o cálculo da amplitude do fasor aplicação de um filtro de média de três amostras, $A_{n}=\left(A_{n}+A_{n-1}+A_{n-2}\right) / 3$.

Feito isso, incrementa-se a janela de dados. Este filtro visa estabilizar o cálculo da amplitude do sinal, eliminando resultados espúrios.

Para o caso de 2) ser verdadeira, inicia-se um processo iterativo, recalculando os filtros ortogonais a partir da nova frequiência calculada (utilizando o método dos mínimos quadrados) e filtrando novamente a janela de dados atual e anterior, obtendo-se $\phi_{n}$ e $\phi_{n+1}$, de onde se pode recalcular a freqüência. Este processo será encerrado quando a diferença entre a freqüência calculada e a frequiência utilizada no projeto dos filtros ortogonais na iteração anterior for menor que uma tolerância $\varepsilon$.

Para cada iteração, antes do recálculo dos coeficientes dos filtros, sugere-se aplicação de um filtro de média de quatro amostras para freqüências abaixo de $40 \mathrm{~Hz}$.

$f_{n}=\left(f_{n}+f_{n-1}+f_{n-2}+f_{n-3}\right) / 4$

A aplicação deste filtro médio, semelhante ao filtro médio para amplitude, visa estabilizar o cálculo da amplitude do sinal, eliminando resultados espúrios, 
especialmente em freqüências abaixo de $40 \mathrm{~Hz}$, pois nesta faixa de freqüências foram verificadas as maiores instabilidades.

Adicionalmente, limites para a freqüência calculada devem ser estabelecidos, de acordo com as características do sistema de potência (faixa de 30 a $70 \mathrm{~Hz}$, neste trabalho).

Na fig. 39 está representado o fluxograma simplificado do AIVF. 


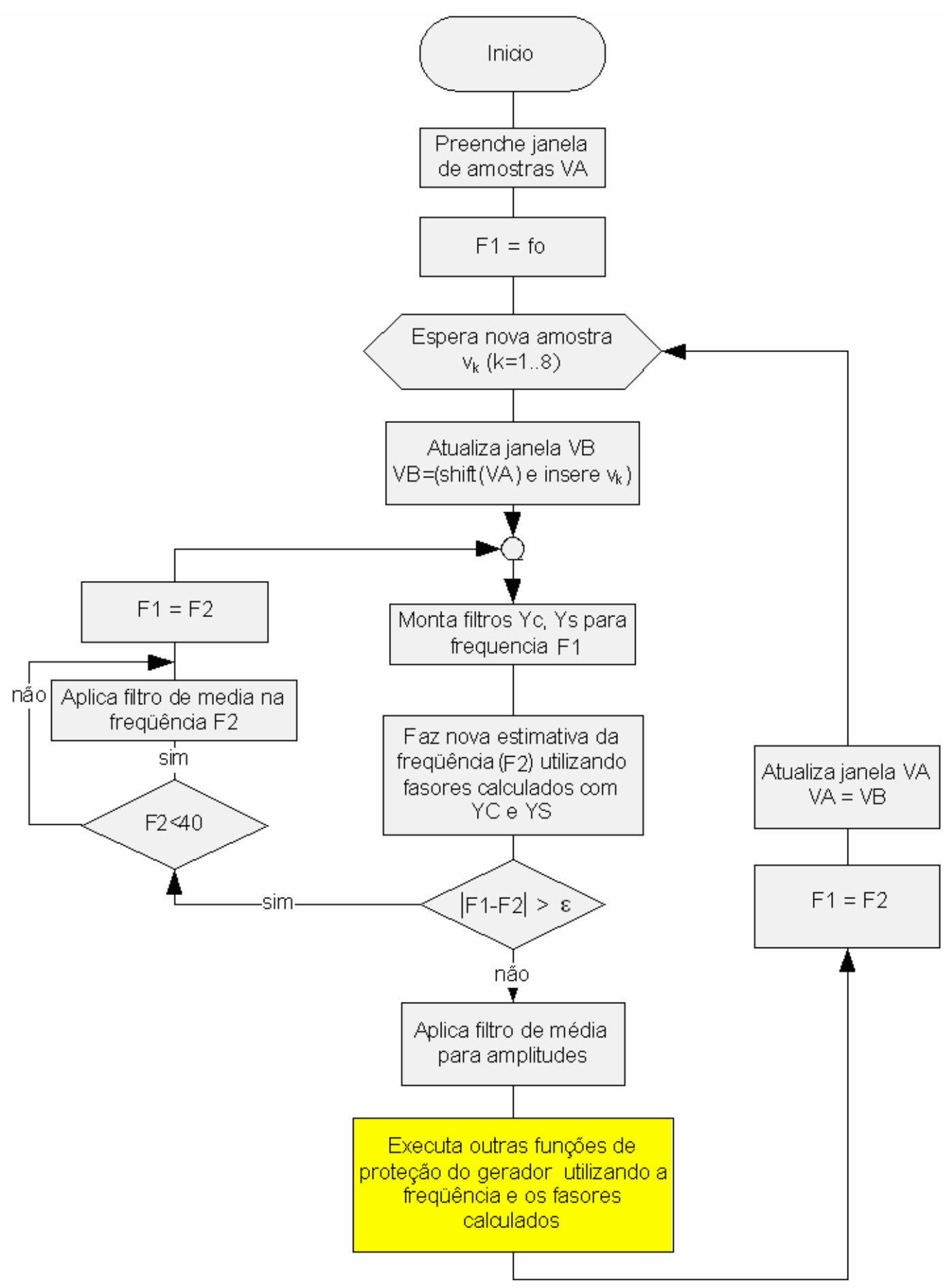

Fig. 39. Fluxograma do algoritmo proposto 
O cálculo dos coeficientes dos filtros, em função da freqüência, será baseado no método dos mínimos quadrados, discutido no anexo B. Aqui se tem uma contribuição deste trabalho, pois em nenhuma das referências pesquisadas houve descrição de como recalcular os coeficientes dos filtros ortogonais.

Vale observar que um ponto extremamente importante no projeto de algoritmos baseados no método dos mínimos quadrados, é a hipótese adotada para o sinal. Assim, por exemplo, caso na hipótese do sinal não se inclua os harmônicos, o filtro projetado poderá apresentar um desempenho insatisfatório quando na presença dessa componente.

Neste item, os filtros serão projetados, inicialmente, adotando-se um modelo para o sinal bastante simplificado, isto é, constituído somente pela componente fundamental. O desempenho destes filtros será, então, analisado e caso necessário, alterações serão implementadas.

Seja um sinal senoidal de amplitude A e freqüência f, como indicado a seguir:

$x(t)=A \cos (\omega t+\alpha)+e(t)$

onde:

$\omega=2 \pi f$

$e(t)$ representa os desvios (erros) entre o sinal real amostrado e o sinal hipoteticamente admitido como puramente senoidal.

Amostrando-se esse sinal com $\mathrm{N}$ amostras/ciclo de $60 \mathrm{~Hz}$, obtêm-se:

$x\left(n T_{A}\right)=A \cos \left(\omega n T_{A}+\alpha\right)+e(t)$

onde:

$T_{A}=\frac{T_{0}}{N}=\frac{1}{f_{0} N}$

Portanto pode-se escrever:

$x\left(n T_{A}\right)=A \cos (\alpha) \cos \left(\omega n T_{A}\right)-A \operatorname{sen}(\alpha) \operatorname{sen}\left(\omega n T_{A}\right)+e\left(n T_{A}\right)$ 
Fazendo-se:

$$
\begin{aligned}
A \cos (\alpha) & =Y_{C} \\
-A \operatorname{sen}(\alpha) & =Y_{S}
\end{aligned}
$$

Tem-se:

$$
\begin{aligned}
& A=\sqrt{Y_{C}{ }^{2}+Y_{S}{ }^{2}} \\
& \alpha=\operatorname{tg}\left(\frac{-Y_{S}}{Y_{C}}\right)
\end{aligned}
$$

De onde tem-se:

$$
\begin{aligned}
& x\left(n T_{A}\right)=Y_{C} \cos \left(\omega n T_{A}\right)+Y_{S} \operatorname{sen}\left(\omega n T_{A}\right)+e\left(n T_{A}\right) \\
& x\left(n T_{A}\right)=Y_{C} \cos (\underbrace{n \frac{2 \pi}{N} \frac{f}{f_{0}}}_{\theta})+Y_{S} \operatorname{sen}(\underbrace{n \frac{2 \pi}{N} \frac{f}{f_{0}}}_{\theta})+e\left(n T_{A}\right) \\
& x\left(n T_{A}\right)=Y_{C} \cos (n \theta)+Y_{S} \operatorname{sen}(n \theta)+e\left(n T_{A}\right)
\end{aligned}
$$

Tomando-se uma janela com m amostras, tem-se:

$$
\begin{array}{ll}
n=0 & X_{0}=Y_{C} \cos (0)+Y_{S} \operatorname{sen}(0)+e_{0} \\
n=1 & X_{1}=Y_{C} \cos (\theta)+Y_{S} \operatorname{sen}(\theta)+e_{1} \\
\cdot & \\
\cdot & \\
n=m-1 & X_{m-1}=Y_{C} \cos ((m-1) \theta)+Y_{S} \operatorname{sen}((m-1) \theta)+e_{m-1}
\end{array}
$$


Representado o conjunto de equações na forma matricial, tem-se:

$$
\underbrace{\left[\begin{array}{c}
X_{0} \\
\cdot \\
\cdot \\
X_{m-1}
\end{array}\right]}_{b}=\underbrace{\left[\begin{array}{cc}
\cos (0) & \operatorname{sen}(0) \\
\cdot & \cdot \\
\cdot & \cdot \\
\cos ((m-1) \theta) & \operatorname{sen}((m-1) \theta)
\end{array}\right]}_{A}[\underbrace{\left[\begin{array}{c}
Y_{C} \\
Y_{S}
\end{array}\right]}_{x}+\underbrace{\left[\begin{array}{c}
e_{0} \\
\cdot \\
\cdot \\
\cdot \\
e_{m-1}
\end{array}\right]}_{\text {erros }}
$$

Os parâmetros $\mathrm{Y}_{\mathrm{C}}$ e $\mathrm{Y}_{\mathrm{S}}$ que minimizam a soma dos quadrados dos erros $\left(\sum_{j=0}^{m-1} e_{j}^{2}\right)$, são dados por:

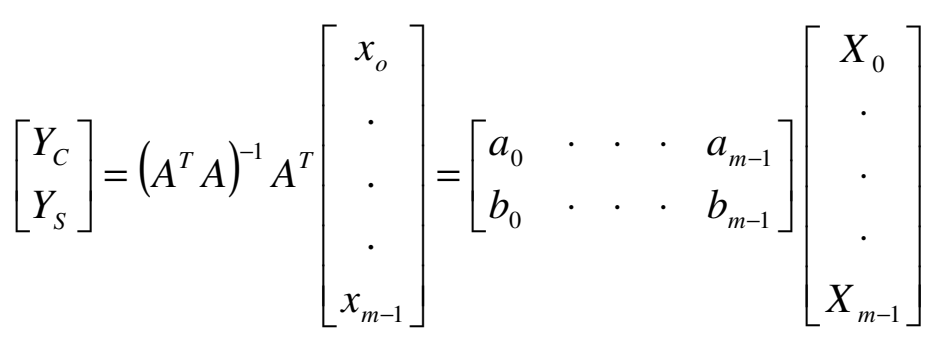

A matriz resultante das operações $\left(A^{T} A\right)^{-1} A^{T}$ é denominada pseudo inversa de A.

Essa equação matricial fornece os dois filtros FIR ("Finite Impulse Response") para o cálculo dos parâmetros $\mathrm{Y}_{\mathrm{C}}$ e $\mathrm{Y}_{\mathrm{S}}$, a partir da janela com $\mathrm{m}$ amostras do sinal.

$$
\begin{aligned}
& Y_{C}=a_{m-1} x_{k}+a_{m-2} x_{k-1}+\ldots+a_{0} x_{k-m+1} \\
& Y_{S}=b_{m-1} x_{k}+b_{m-2} x_{k-1}+\ldots+b_{0} x_{k-m+1}
\end{aligned}
$$

De onde tem-se os filtros Yc e Ys.

Do resultado obtido na eq. 23 observa-se que o ângulo $\theta$ é função da freqüência do sinal amostrado o que, conseqüentemente, permite o recálculo dos coeficientes do filtro em função da frequiência do sinal do sistema de potência. Eis um aspecto 
peculiar da aplicação do método dos mínimos quadrados pois, permite aplicação de um processo iterativo, como representado no fluxograma da fig. 39.

No restante deste trabalho será considerada uma taxa de amostragem dos sinais de 16 amostras/ciclo, que é um valor bastante comum na maioria dos relés disponíveis comercialmente. Dessa forma, os filtros $Y_{C}$ e $Y_{S}$ (eq. 24) serão implementados considerando uma janela de 16 amostras, o que corresponde a um ciclo da freqüência fundamental.

Nas figuras 40 e 41 é apresentada a resposta em freqüência de alguns filtros, projetados, através da metodologia descrita neste item, para estimar o fasor da componente fundamental de sinais cujas freqüências variam desde 30 até $70 \mathrm{~Hz}$. 


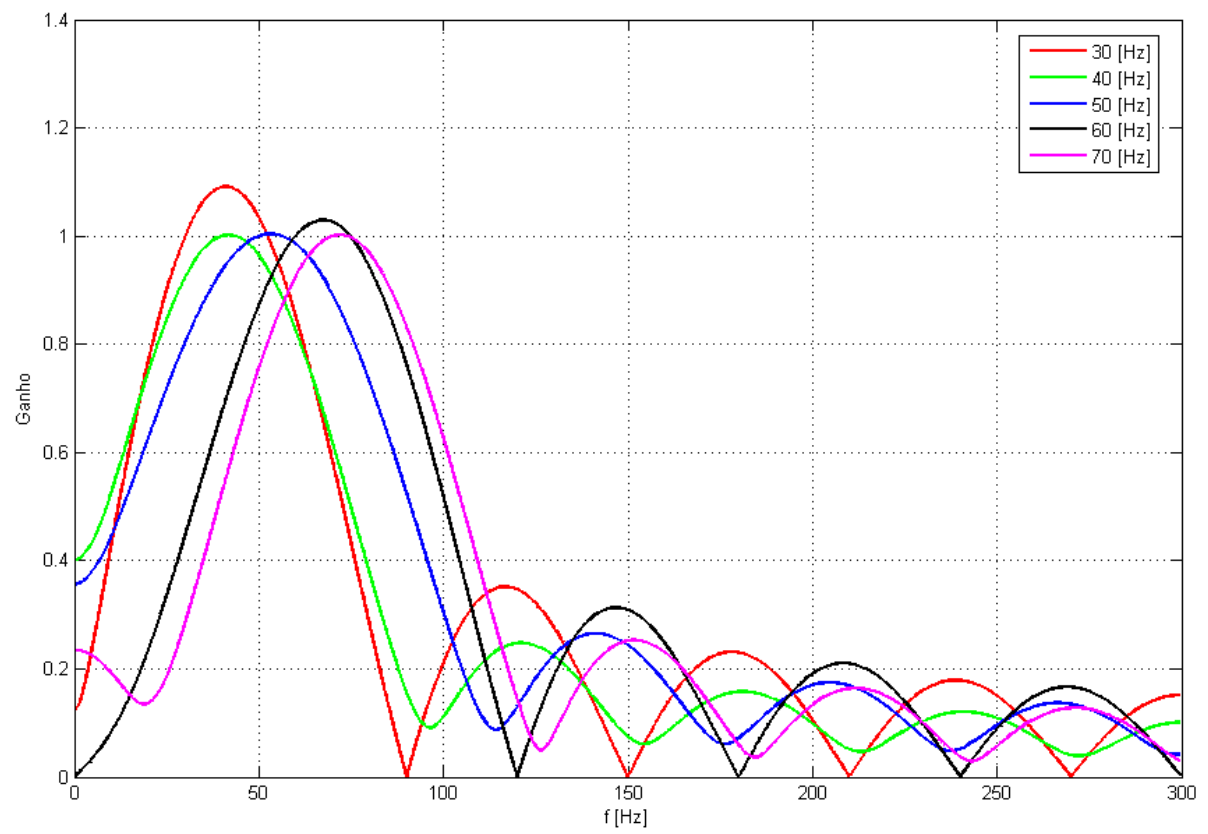

Fig. 40. Resposta em frequiência dos filtros Yc

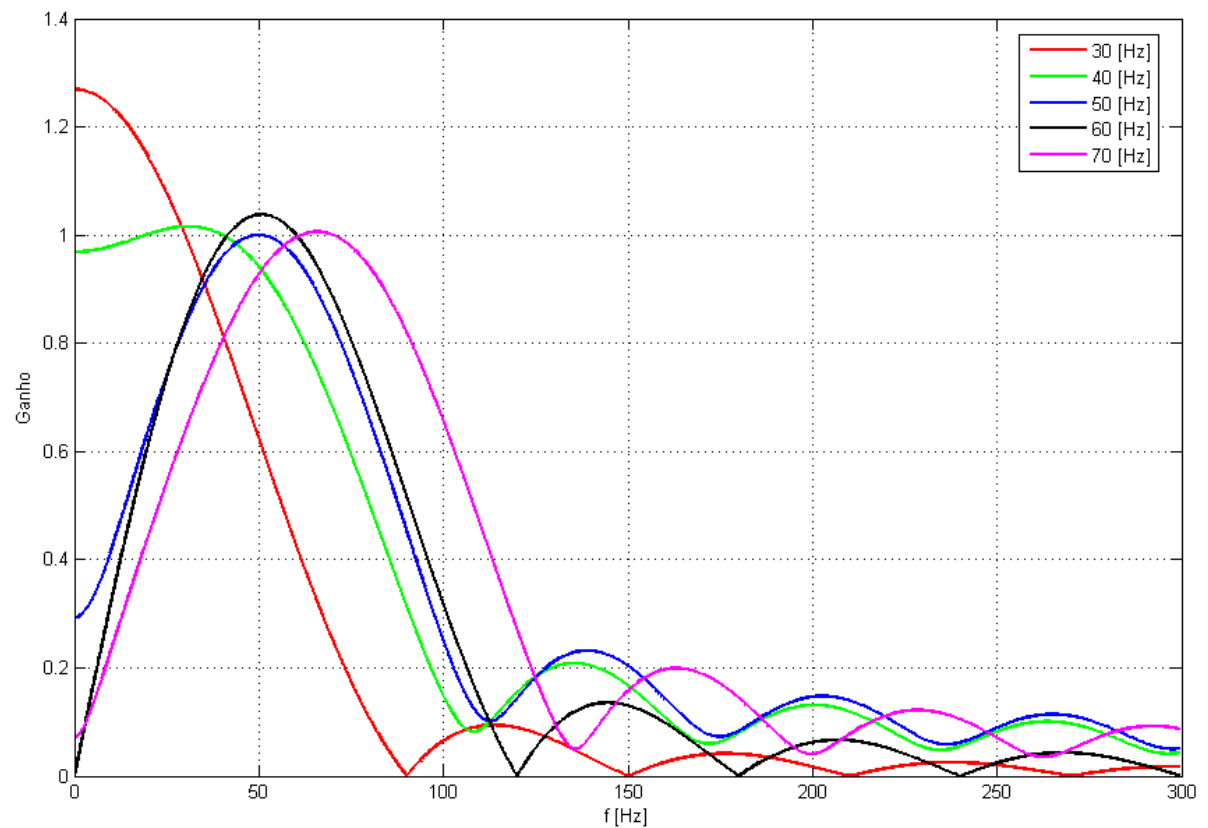

Fig. 41. Resposta em frequiência dos filtros Ys 
Comparando-se as figuras 40 e 41 com a figura 25, verifica-se uma degradação da resposta em freqüência em relação ao método de Fourier tradicional, com a não atenuação de harmônicos e da componente exponencial amortecida, o que certamente compromete a performance do algoritmo frente a sinais com estas características.

Essa degradação da resposta em freqüência decorre da hipótese adotada para o sinal (constituído somente pela fundamental). A solução adotada para minimizar essa degradação é apresentada a seguir.

Duas alternativas foram testadas para minimizar a sensibilidade à componente exponencial e a harmônicos, que são:

Alternativa 1: Inclusão da componente exponencial e do terceiro e quinto harmônicos, no modelo do sinal utilizado no método dos mínimos quadrados;

Alternativa 2: Inclusão apenas do terceiro e quinto harmônico no método dos mínimos quadrados associado à pré-filtragem do sinal por um filtro projetado especificamente para atenuar a componente exponencial (filtro off-set). A figura 42 ilustra o esquema proposto nesta alternativa.

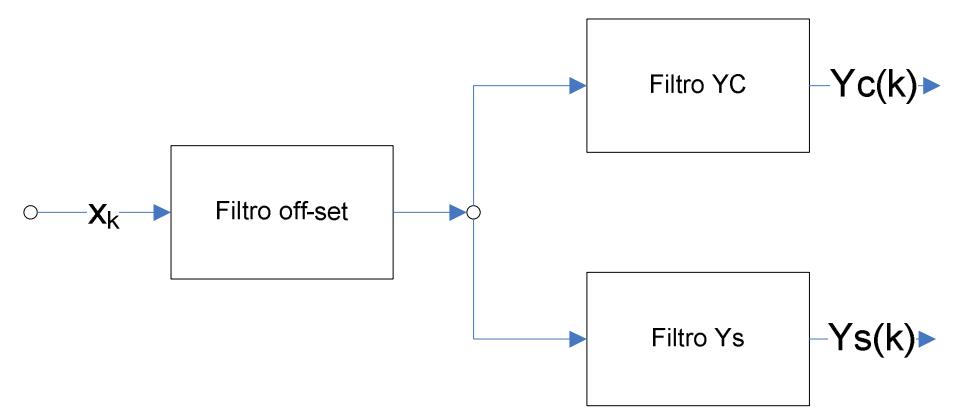

Fig. 42. Esquema proposto na alternativa 2 
Para a alternativa 1, o seguinte modelo para o sinal de tempo contínuo foi considerado:

$x(t)=A_{1} \cos (\omega t+\alpha)+A_{3} \cos \left(3 \omega t+\alpha_{3}\right)+A_{5} \cos \left(5 \omega t+\alpha_{5}\right)+A_{o} e^{-\alpha_{o} t}$

De um desenvolvimento similar ao efetuado na equação 22 , tem-se o seguinte sinal de tempo discreto:

$x\left(n T_{A}\right)=Y_{C 1} \cos (n \theta)+Y_{S 1} \operatorname{sen}(n \theta)+Y_{C 3} \cos (3 n \theta)+Y_{S 3} \operatorname{sen}(3 n \theta)+Y_{C 5} \cos (5 n \theta)$

$+Y_{S 5} \operatorname{sen}(5 n \theta)+Y_{O} e^{-\infty n T_{A}}$

Tomando-se uma janela com 16 amostras, tem-se:

$n=0 \quad X_{0}=Y_{C 1} \cos (0)+Y_{S 1} \operatorname{sen}(0)+Y_{C 3} \cos (0)+Y_{S 3} \operatorname{sen}(0)+Y_{C 5} \cos (0)+Y_{S 5} \operatorname{sen}(0)+Y_{0}+e_{0}$

$n=1 \quad X_{1}=Y_{C 1} \cos (\theta)+Y_{S 1} \operatorname{sen}(\theta)+Y_{C 3} \cos (3 \theta)+Y_{S 3} \operatorname{sen}(3 \theta)+Y_{C 5} \cos (5 \theta)+Y_{S 5} \operatorname{sen}(5 \theta)+$

$+Y_{0} e^{-\alpha_{0} T_{A}}+e_{1}$

$n=15 \quad X_{15}=Y_{C 1} \cos (15 \theta)+Y_{S 1} \operatorname{sen}(15 \theta)+Y_{C 3} \cos (45 \theta)+Y_{S 3} \operatorname{sen}(45 \theta)+Y_{C 5} \cos (75 \theta)+$

$+Y_{S 5} \operatorname{sen}(75 \theta)+Y_{0} e^{-\alpha_{0} 15 T_{A}}+e_{15}$

Representado o conjunto de equações na forma matricial, tem-se:

$\left[\begin{array}{c}X_{0} \\ \cdot \\ \cdot \\ \cdot \\ X_{15}\end{array}\right]=\left[\begin{array}{lllllll}\cos (0) & \operatorname{sen}(0) & \cos (0) & \operatorname{sen}(0) & \cos (0) & \operatorname{sen}(0) & 1 \\ \cdot & & & & & \\ \cdot & & & & & \\ \cdot & & & & & \\ \cos (15 \theta) & \operatorname{sen}(15 \theta) & \cos (45 \theta) & \operatorname{sen}(45 \theta) & \cos (75 \theta) & \operatorname{sen}(75 \theta) & e^{-\alpha 15 T_{A}}\end{array}\right] \cdot\left[\begin{array}{l}Y_{C 1} \\ Y_{S 1} \\ Y_{C 3} \\ Y_{S 3} \\ Y_{C 5} \\ Y_{S 5} \\ Y_{0}\end{array}\right]+\left[\begin{array}{l}e_{0} \\ \cdot \\ \cdot \\ e_{15}\end{array}\right]$ 
Os parâmetros $\mathrm{Y}_{\mathrm{C} 1}$ e $\mathrm{Y}_{\mathrm{S} 1}$ que minimizam a soma dos quadrados dos erros $\left(\sum_{j=0}^{m-1} e_{j}^{2}\right)$, são dados por:

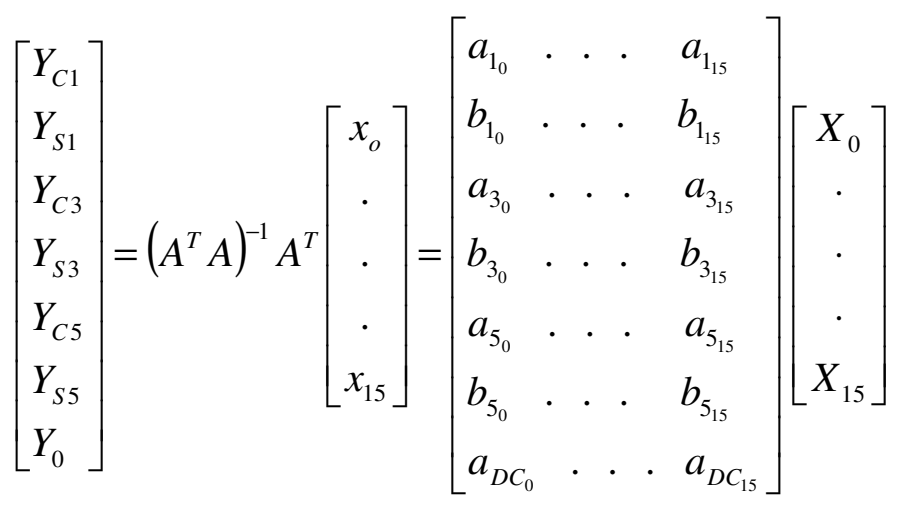

Os coeficientes dos filtros Yc e Ys, responsáveis pela extração da componente fundamental, correspondem, respectivamente, aos parâmetros $a_{1 j} e b_{1 j}(\mathrm{j}=1 \ldots 15)$ na equação acima.

Nas figuras 43 e 44 são mostradas as respostas em freqüência de alguns filtros, projetados para estimar o fasor da componente fundamental de sinais desde 30 até $70 \mathrm{~Hz}$. 


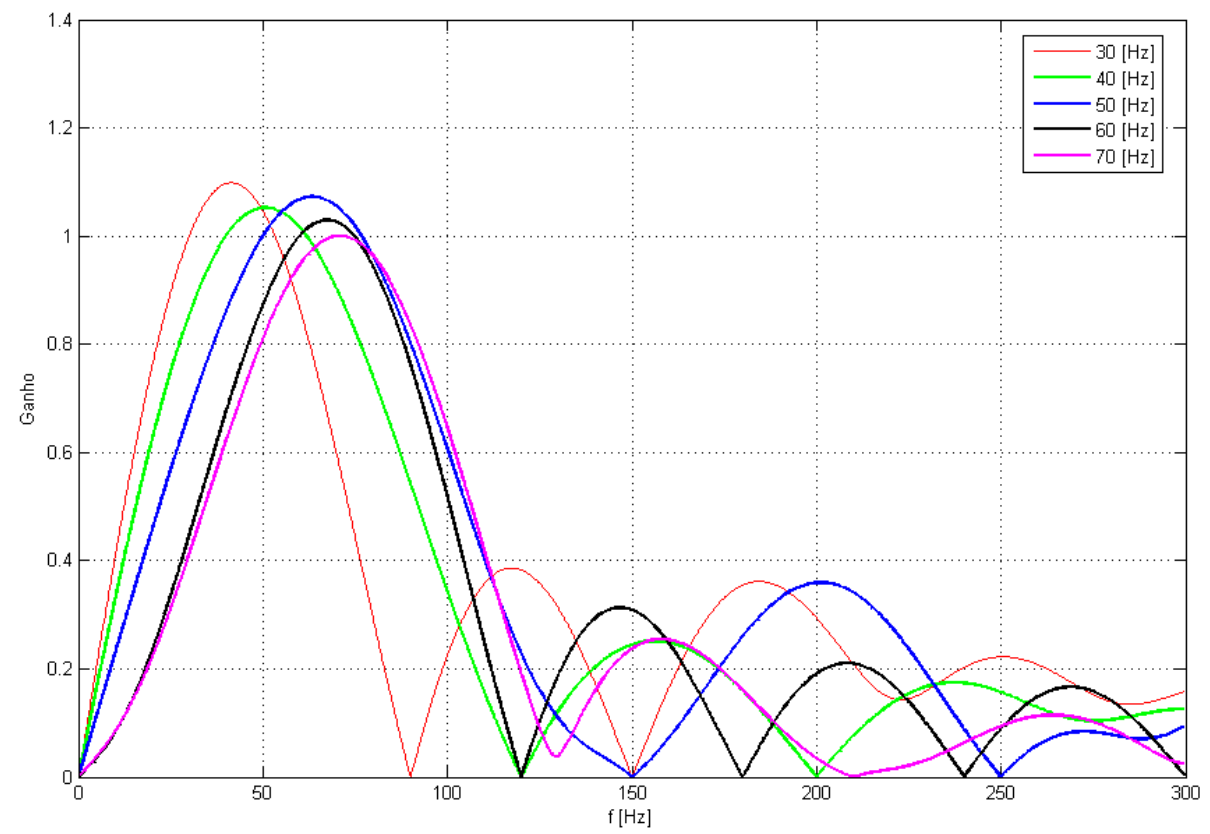

Fig. 43. Resposta em freqüência dos filtros Yc projetados para atenuar a componente exponencial, terceiro e quinto harmônicos

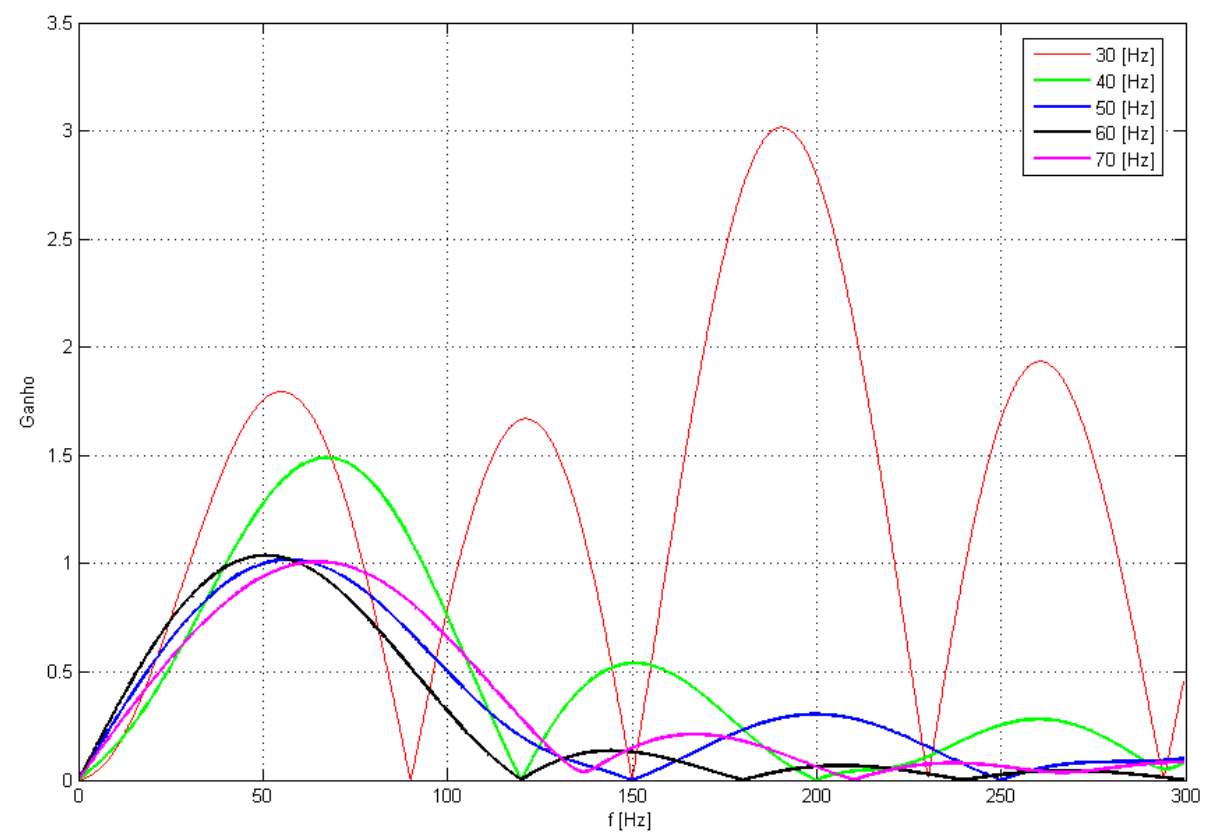

Fig. 44. Resposta em freqüência dos filtros Ys projetados para atenuar a componente exponencial, terceiro e quinto harmônicos 
Das figuras 43 e 44 verifica-se a atenuação do terceiro e quinto harmônicos e das baixas freqüências (conseqüentemente da componente exponencial), entretanto no filtro Ys, lóbulos com ganhos elevados são observados para os filtros projetados para as freqüências menores de $40 \mathrm{~Hz}$.

Os lóbulos com ganhos elevados são produzidos pela componente aperiódica incluídas na hipótese do sinal. Para melhorar o desempenho dos filtros neste aspecto, eles serão reprojetados sem essa hipótese. Para que eles não fiquem susceptíveis a essa componente, como descrito na alternativa 2, será utilizado a pré-filtagem por um filtro especifico para atenuar essa componente.

Para a técnica descrita na alternativa 2, o seguinte modelo para o sinal de tempo contínuo foi considerado:

$$
x(t)=A_{1} \cos (\omega t+\alpha)+A_{3} \cos \left(3 \omega t+\alpha_{3}\right)+A_{5} \cos \left(5 \omega t+\alpha_{5}\right)
$$

Deste sinal resultaram filtros Yc e Ys cuja resposta em freqüência pode ser observada nas figuras 45 e 46 (para algumas freqüências).

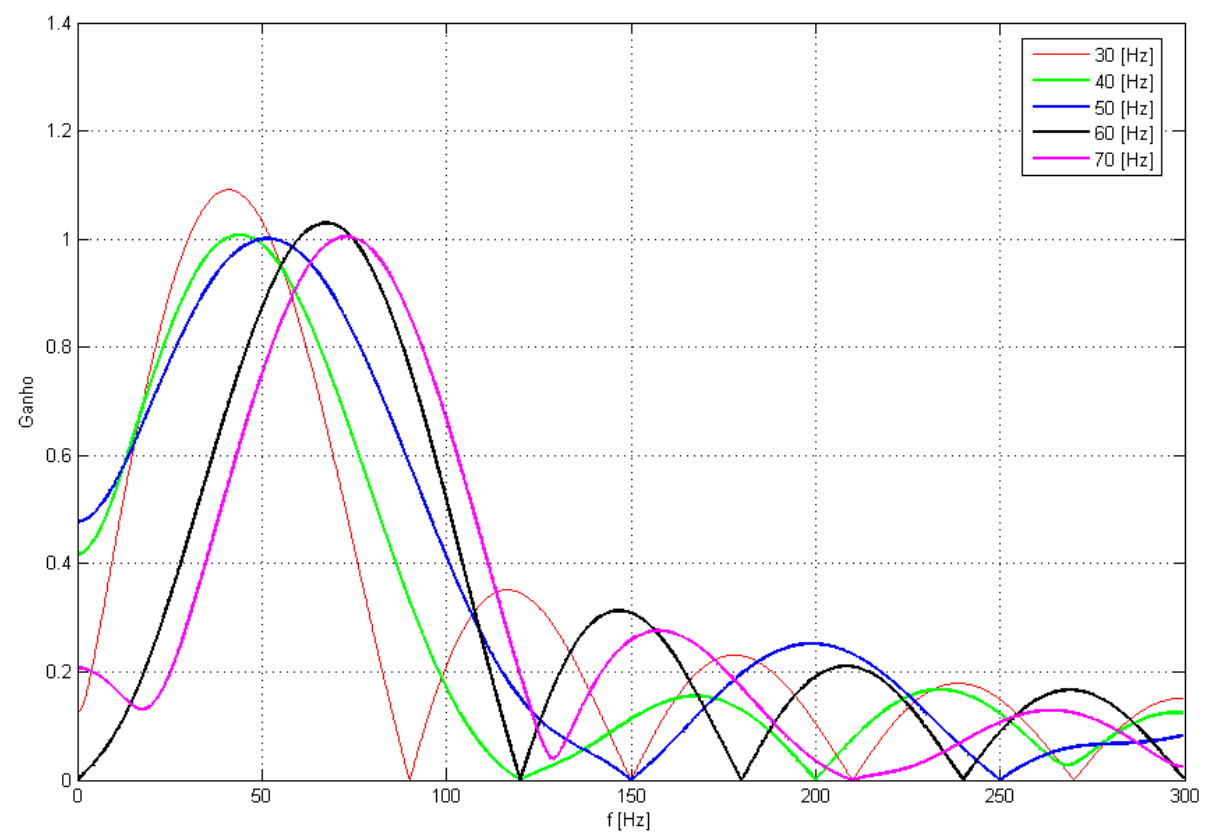

Fig. 45. Resposta em freqüência dos filtros Yc projetados para atenuar o terceiro e quinto harmônicos 


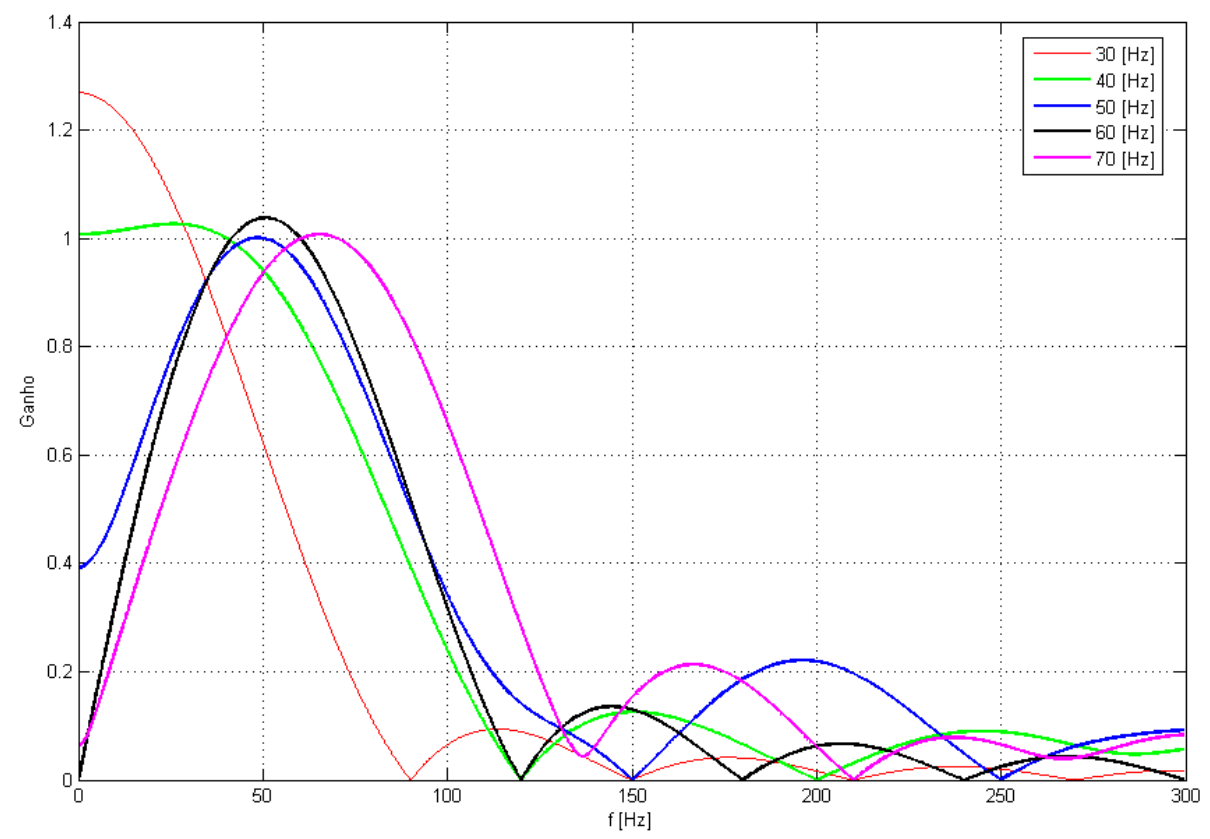

Fig. 46. Resposta em freqüência dos filtros Ys projetados para atenuar o terceiro e quinto harmônicos

Das figuras 45 e 46 verifica-se a completa atenuação do terceiro e quinto harmônicos e um ganho bastante elevado para as baixas freqüências o que implica em um desempenho ruim para a componente exponencial amortecida. Dessa forma, torna-se necessário à utilização, em complemento, de um filtro digital desenvolvido em um trabalho de pesquisa anterior [25] e projetado especificamente para eliminar a componente aperiódica presente nos sinais de corrente.

A função de transferência deste filtro é dada por:

$H(z)=G\left[a-z^{-4}\right]$

Sendo:

$G=\left[1+a^{2}-2 a \cos \left(\frac{2 \pi}{N} \frac{f}{f_{0}} m\right)\right]^{-1 / 2}$

$a=e^{\alpha m T_{A}}$ 
Sendo $\alpha$ o inverso da constante de tempo da exponencial amortecida que se deseja atenuar, $\mathrm{N}$ o número de amostras por ciclo e fo $=60 \mathrm{~Hz}$. Adotou-se, conforme sugerido na referência, o valor de $\mathrm{m}=4$ e $\alpha=25$.

A resposta em freqüência do filtro para a componente exponencial amortecida pode ser observada na figura 47.

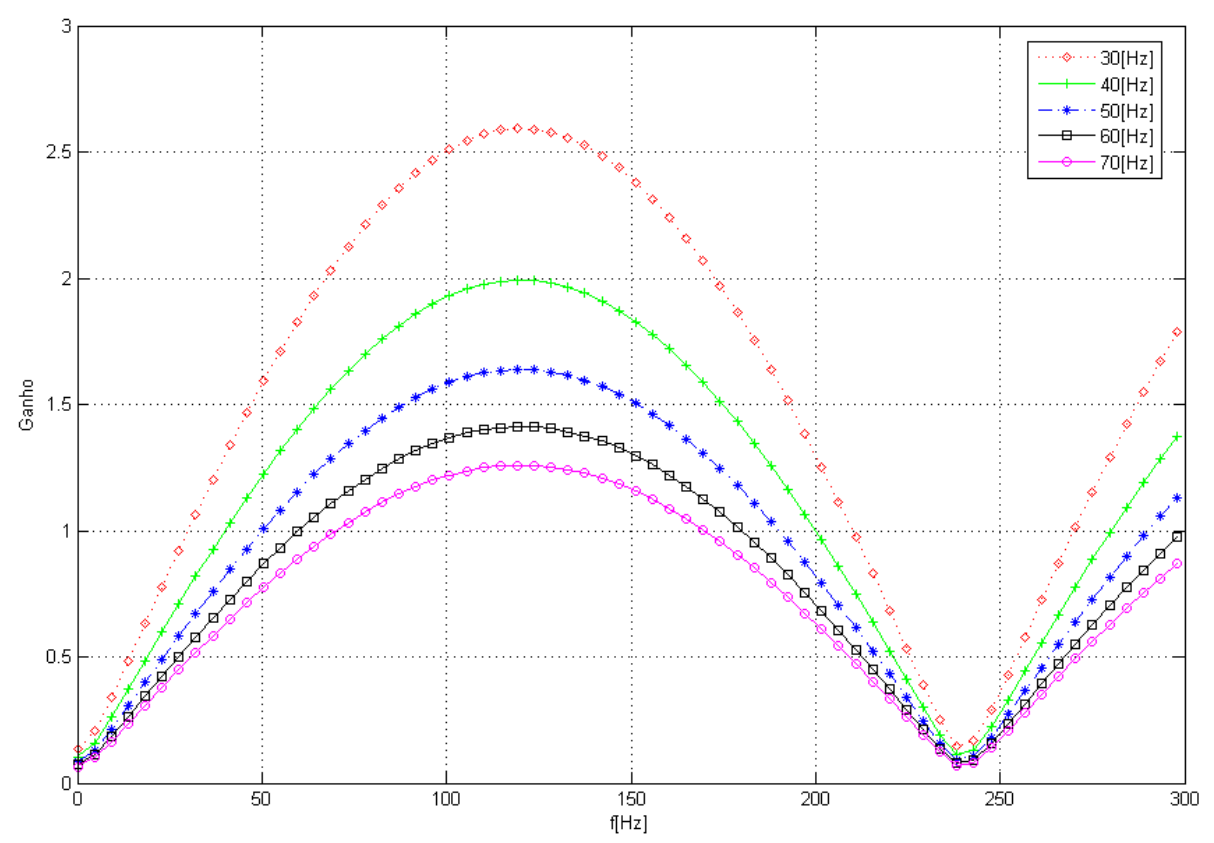

Fig. 47. Resposta em freqüência dos filtros projetados para atenuar a componente exponencial amortecida

Da figura 47, verifica-se a atenuação para baixas frequiências e ganho unitário para a freqüência da fundamental, para as diversas frequiências apresentadas.

Entretanto é necessário visualizar o comportamento no domínio do tempo para verificar-se o grau de atenuação dos filtros para a componente exponencial amortecida.

Para tal, um sinal característico de curto-circuito com fundamental de $40 \mathrm{~Hz}$ e componente exponencial foi utilizado para esta avaliação, como representado na figura 48 . 

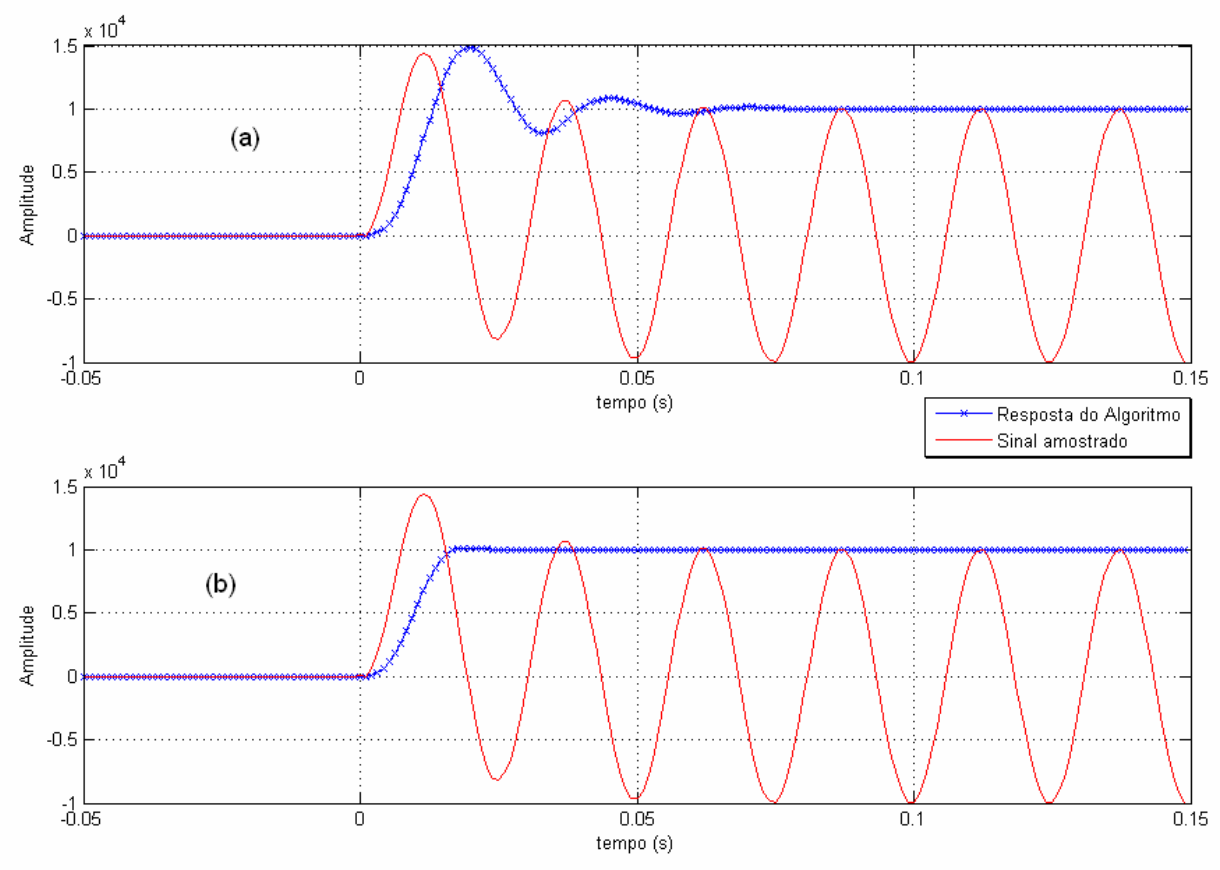

Fig. 48. Resposta no domínio do tempo a um sinal característico de curto-circuito com fundamental de $40 \mathrm{~Hz}$ e componente exponencial amortecida. (a) Sem filtro para atenuar a componente exponencial amortecida; (b) Com filtro para atenuar a componente exponencial amortecida

Na figura 48 (a) somente filtros Yc e Ys foram utilizados para se avaliar a amplitude do sinal; desta figura, pode-se verificar erros elevados durante o tempo em que a componente exponencial existe no sinal.

Já na figura 48 (b) filtros Yc e Ys foram utilizados em conjunto com o filtro para atenuar a componente exponencial amortecida, de onde se pode verificar a atenuação desta componente.

A utilização conjunta dos filtros para a componente exponencial e dos filtros Yc e Ys desenvolvidos para atenuar o terceiro e quinto harmônicos conduziu a filtros cuja resposta em frequiência pode ser observada nas figuras 49 e 50. 


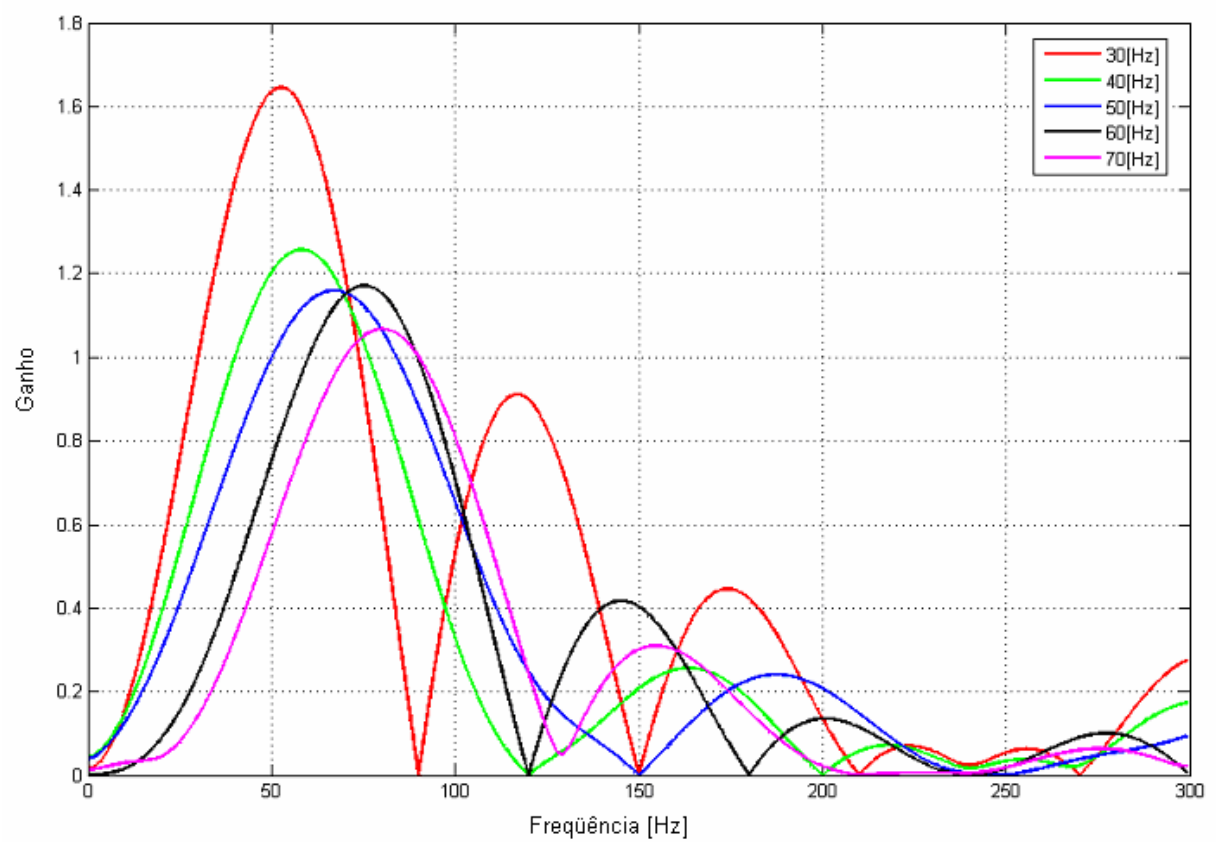

Fig. 49. Resposta em freqüência dos filtros Yc resultantes da utilização combinada do método dos mínimos quadrados e do filtro para atenuar a componente exponencial

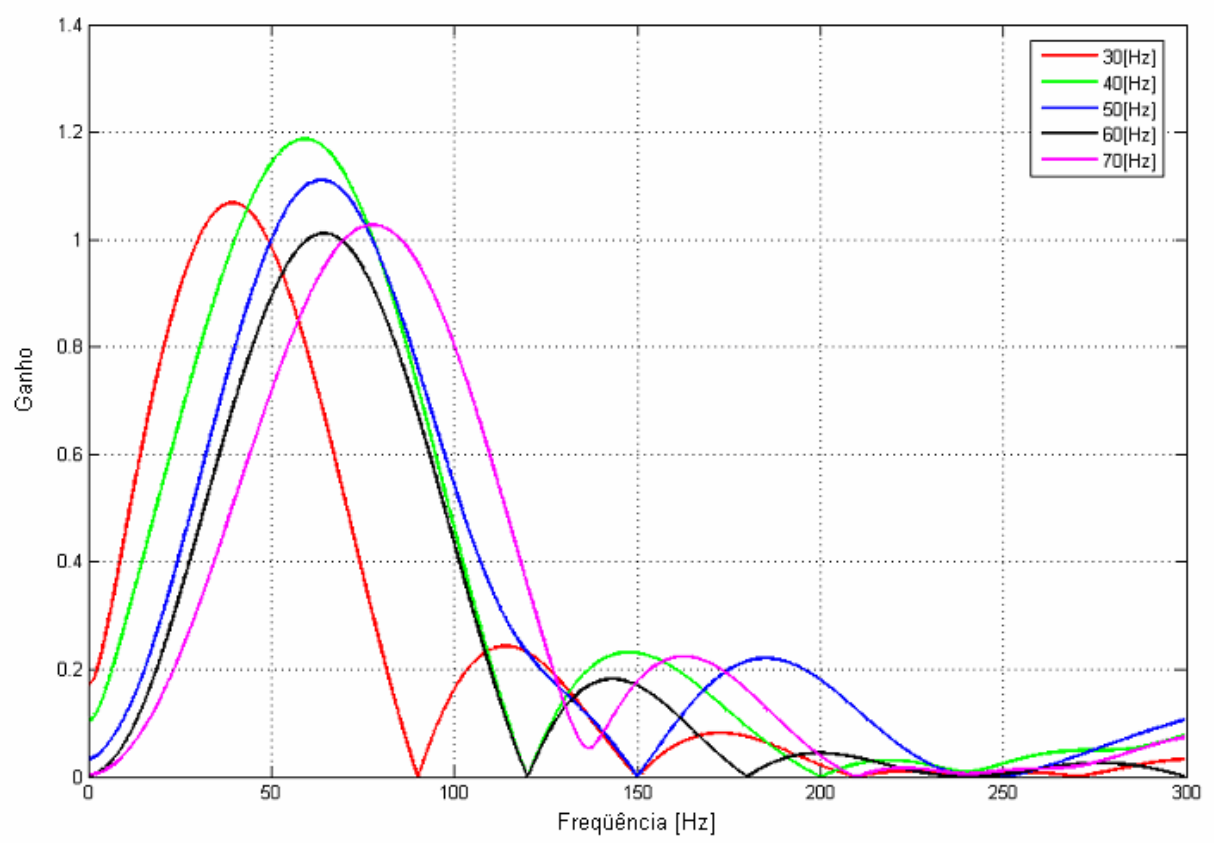

Fig. 50. Resposta em freqüência dos filtros Ys resultantes da utilização combinada do método dos mínimos quadrados e do filtro para atenuar a componente exponencial 
Devido ao melhor desempenho, observado das respostas em freqüência, optou-se pela utilização da tecnica descrita como alternativa 2 para o cálculo dos filtros do AIVF, isto é, utilização combinada de um filtro exclusivo para a componente exponencial e inclusão do terceiro e quinto harmônicos no método dos mínimos quadrados.

Como já comentado, tanto o filtro off-set quanto os filtros Yc e Ys tem seus parâmetros dependentes da freqüência do sinal. O calculo "on-line" desses parâmetros no relé é inviável devido à carga computacional envolvida. A solução encontrada é pré-calcular esses parâmetros para freqüências variando entre 30 e 70 $\mathrm{Hz}$ com passo de $1 \mathrm{~Hz}$ e armazená-los em uma tabela na memória do hardware digital. Em cada iteração do método proposto, a partir da frequiência calculada, o processador busca na memória os parâmetros mais adequados para essa freqüência. No anexo C, são mostrados, a título de exemplo, os parâmetros desses três filtros para freqüências entre 30 e $70 \mathrm{~Hz}$, porém com um passo de $5 \mathrm{~Hz}$.

Vale ainda observar que no projeto dos filtros não se optou pela atenuação da segundo harmonico. Isto se deu pelo fato de que incluindo o segundo harmônicos, juntamente com o terceiro e quinto no modelo para o sinal utilizado no método dos mínimos quadrados, a resposta em freqüência dos filtros obtidos apresenta um resultado ruim, como mostrado nas figuras 51 e 52 (lóbulos com ganho elevado nos projetos dos filtros para as freqüências baixas). 


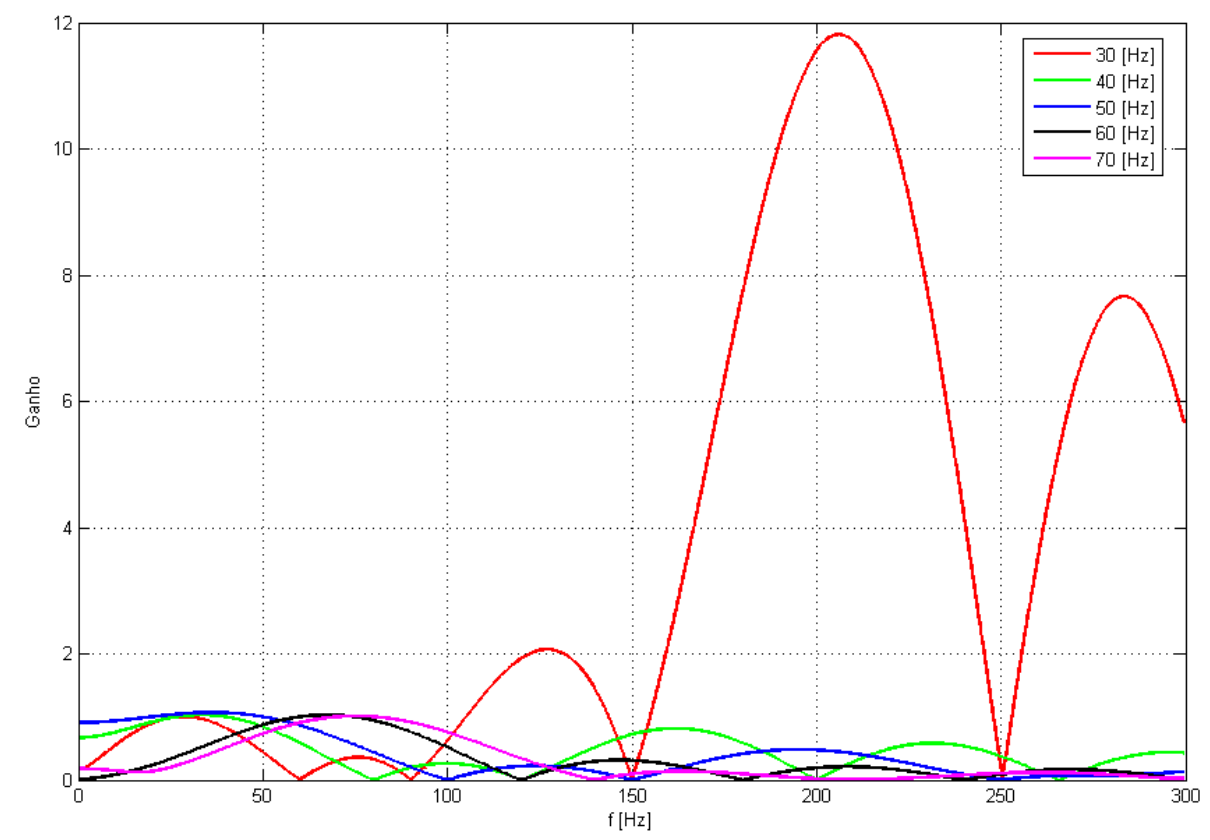

Fig. 51. Resposta em freqüência dos filtros Yc projetados para atenuar o segundo, terceiro e quinto harmônicos

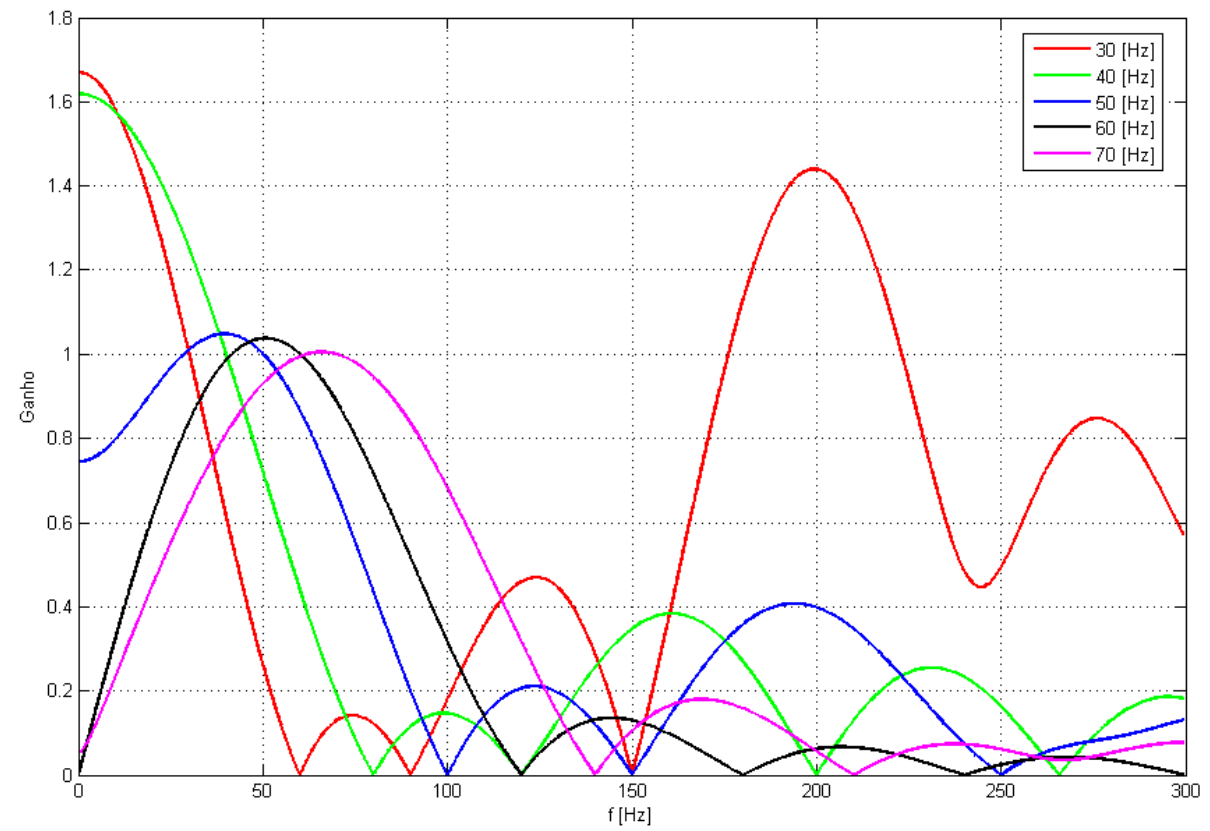

Fig. 52. Resposta em freqüência dos filtros Ys projetados para atenuar o segundo, terceiro e quinto harmônicos 


\subsection{Simulações e Analise do Desempenho do AIVF}

Neste item o comportamento do AIVF será avaliado a partir da aplicação de sinais com características diversas como variação da freqüência e amplitude, harmônicos e componente exponencial amortecida, como mostrado a seguir.

\subsubsection{Comportamento frente a sinais não distorcidos}

O propósito deste item é verificar o comportamento do AIVF a sinais que mudam dinamicamente sua amplitude e freqüência em função do tempo, mas que não estejam distorcidos com harmônicos e/ou componente exponencial amortecida.

A variação de freqüência se dará conforme representado na figura 53.

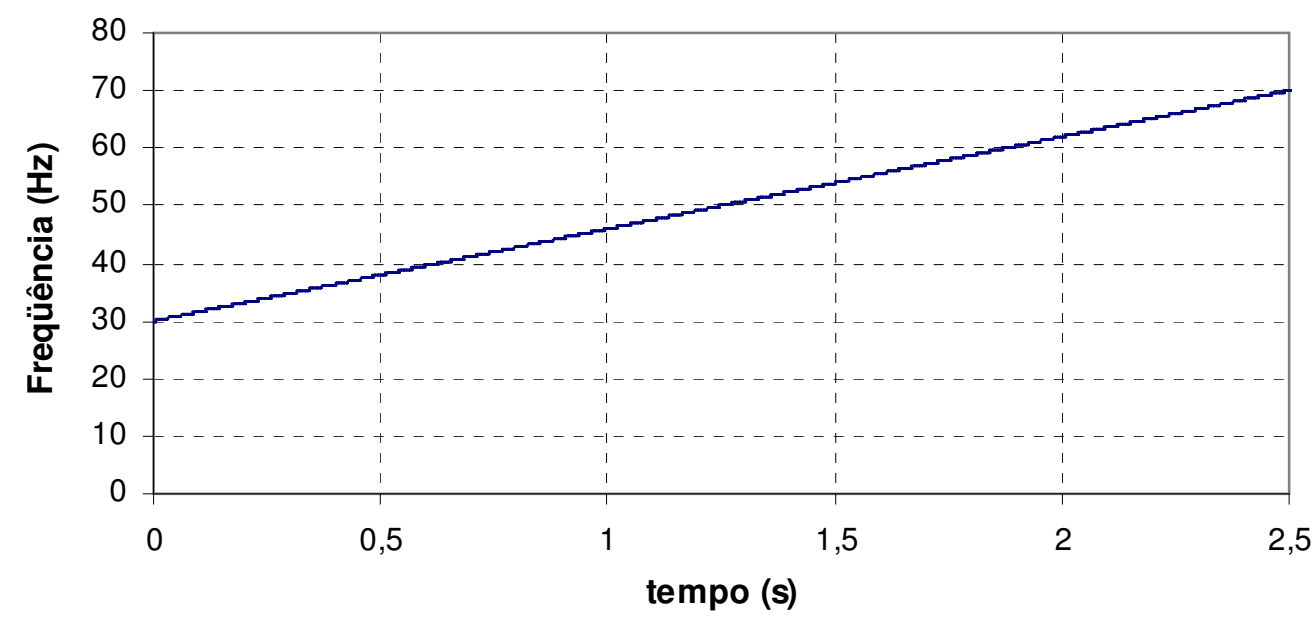

Fig. 53. Variação de freqüência utilizada para gerar os sinais de teste deste capítulo

O sinal com a variação de freqüência descrita na figura 53 é mostrado na figura 54. 


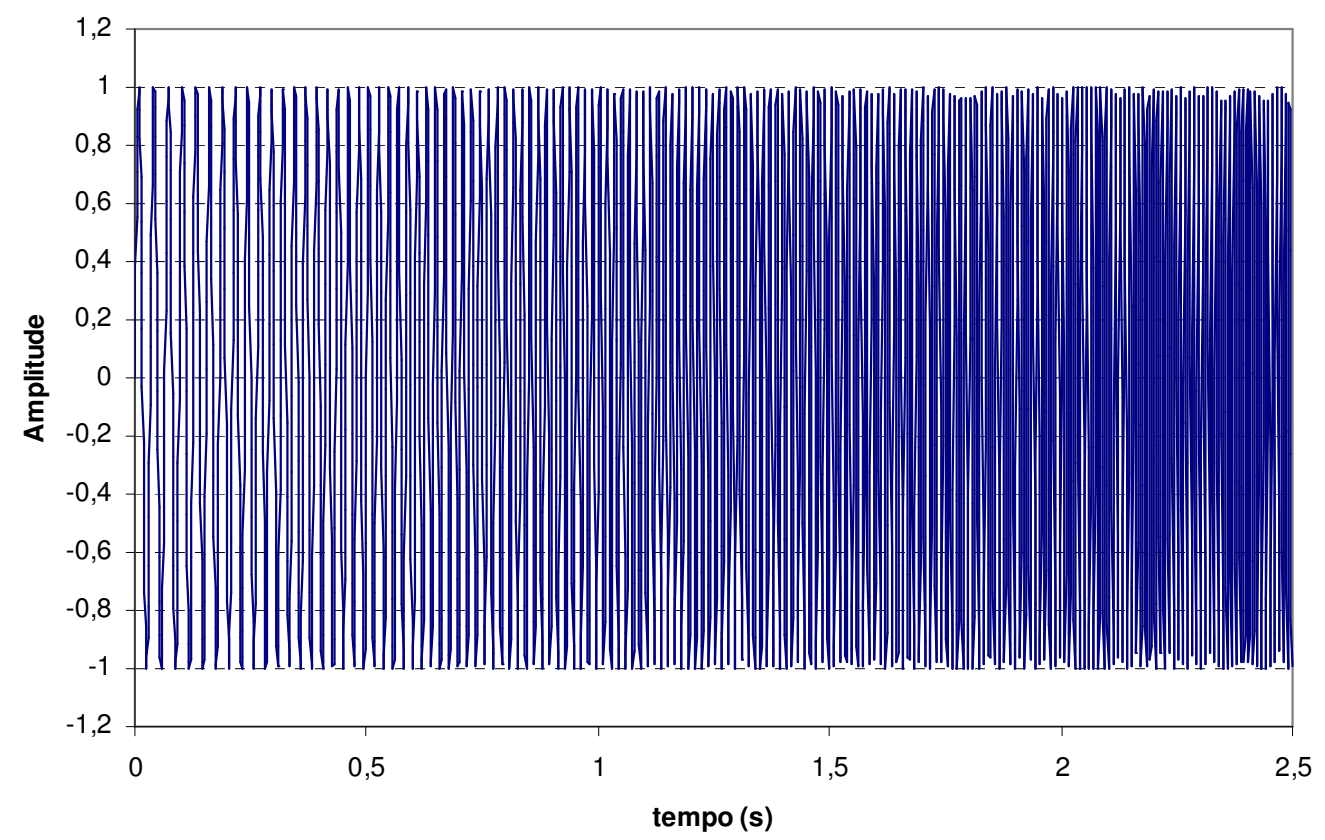

Fig. 54. Sinal de teste com variação linear de frequiência e amplitude constante

A figura 55 apresenta a amplitude do fasor calculado utilizando o AIVF para o sinal mostrado na figura 54.

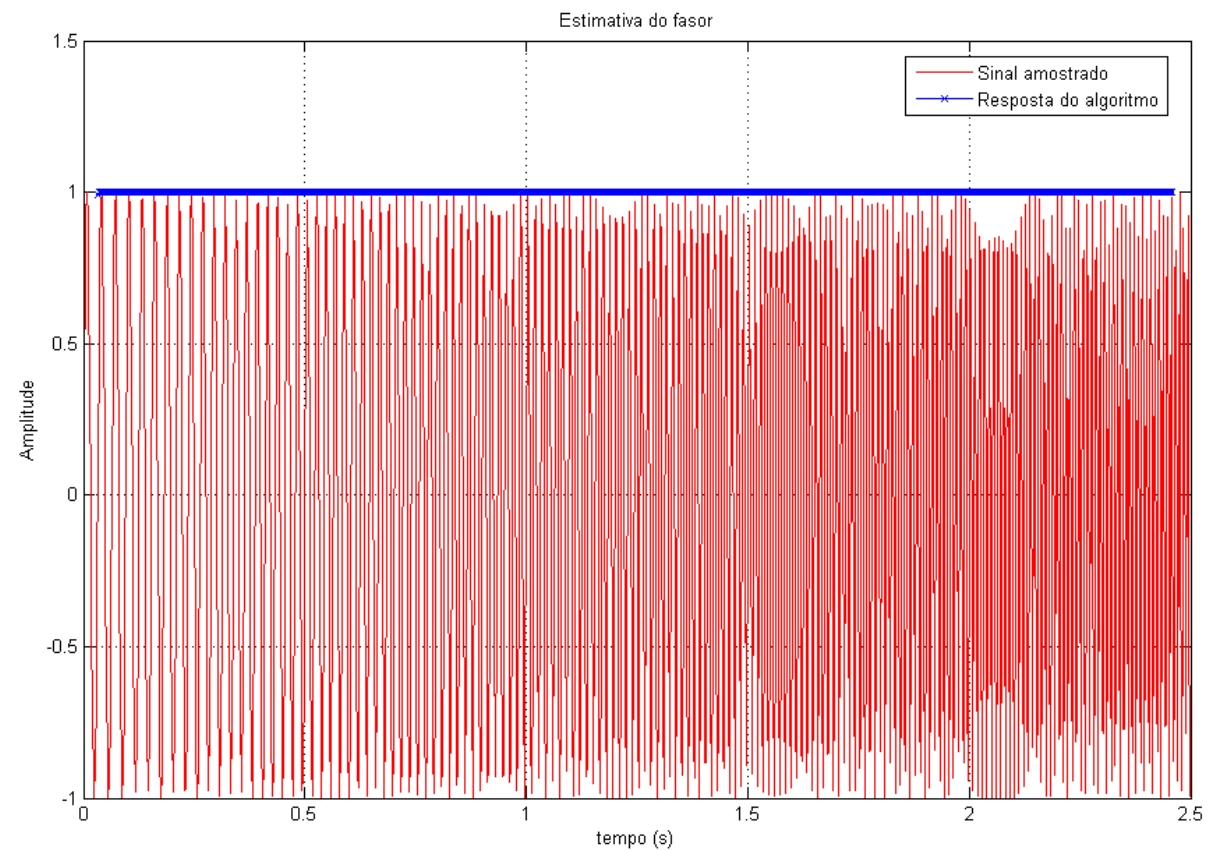

Fig. 55. Resposta do AIVF ao sinal representado na figura 54 
Da figura 55 verifica-se a correta avaliação da amplitude pelo AIVF, apesar da freqüência estar variando continua e rapidamente. Algoritmos que utilizam filtros ortogonais calculados somente para $60 \mathrm{~Hz}$, quando aplicados a esse mesmo sinal tem o comportamento mostrado na figura 56. Dessa figura verifica-se a sub-avaliação da amplitude do sinal, o que pode levar a não atuação das funções de proteção.

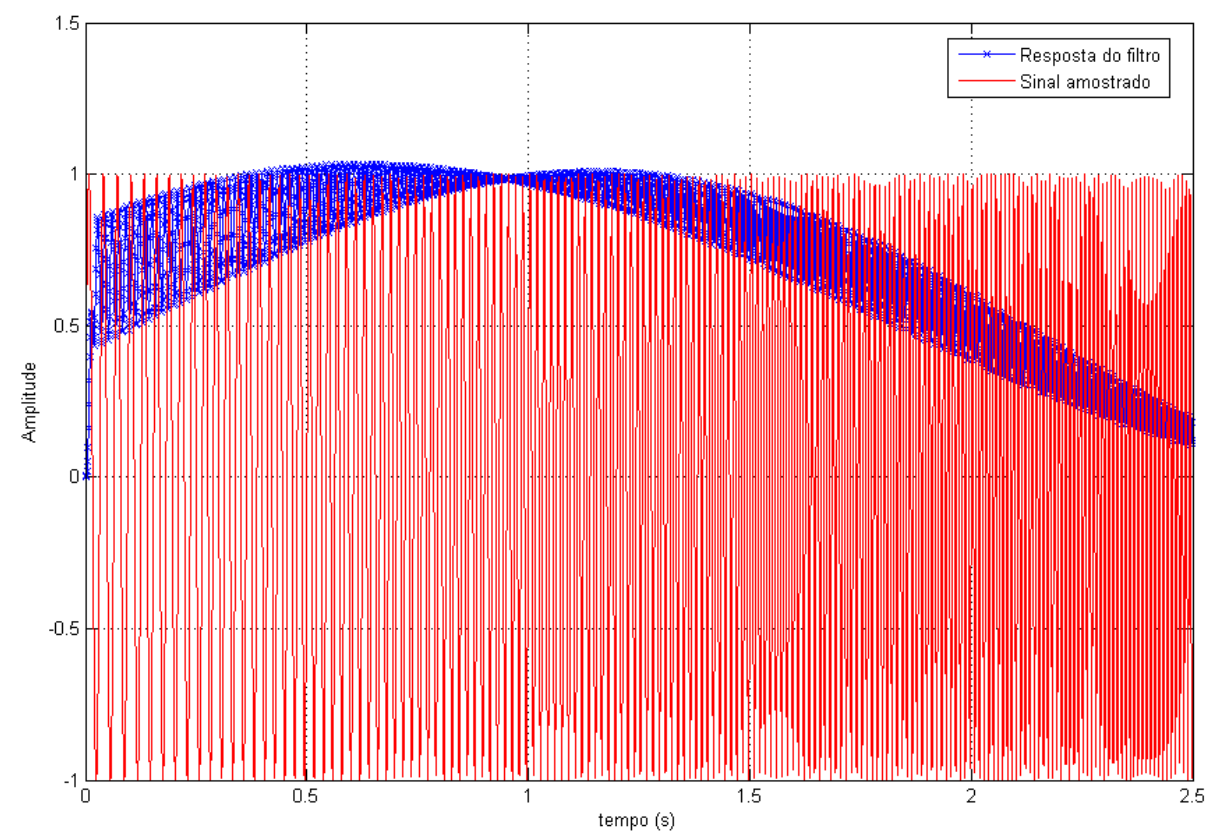

Fig. 56. Comportamento de filtros calculados somente para $60 \mathrm{~Hz}$ ao sinal da figura 54

A seguir o comportamento do AIVF é avaliado para um sinal com variação continua da freqüência (de acordo com a figura 53) e variação da amplitude em degraus, conforme representado na figura 57. 


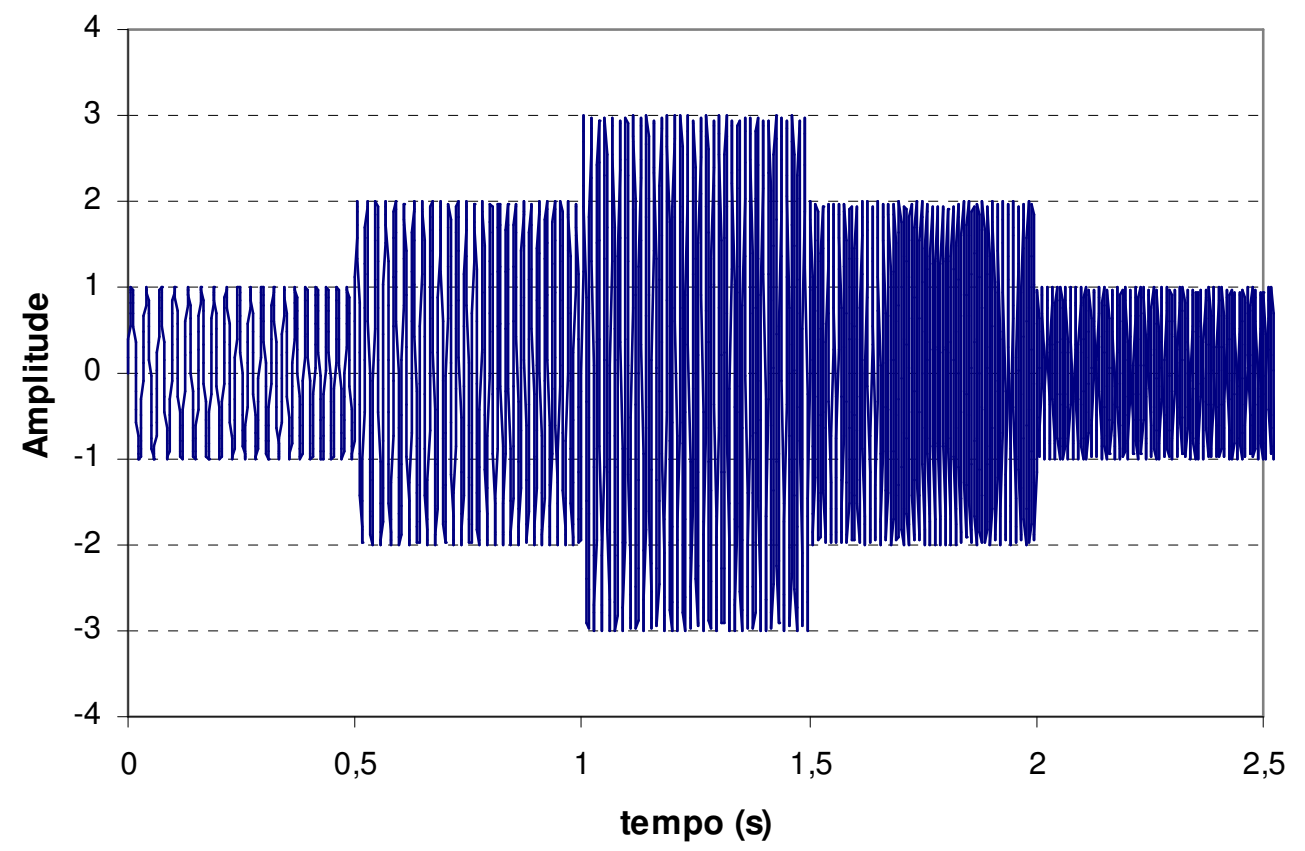

Fig. 57. Sinal de teste com variação linear de frequiência e variação da amplitude em degraus

Na figura 58, tem-se a resposta do AIVF.

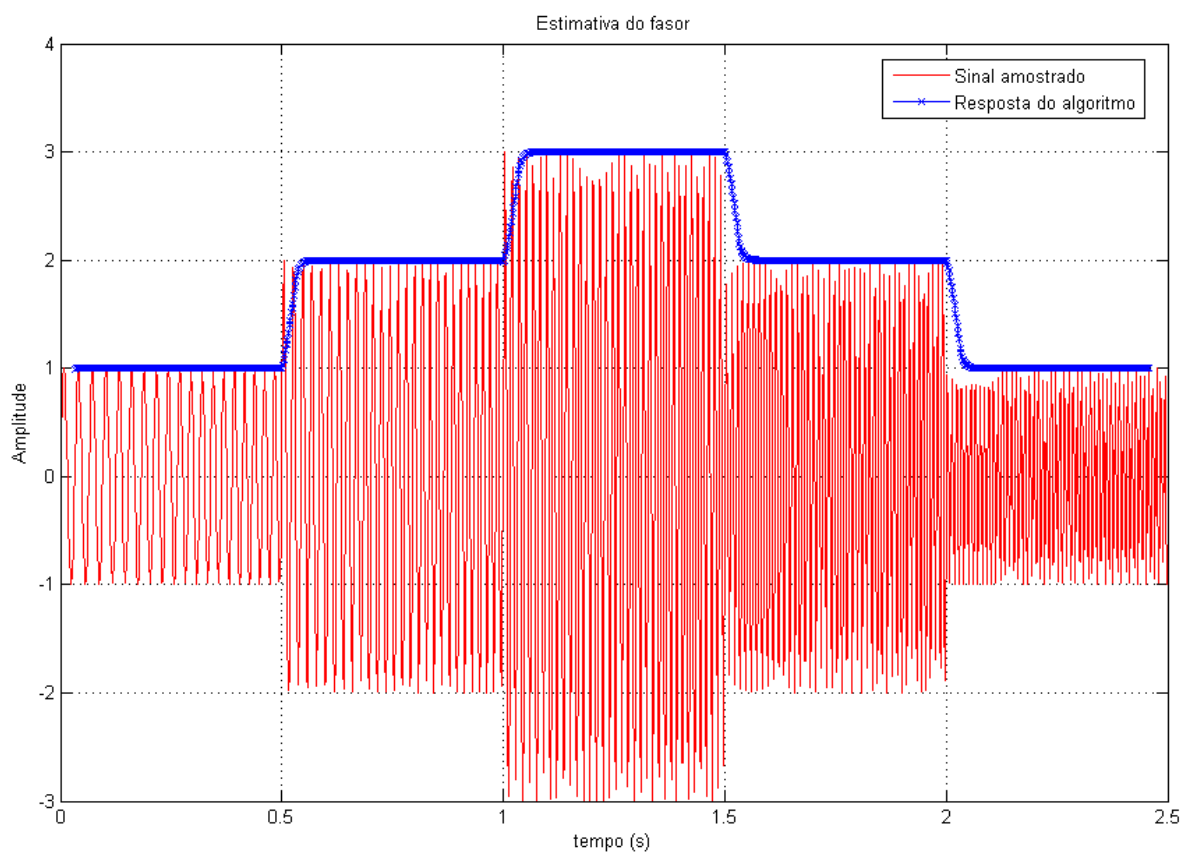

Fig. 58. Resposta do AIVF ao sinal representado na figura 57 
Da figura 58 verifica-se a correta avaliação da amplitude pelo AIVF, apesar da variação continua da frequiência e da variação em degraus da amplitude. Um aspecto importante que se pode verificar é o tempo necessário para o AIVF convergir para o novo valor de amplitude; o AIVF levou, para tal, aproximadamente 20 amostras.

Algoritmos que utilizam filtros ortogonais calculados somente para $60 \mathrm{~Hz}$, quando aplicados a esse mesmo sinal apresentam o comportamento mostrado na figura 59. Dessa figura, novamente, verifica-se a sub-avaliação da amplitude do sinal, o que pode levar a não atuação das funções de proteção.

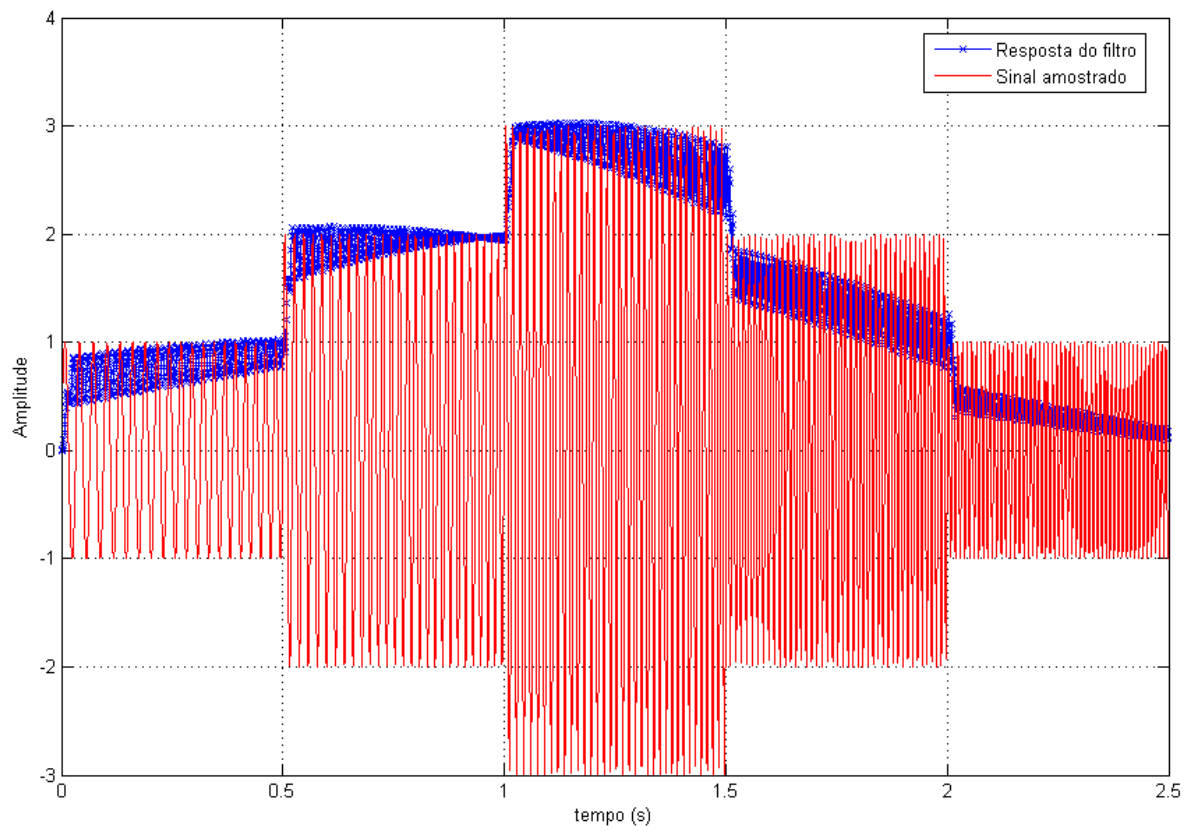

Fig. 59. Comportamento de filtros calculados somente para $60 \mathrm{~Hz}$ ao sinal da figura 57 


\subsubsection{Comportamento frente a componente exponencial amortecida e a}

\section{harmônicos}

Inicialmente serão avaliados curtos-circuitos afastados do gerador, onde não se percebe o efeito das reatâncias transitória e subtransitória.

Sinais com fundamental de 40, 60 e $70 \mathrm{~Hz}$, com componente exponencial e em algumas situações com harmônicos servirão de teste para o AIVF, neste item.

Para as fundamentais de 40, 60 e $70 \mathrm{~Hz}$, as seguintes situações serão testadas:

a) Fundamental e componente exponencial amortecida;

b) Fundamental, componente exponencial amortecida e $20 \%$ de terceiro e quinto harmônicos;

c) Fundamental, componente exponencial amortecida e 5\% de segundo harmônico.

Para fundamental de $40 \mathrm{~Hz}$, tem-se:

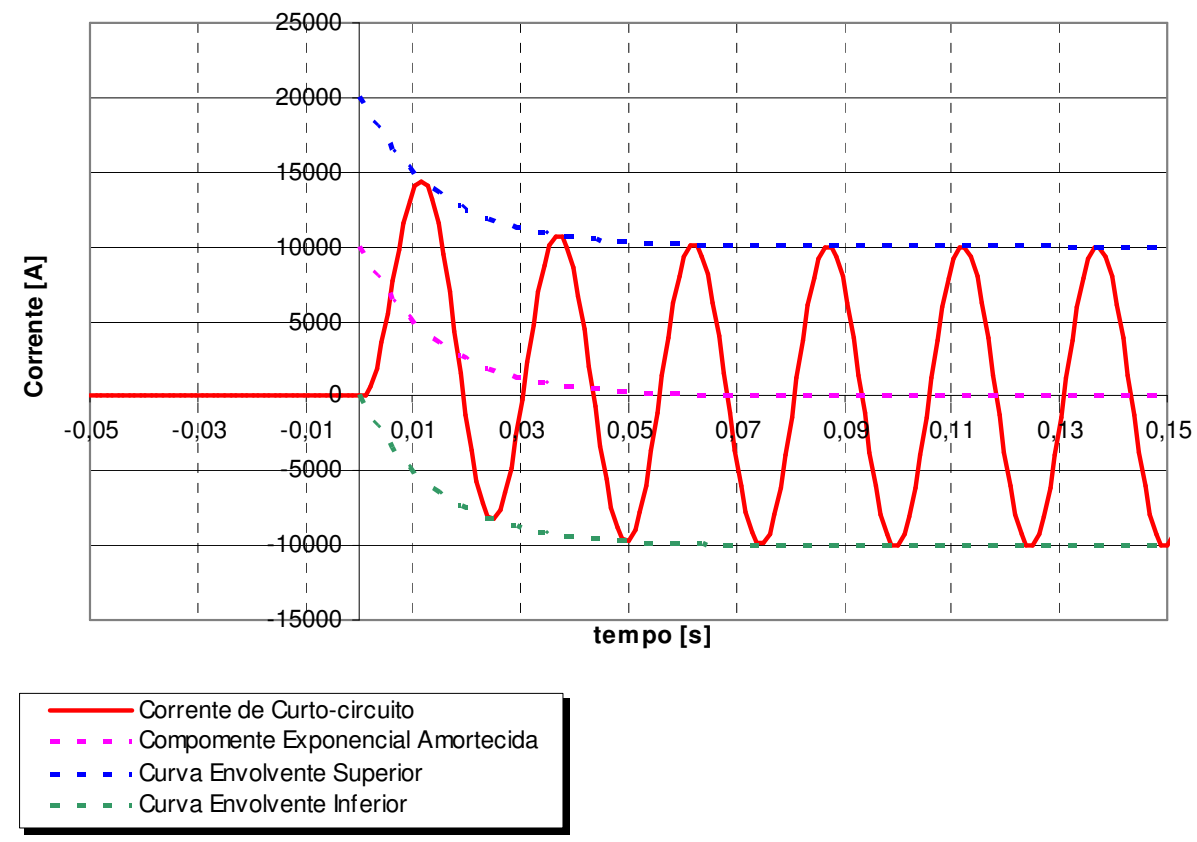

Fig. 60. Forma de onda teste com fundamental de $40 \mathrm{~Hz}$ e componente exponencial amortecida 
$\mathrm{Na}$ figura 59 tem-se a resposta do AIVF.

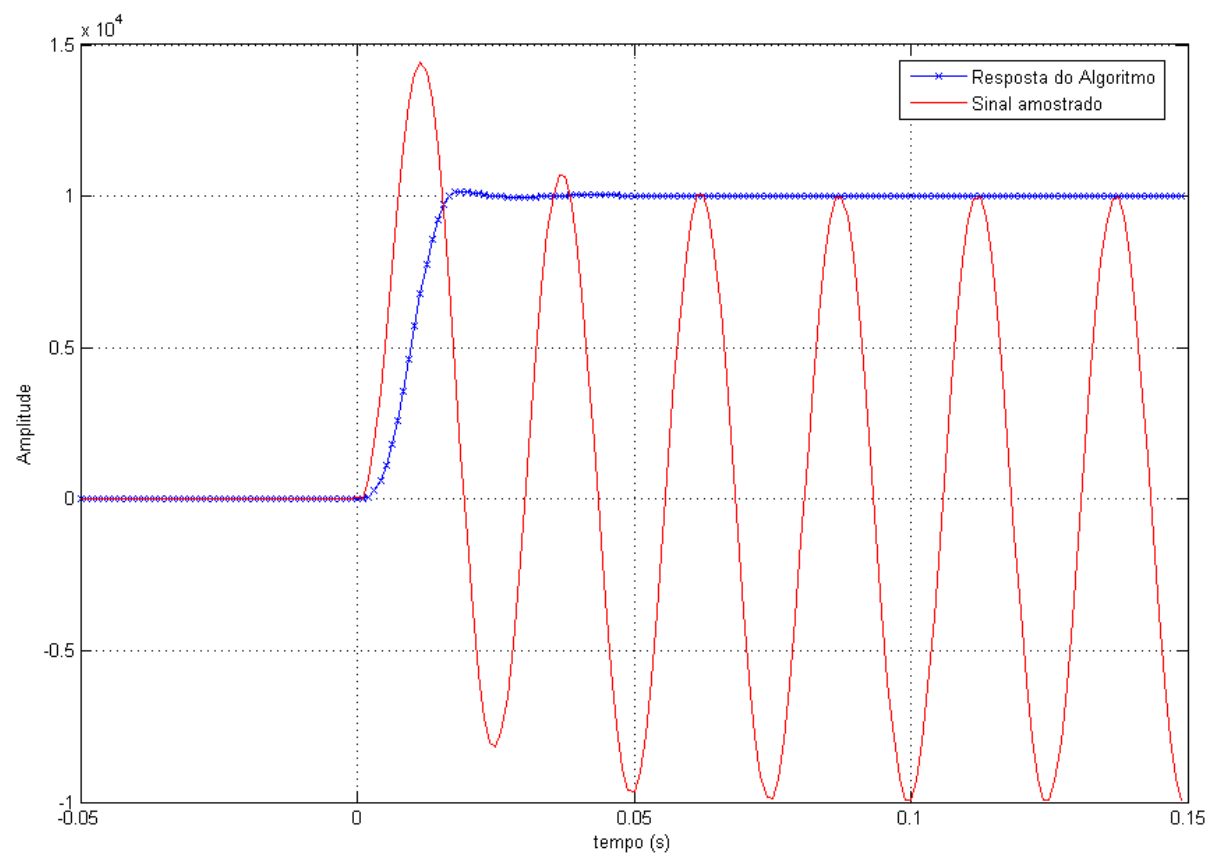

Fig. 61. Resposta do AIVF ao sinal representado na figura 60

Da figura 61 verifica-se atenuação da componente exponencial amortecida e um erro máximo na avaliação da amplitude menor do que $1 \%$.

Adicionando-se $20 \%$ de terceiro e quinto harmônicos à forma de onda teste da figura 60, tem-se a seguinte resposta do AIVF. 


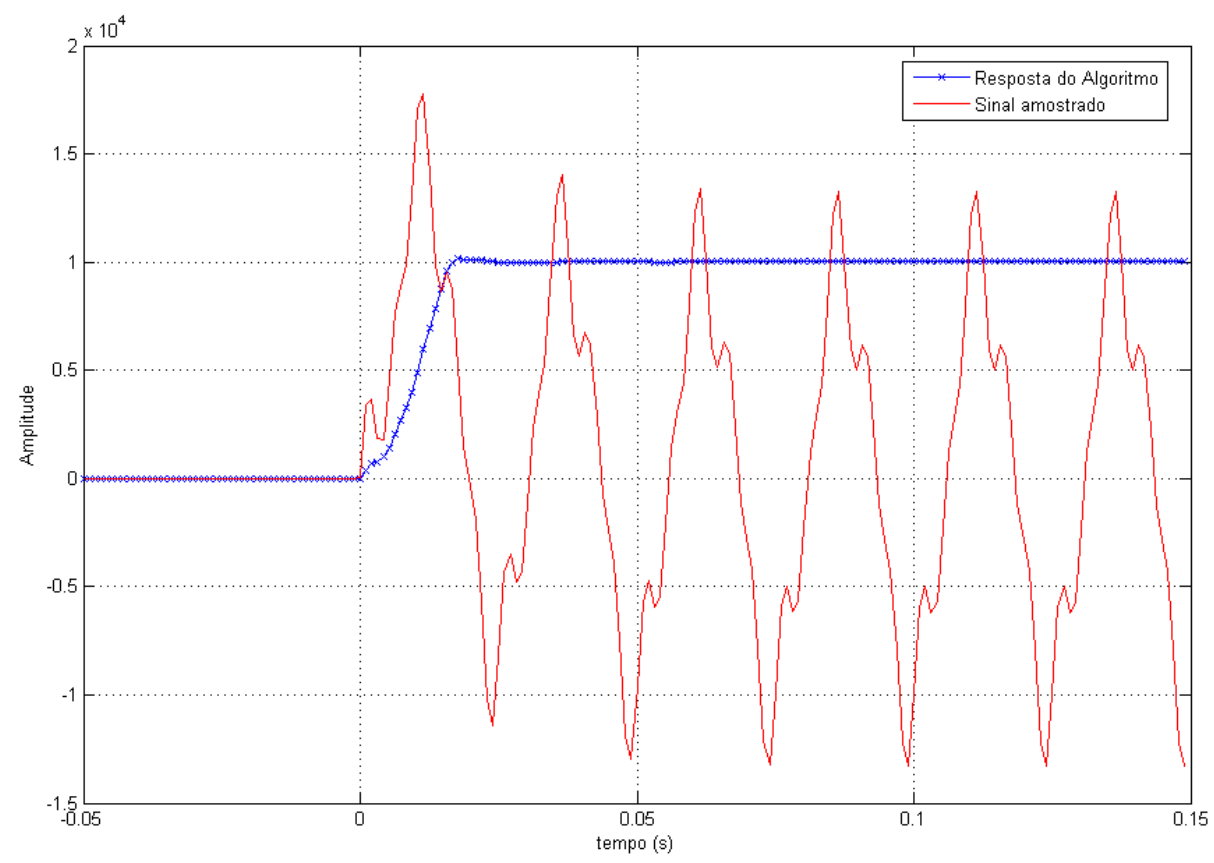

Fig. 62. Resposta do AIVF ao sinal representado na figura 60 adicionado de $20 \%$ do terceiro e quinto harmônicos

Da figura 62 verifica-se a atenuação total do terceiro e quinto harmônicos. O erro devido a componente exponencial amortecida manteve-se.

Adicionando-se $5 \%$ de segundo harmônico à forma de onda teste da figura 60 , temse a seguinte resposta do AIVF. 


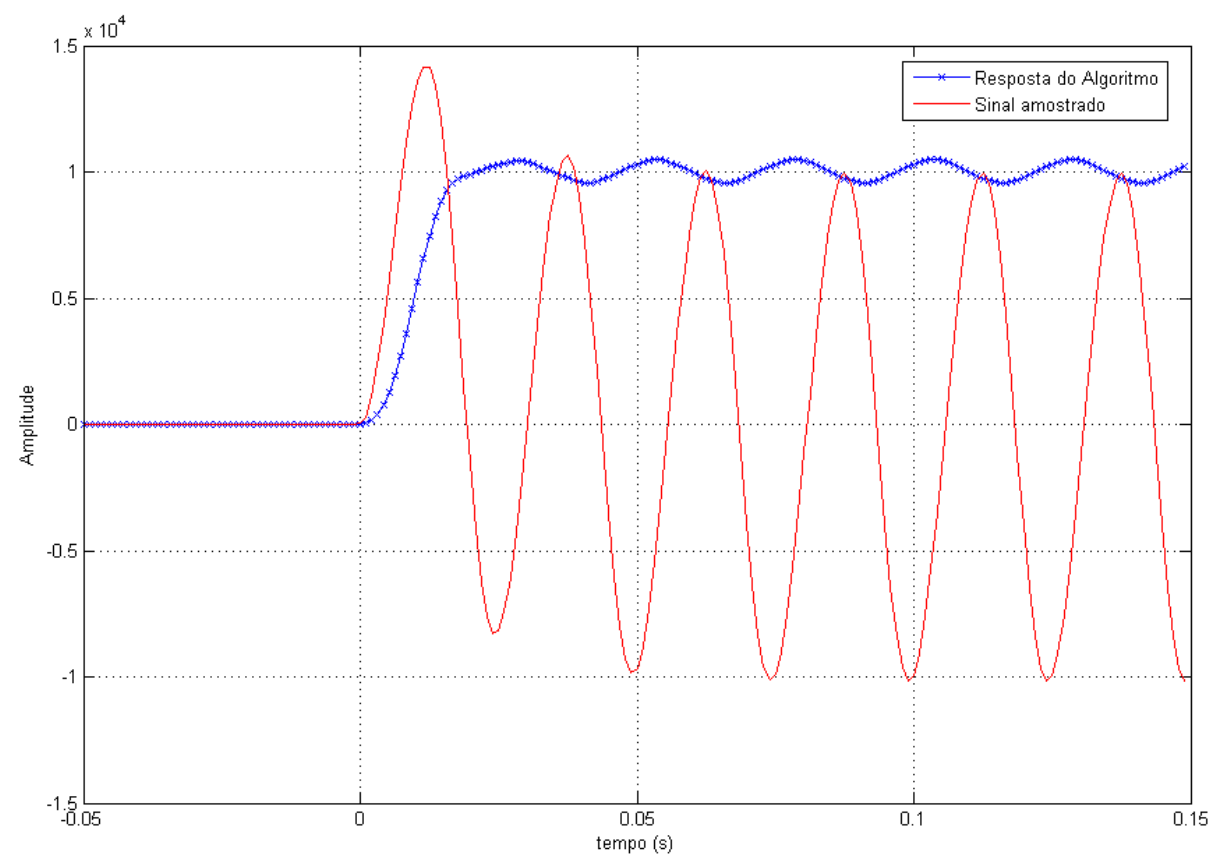

Fig. 63. Resposta do AIVF ao sinal representado na figura 58 adicionado de 5\% do segundo harmônico

Da figura 63 verifica-se a sensibilidade ao segundo harmônico; 5\% de segundo harmônico levou a uma oscilação no cálculo da amplitude que, juntamente com o efeito produzido pela componente exponencial amortecida, levou a um erro máximo de aproximadamente 5\%. A sensibilidade à segunda harmônica é maior nos filtros projetados para as frequiências mais baixas, como pode ser observado nas respostas em freqüência das figuras 49 e 50 . Para as freqüências próximas ao $60 \mathrm{~Hz} \mathrm{a}$ atenuação que os filtros impõem à segunda harmônica é bastante satisfatória como será mostrado nas simulações a seguir. 
Para fundamental de $60 \mathrm{~Hz}$, tem-se:
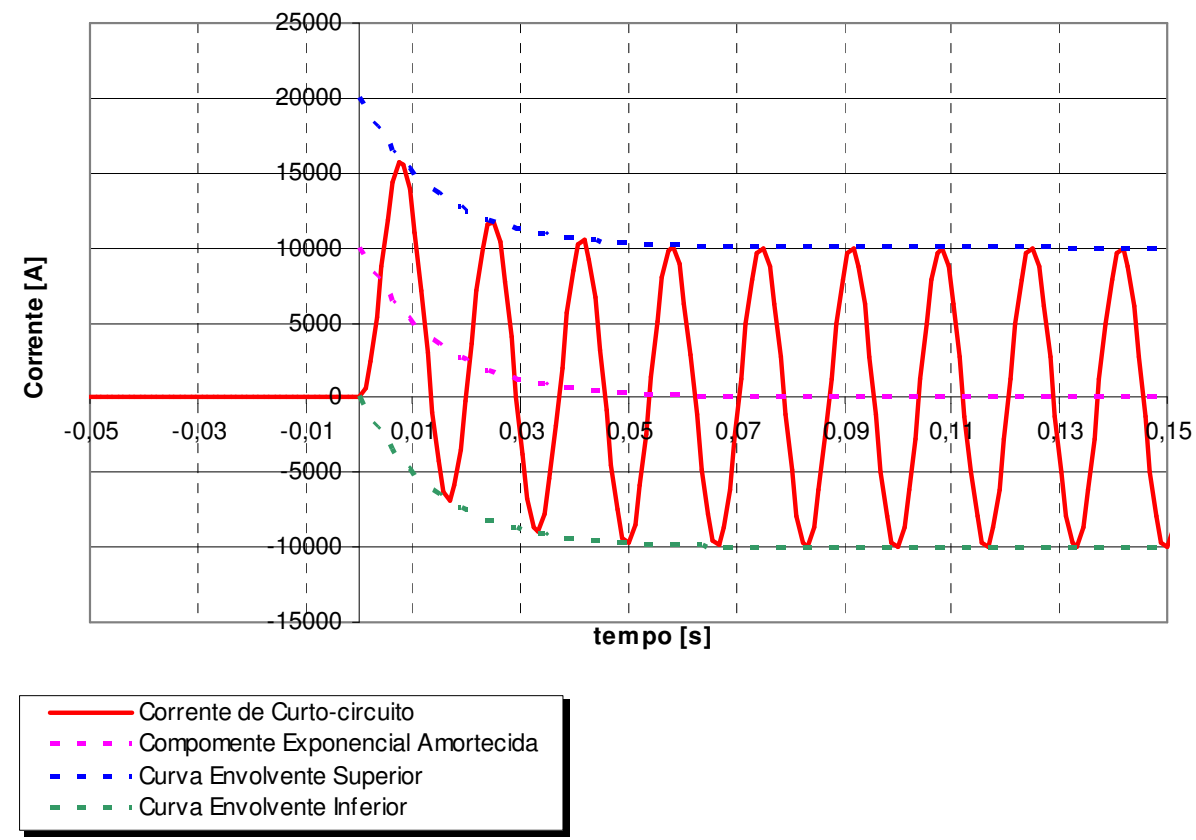

Fig. 64. Forma de onda teste com fundamental de $60 \mathrm{~Hz}$ e componente exponencial amortecida

$\mathrm{Na}$ figura 65 tem-se a resposta do AIVF.

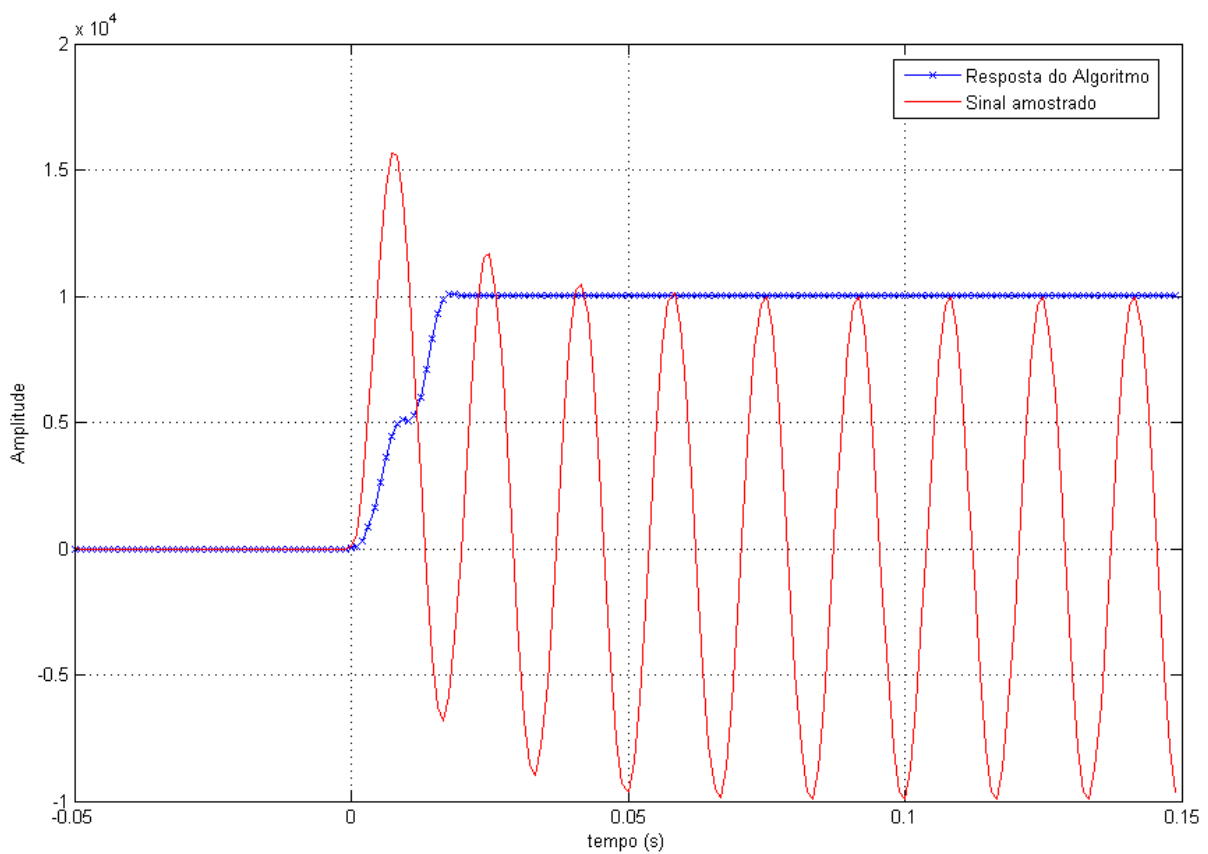

Fig. 65. Resposta do AIVF ao sinal representado na figura 64 
Da figura 65 verifica-se atenuação da componente exponencial amortecida e um erro máximo na avaliação da amplitude menor do que $1 \%$.

Adicionando-se $20 \%$ de terceiro e quinto harmônicos à forma de onda teste da figura 64, tem-se a seguinte resposta do AIVF.

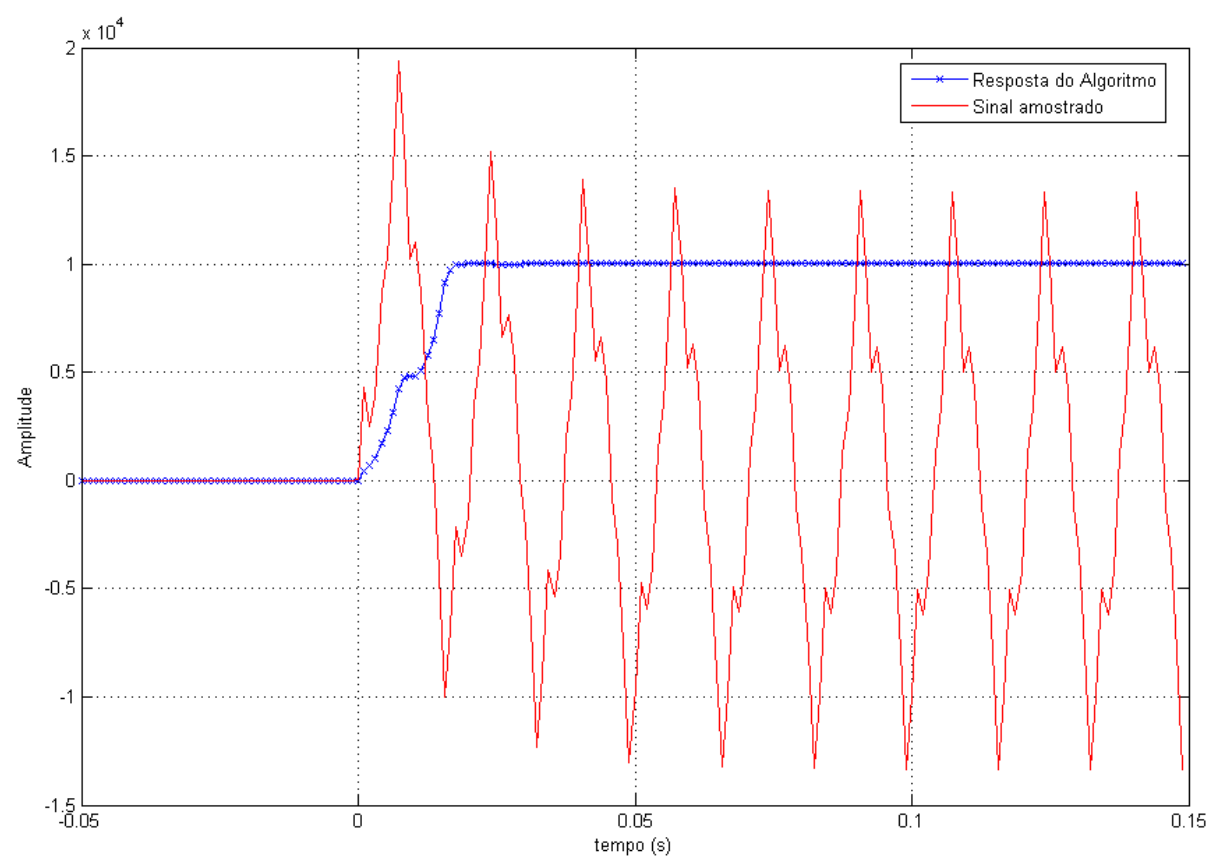

Fig. 66. Resposta do AIVF ao sinal representado na figura 64 adicionado de $20 \%$ do terceiro e quinto harmônicos

Da figura 66 verifica-se a atenuação total do terceiro e quinto harmônicos. O erro devido a componente exponencial amortecida manteve-se.

Adicionando-se 5\% de segundo harmônico à forma de onda teste da figura 64, temse a seguinte resposta do AIVF. 


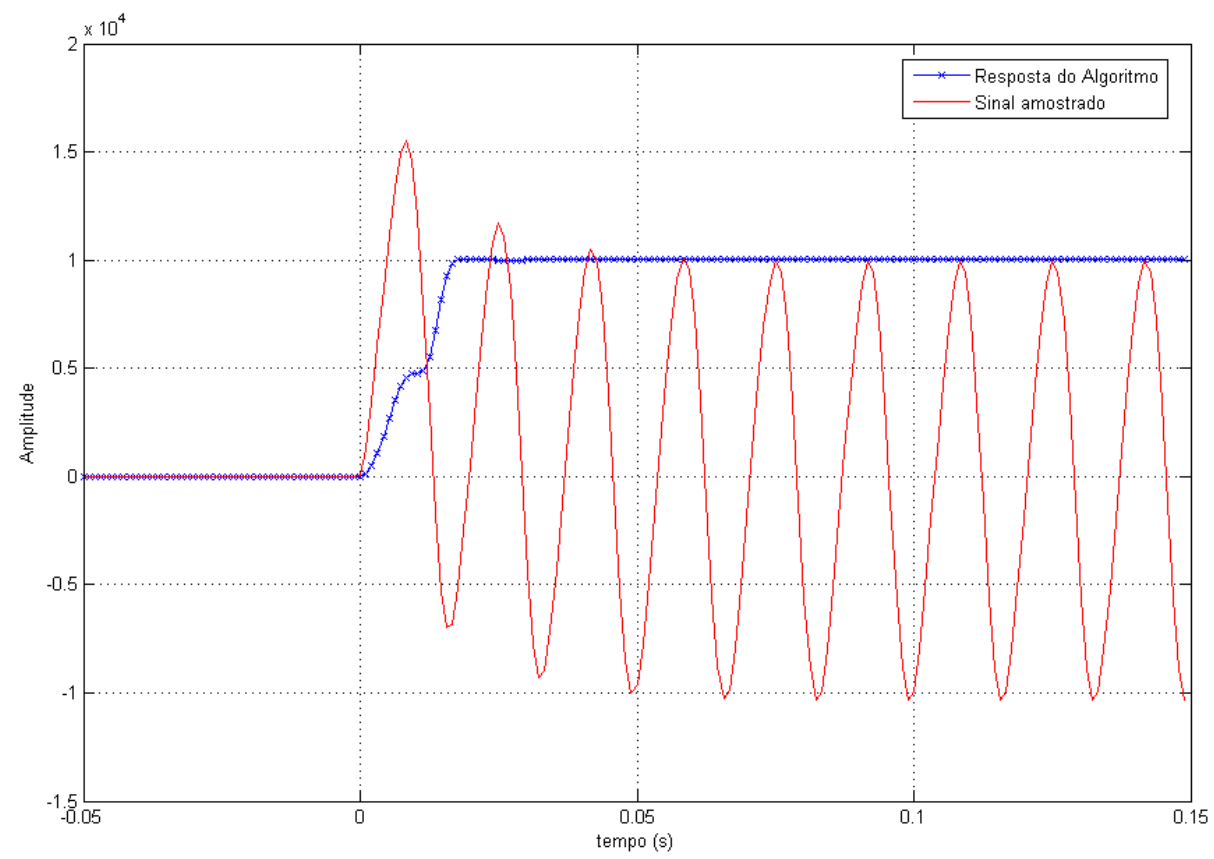

Fig. 67. Resposta do AIVF ao sinal representado na figura 64 adicionado de 5\% do segundo harmônico

Da figura 65 verifica-se a atenuação do segundo harmônico, como pôde ser observado na resposta em frequiência (figuras 49 e 50). A atenuação do segundo harmônico se deu naturalmente para esta freqüência $(60 \mathrm{~Hz})$.

O erro devido a componente exponencial amortecida manteve-se. 
Para fundamental de $70 \mathrm{~Hz}$, tem-se:

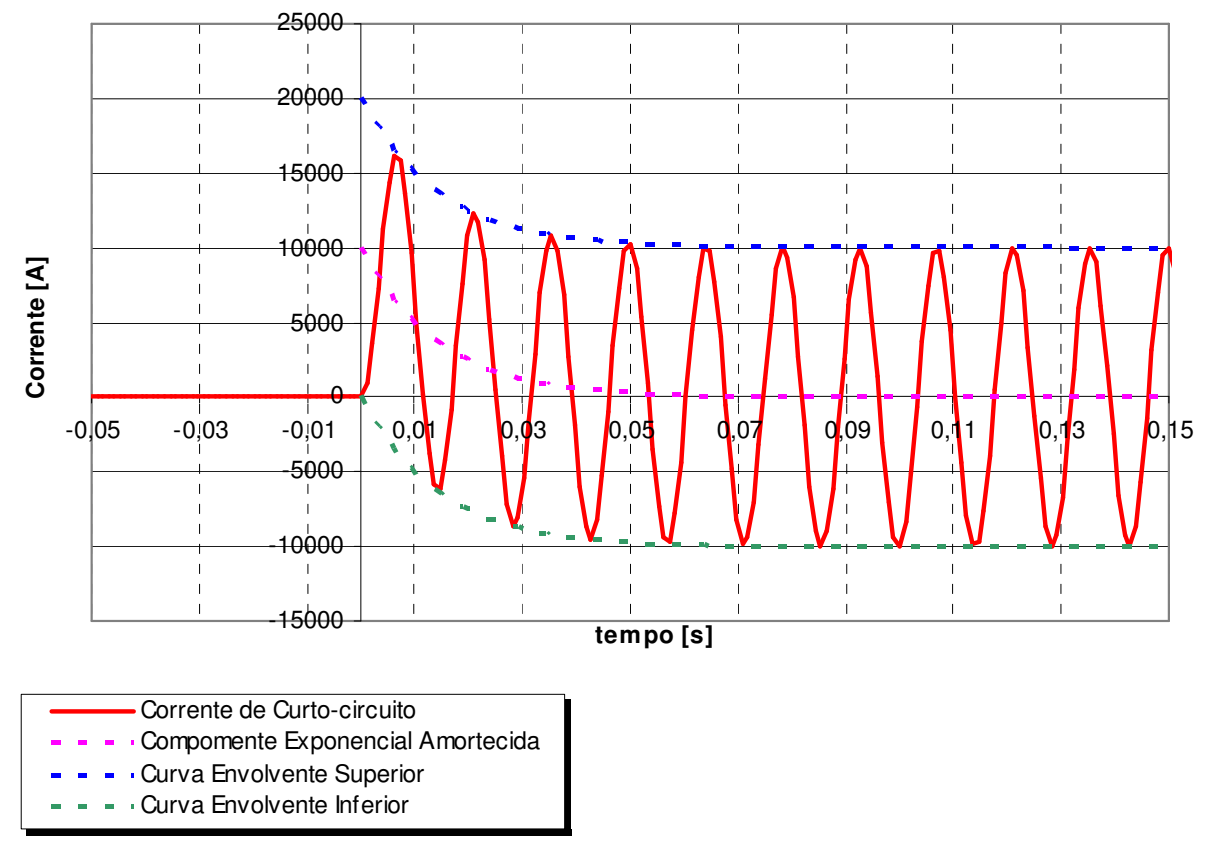

Fig. 68. Forma de onda teste com fundamental de $70 \mathrm{~Hz}$ e componente exponencial amortecida

Na figura 69 tem-se a resposta do AIVF.

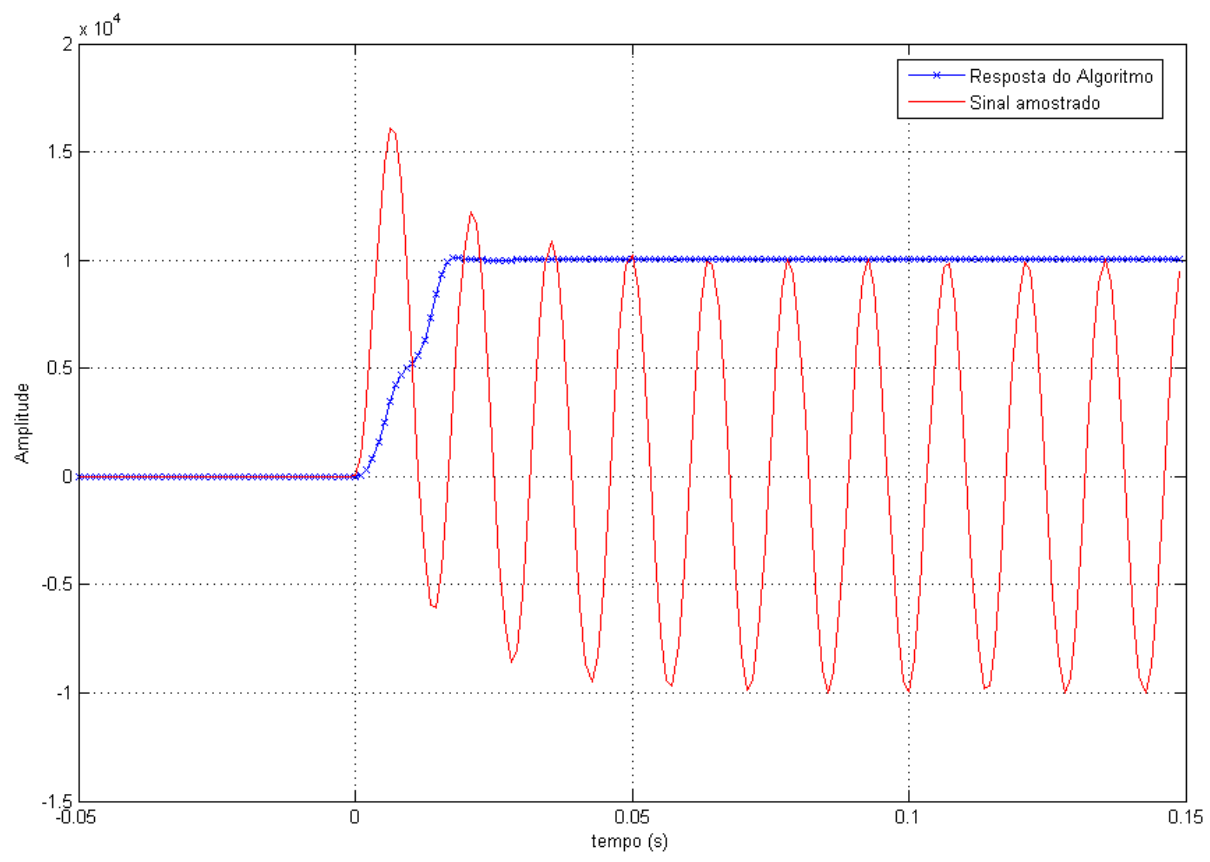

Fig. 69. Resposta do AIVF ao sinal representado na figura 68 
Da figura 69 verifica-se atenuação da componente exponencial amortecida e um erro máximo na avaliação da amplitude menor do que $1 \%$.

Adicionando-se $20 \%$ de terceiro e quinto harmônicos à forma de onda teste da figura 68, tem-se a seguinte resposta do AIVF.

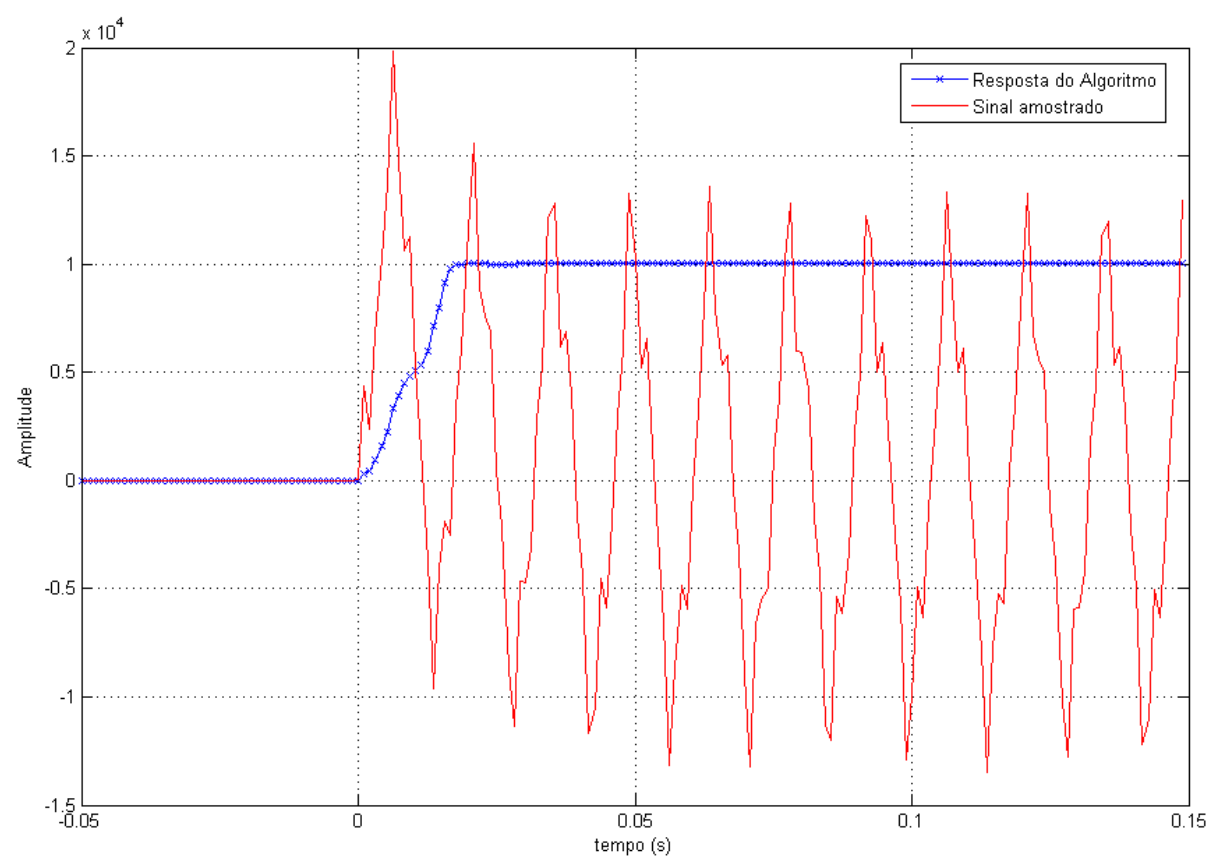

Fig. 70. Resposta do AIVF ao sinal representado na figura 68 adicionado de $20 \%$ de terceiro e quinto harmônicos

Da figura 70 verifica-se a atenuação total do terceiro e quinto harmônicos. O erro devido a componente exponencial amortecida manteve-se.

Adicionando-se 5\% de segundo harmônico à forma de onda teste da figura 68 , temse a seguinte resposta do AIVF. 


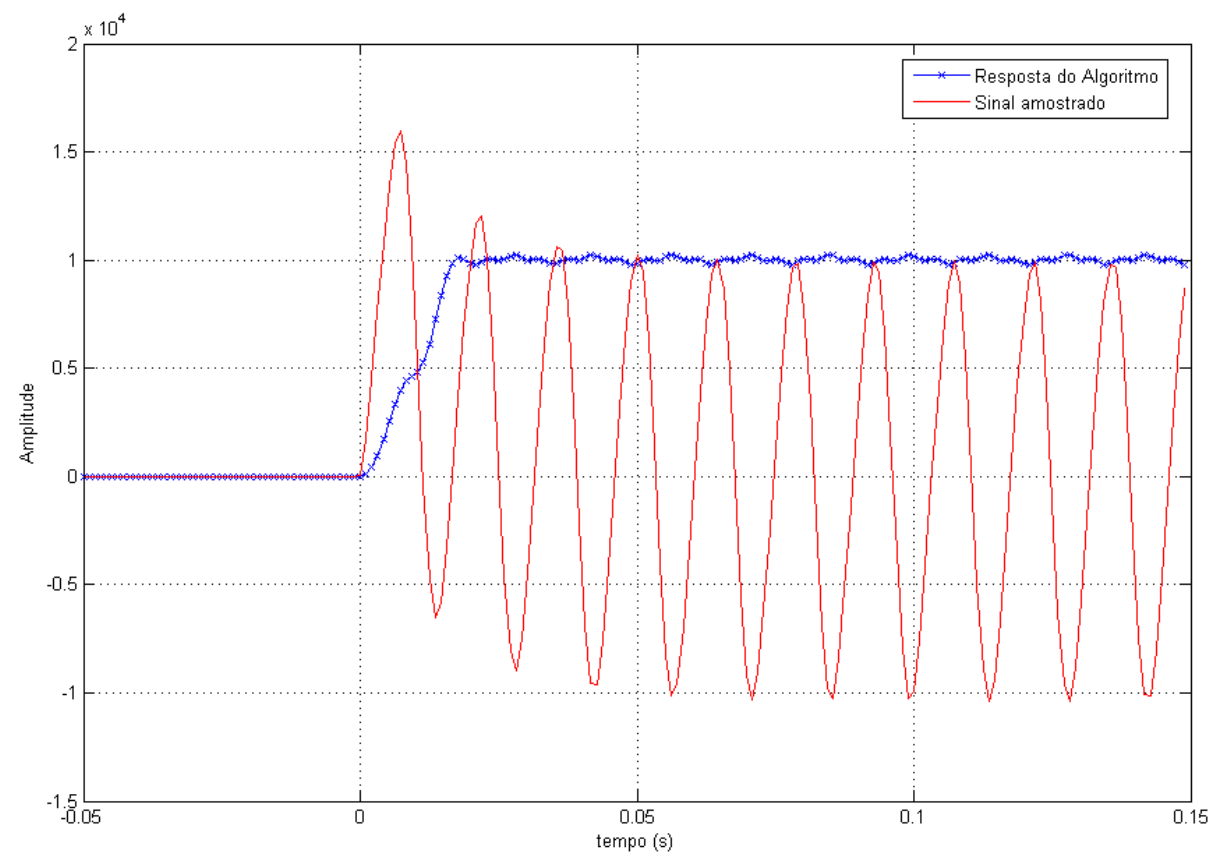

Fig. 71. Resposta do AIVF ao sinal representado na figura 68 adicionado de $5 \%$ de segundo harmônico

Da figura 71 verifica-se pequena sensibilidade ao segundo harmônico. A presença deste harmônico levou a uma pequena oscilação no cálculo da amplitude, conduzindo a um erro máximo de aproximadamente 2,5\%. 
Visando observar o comportamento do AIVF a sinais característicos de curto-circuito nos terminais de um gerador, duas formas de onda serão avaliadas:

a) Curto circuito com fundamental de $50 \mathrm{~Hz}$, sem componente exponencial amortecida e;

b) Curto circuito com fundamental de $50 \mathrm{~Hz}$, com componente exponencial amortecida.

Os dados principais do gerador são:

$$
\begin{aligned}
& \mathrm{S}=7,35 \mathrm{MVA} \\
& \mathrm{V}=600 \mathrm{~V} \\
& \mathrm{Xd}=1 \text { p.u. } \\
& \mathrm{Xd} \mathrm{d}^{\prime}=0,6 \mathrm{p} . \mathrm{u} . \\
& \mathrm{Xd}=0,35 \mathrm{p} . \mathrm{u} . \\
& \text { Td" }=17,5 \mathrm{~ms} \\
& \mathrm{Td} d^{\prime}=30 \mathrm{~ms} \\
& \mathrm{Tg}=26 \mathrm{~ms}
\end{aligned}
$$

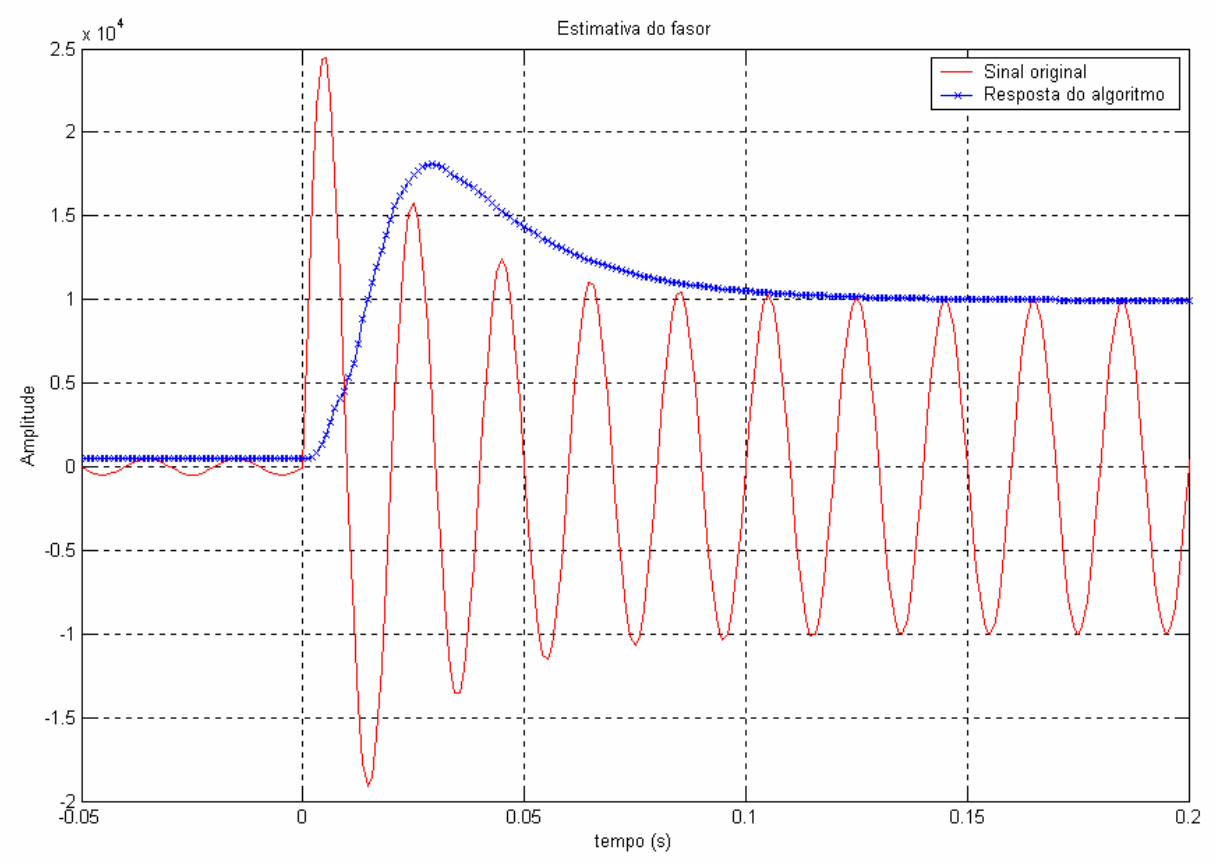

Fig. 72. Reposta do AIVF a um curto-circuito nos terminais do gerador, com fundamental de $50 \mathrm{~Hz}$ 
Veja que no caso de curto-circuitos nos terminais de um gerador, o valor da corrente que circula imediatamente após a ocorrência da falta, o valor que circula após uns poucos ciclos e o valor sustentado ou de regime permanente, diferem consideravelmente devido ao efeito da corrente do estator (armadura) sobre o fluxo gerado pelo enrolamento de campo (reação da armadura).

Deste efeito, configuram-se três períodos distintos que são o período subtransitório, transitório e sustentado do curto-circuito.

O AIVF neste caso conseguiu perceber a mudança na amplitude do sinal, como pode ser observado na figura 72.

Na figura 73 o AIVF é submetido ao mesmo sinal anterior acrescentando-se porém uma componente exponencial amortecida. Comparando-se a figura 72 e 73 , a resposta do AIVF é praticamente a mesma, o que evidencia a atenuação da componente exponencial amortecida.

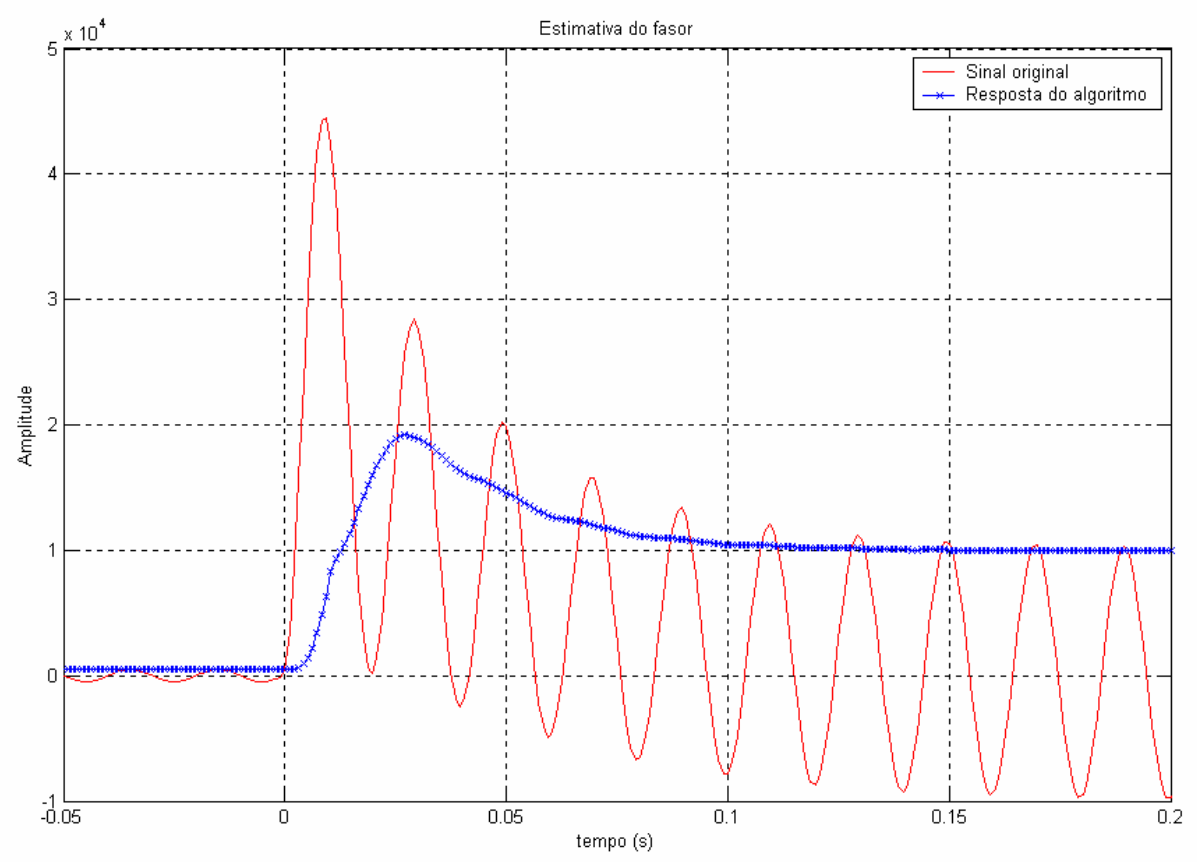

Fig. 73. Reposta do AIVF a um curto-circuito nos terminais do gerador, com fundamental de $50 \mathrm{~Hz}$ e componente exponencial amortecida 


\subsection{CONCLUSÕES}

Inicialmente foram apresentados aspectos inerentes à proteção de geradores como aterramento e principais proteções recomendadas para geradores de até 50MVA.

O propósito principal deste trabalho, entretanto, é a investigação de um algoritmo que busca minimizar os erros no cálculo dos fasores do sistema de potência quando há variação na freqüência fundamental dos sinais.

Esses erros ocorrem quando se utilizam algoritmos baseados no método de Fourier, com freqüência de amostragem fixa, e existe uma excursão significativa da freqüência fundamental do sinal. Isto ocorre porque os filtros baseados no método de Fourier são projetados considerando um número inteiro e conhecido de amostras por ciclo. Quando há variação na freqüência do sinal, o número de amostras pro ciclo varia, acarretado erros significativos na estimativa dos fasores.

Relés para proteção de geradores com grande penetração no mercado mundial utilizam freqüência de amostragem variável, tentando manter constante o número de amostras por ciclo na faixa de freqüências em que os geradores podem operar. Este método implica na utilização de um hardware diferenciado dos demais relés de proteção permitindo a amostragem variável.

Tomando como base os trabalhos de Sidhu e Sachdev [17, 18] que descrevem uma técnica iterativa de recálculo dos coeficientes dos filtros digitais, permitindo compensação dos erros a partir de uma freqüência de amostragem constante, foi proposto e desenvolvido a aplicação do método dos mínimos quadrados para recálculo dos filtros e a utilização de filtros de média para amplitude e frequiência visando melhores resultados. O algoritmo foi então chamado de AIVF (Algoritmo Inume a Variações de Freqüências).

No capítulo 4.4 o comportamento do AIVF foi investigado para uma série de sinais com variação de freqüência e amplitude.

Verificou-se que algoritmos convencionais que não corrigem as variações de freqüência, sub-avaliam a amplitude do fasor referente à componente fundamental dos sinais, podendo levar à não atuação de algumas das funções de proteção que utilizam esses resultados. 
O atraso do algoritmo, verificado nas simulações foi de aproximadamente 20 amostras que representam, para as condições simuladas 20,8ms; o que pode ser considerado satisfatório.

Vale observar que o AIVF foi testado, neste trabalho, para sinais com características de freqüência e amplitude variando com uma dinâmica que muitas vezes não pode ser encontrada em situações reais. Mesmo assim demonstrou estabilidade e bom desempenho.

O AIVF também apresentou resultados satisfatórios frente a sinais com componente exponencial e harmônicos, para diferentes freqüências de fundamental. Cabendo somente uma ressalva quanto à sensibilidade ao segundo harmônico para sinais com freqüência abaixo de $50 \mathrm{~Hz}$. 


\section{ANEXOS}

\section{ANEXO A: SÉRIE DE FOURIER}

Sendo s(t) uma função periódica com período To, ela pode ser representada por uma série de Fourier como segue:

$s(t)=\frac{a_{0}}{2}+\sum_{k=1}^{\infty} A_{k} \cos \left(k \omega_{0} t+\phi_{k}\right) \quad k \in Z$

Expandindo a eq. a1, tem-se:

$$
s(t)=\frac{a_{0}}{2}+\sum_{k=1}^{\infty} \underbrace{A_{k} \cos \phi_{k}}_{a_{k}} \cos \left(k \omega_{0} t\right) \underbrace{-A_{k} \operatorname{sen} \phi_{k}}_{b_{k}} \operatorname{sen}\left(k \omega_{0} t\right)
$$

Sendo:

$$
\begin{aligned}
& A_{k}=\sqrt{a_{k}^{2}+b_{k}^{2}} \\
& \phi_{k}=\operatorname{tg}^{-1}\left(\frac{-b_{k}}{a_{k}}\right)
\end{aligned}
$$

Onde:

$$
\begin{aligned}
& \frac{a_{0}}{2}=\frac{2}{T_{0}} \int_{0}^{T_{0}} s(t) d t \\
& a_{k}=\frac{2}{T_{0}} \int_{0}^{T_{0}} s(t) \cos \left(k \omega_{0} t\right) d t \\
& b_{k}=\frac{2}{T_{0}} \int_{0}^{T_{0}} s(t) \operatorname{sen}\left(k \omega_{0} t\right) d t
\end{aligned}
$$

As equações a.6 e a.7 são conhecidas como a forma trigonométrica ou real da série de Fourier. Esta série também pode ser escrita da forma complexa, como segue.

Sendo:

$$
\cos \left(k \omega_{0} t\right)=\frac{1}{2}\left(e^{j k \omega_{0} t}+e^{-j k \omega_{0} t}\right)
$$


$\operatorname{sen}\left(k \omega_{0} t\right)=\frac{1}{2 j}\left(e^{j k \omega_{0} t}-e^{-j k \omega_{0} t}\right)$

De eq. a8 e eq. a9 na eq. a2, tem-se:

$$
s(t)=\underbrace{\frac{a_{0}}{2}}_{C_{0}}+\sum_{k=1}^{\infty}[\underbrace{\frac{1}{2}\left(a_{k}-j b_{k}\right)}_{C_{k}} e^{j k \omega_{0} t}+\underbrace{\frac{1}{2}\left(a_{k}+j b_{k}\right)}_{C_{-k}} e^{-j k \omega_{0} t}]
$$

Admitindo-se a possibilidade de existirem freqüências negativas, a expressão da série de Fourier pode ser escrita mais sucintamente como representado na eq. 25.

$$
s(t)=C_{0}+\sum_{k=-\infty}^{\infty} C_{k} e^{j k \omega_{0} t}
$$

Sendo,

$$
C_{k}=\frac{1}{T_{0}} \int_{0}^{T_{0}} s(t) e^{-j k \omega_{0} t} d t
$$

As equações a11 e a12 são conhecidas como a forma complexa de Fourier.

Veja que $\left|C_{k}\right|=A_{k} / 2$ e que $\phi_{k}=\angle C_{k}$. 
Como o algoritmo de filtragem deve tratar com valores amostrados dos sinais do sistema de potência, a adaptação da série de Fourier a esta característica é desejável.

Aproximando-se o cálculo de $\mathrm{C}_{\mathrm{k}}$ a partir do método de Euler com $\mathrm{dt} \rightarrow \mathrm{T}_{\mathrm{A}}, \mathrm{t}=\mathrm{nT}_{\mathrm{A}} \mathrm{e}$ $\mathrm{To}=\mathrm{NT}_{\mathrm{A}}$, tem-se:

$C_{k} \cong \frac{1}{N} \sum_{l=0}^{N-1} s(n-(N-1)+l) e^{-j k \frac{2 \pi}{N} l}$

A partir da expansão da eq. a13, pode-se extrair a componente fundamental de qualquer sinal amostrado $(\mathrm{k}=1)$, da seguinte forma:

$$
A_{1} \angle \phi_{1}=[\underbrace{\frac{2}{N} \sum_{l=0}^{N-1} s(n-(N-1)+l) \cos \left(\frac{2 \pi}{N} l\right)}_{Y_{C}}-j \underbrace{\frac{2}{N} \sum_{l=0}^{N-1} s(n-(N-1)+l) \operatorname{sen}\left(\frac{2 \pi}{N} l\right)}_{Y_{S}}]
$$

Portanto:

$$
\begin{aligned}
& A_{1} \angle \phi_{1}=Y_{C}-j Y_{S} \\
& A_{1}=\sqrt{Y_{C}^{2}+Y_{S}^{2}} \quad \text { e } \quad \phi_{1}=\operatorname{tg}^{-1}\left(\frac{-Y_{S}}{Y_{C}}\right)
\end{aligned}
$$




\section{ANEXO B: MÉTODO DOS MÍNIMOS QUADRADOS}

Seja um sistema de equações com mais equações do que incógnitas $A x=b$, onde $\mathrm{x}$ é o vetor das incógnitas e A e b são conhecidos.

Considerando o seguinte exemplo:

$$
\left[\begin{array}{cc}
1 & 0 \\
1 & -1 \\
0 & 1
\end{array}\right]\left[\begin{array}{l}
x_{1} \\
x_{2}
\end{array}\right]=\left[\begin{array}{c}
5 / 4 \\
-1 / 4 \\
3 / 4
\end{array}\right]
$$

A primeira linha é satisfeita por $\mathrm{x}_{1}=5 / 4$ e a terceira por $\mathrm{x}_{2}=3 / 4$. Resulta para a segunda linha:

$1 / 2$ “=” $-1 / 4$

Como esta situação não é admissível, deve-se reconhecer que existe um erro na solução do sistema de equações, podendo-o reescrever como:

$A x+e=b$, sendo $e=b-A x$

Para a solução apresentada, $e=\left[\begin{array}{c}0 \\ -3 / 4 \\ 0\end{array}\right]$.

O método dos mínimos quadrados fornece a solução que minimiza a soma dos quadrados dos erros, isto é, fornece x tal que a soma dos quadrados dos erros $\left(e^{T} e\right)$ é mínimo.

$$
\begin{aligned}
& e^{T} e=(b-A x)^{T}(b-A x) \\
& e^{T} e=\left(b^{T}-x^{T} A^{T}\right)(b-A x) \\
& e^{T} e=x^{T} A^{T} A x-x^{T} A^{T} b-b^{T} A x+b^{T} b
\end{aligned}
$$


$\mathrm{O} \times$ que minimiza $e^{T} e$ pode ser obtido calculando as derivadas parciais da eq. $1 \mathrm{~b}$ com relação a componente de x e igualando a zero como demonstrado em [20]. O resultado é:

$x=\left(A^{T} A\right)^{-1} A^{T} b$

Sendo $\left(A^{T} A\right)^{-1} A^{T}$ denominada a matriz pseudoinversa de A.

Para o exemplo considerado, tem-se:

$$
\begin{aligned}
& \left(A^{T} A\right)^{-1} A^{T}=\left\{\left[\begin{array}{ccc}
1 & 1 & 0 \\
0 & -1 & 1
\end{array}\right]\left[\begin{array}{cc}
1 & 0 \\
1 & -1 \\
0 & 1
\end{array}\right]\right\}^{-1}\left[\begin{array}{ccc}
1 & 1 & 0 \\
0 & -1 & 1
\end{array}\right] \\
& \left(A^{T} A\right)^{-1} A^{T}=\frac{1}{3}\left[\begin{array}{ccc}
2 & 1 & 1 \\
1 & -1 & 2
\end{array}\right] \\
& x=\frac{1}{3}\left[\begin{array}{ccc}
2 & 1 & 1 \\
1 & -1 & 2
\end{array}\right]\left[\begin{array}{c}
5 / 4 \\
-1 / 4 \\
3 / 4
\end{array}\right]=\left[\begin{array}{l}
1 \\
1
\end{array}\right] \\
& e=b-A x=\left[\begin{array}{c}
1 / 4 \\
-1 / 4 \\
-1 / 4
\end{array}\right]
\end{aligned}
$$

Coincidentemente os erros do exemplo anterior têm a mesma magnitude, entretanto é razoável assumir que eles devam ter aproximadamente a mesma magnitude, pois o procedimento minimiza a soma do quadrado de todos os erros. 
ANEXO C: COEFICIENTES DOS FILTROS UTILIZADOS

\begin{tabular}{|c|c|c|c|c|c|c|c|c|c|}
\hline & \multicolumn{7}{|c|}{ YC - Coeficientes } & \multicolumn{2}{|c|}{$\mathrm{a}_{6}$} \\
\hline Freq. [Hz] & $\mathrm{a}_{0}$ & $\mathrm{a}_{1}$ & $\mathrm{a}_{2}$ & $\mathrm{a}_{3}$ & $\mathrm{a}_{4}$ & $\mathrm{a}_{5}$ & $\mathrm{a}_{8}$ \\
\hline 30 & 0.1250 & 0.1226 & 0.1155 & 0.1039 & 0.0884 & 0.0694 & 0.0478 & 0.0244 & 0.0000 \\
\hline 35 & 0.0826 & 0.0742 & 0.0920 & 0.1106 & 0.1018 & 0.0640 & 0.0200 & -0.0105 & -0.0316 \\
\hline 40 & 0.1015 & 0.0715 & 0.0653 & 0.0725 & 0.0684 & 0.0421 & 0.0024 & -0.0400 & -0.0834 \\
\hline 45 & 0.1088 & 0.0820 & 0.0766 & 0.0640 & 0.0352 & 0.0047 & -0.0292 & -0.0833 & -0.1440 \\
\hline 50 & 0.1169 & 0.0901 & 0.0853 & 0.0595 & 0.0242 & -0.0042 & -0.0604 & -0.1466 & -0.1880 \\
\hline 55 & 0.1343 & 0.0905 & 0.0935 & 0.0578 & 0.0032 & -0.0139 & -0.0645 & -0.1622 & -0.1810 \\
\hline 60 & 0.1250 & 0.1155 & 0.0884 & 0.0478 & 0.0000 & -0.0478 & -0.0884 & -0.1155 & -0.1250 \\
\hline 70 & 0.0917 & 0.1070 & 0.0987 & 0.0331 & -0.0144 & -0.0710 & -0.1192 & -0.0998 & -0.0971 \\
\hline & $0.1003-$ & 0.0821 & 0.0800 & 0.0297 & -0.0366 & -0.0994 & 0.1270 & -0.0951 & -0.0828 \\
\hline
\end{tabular}




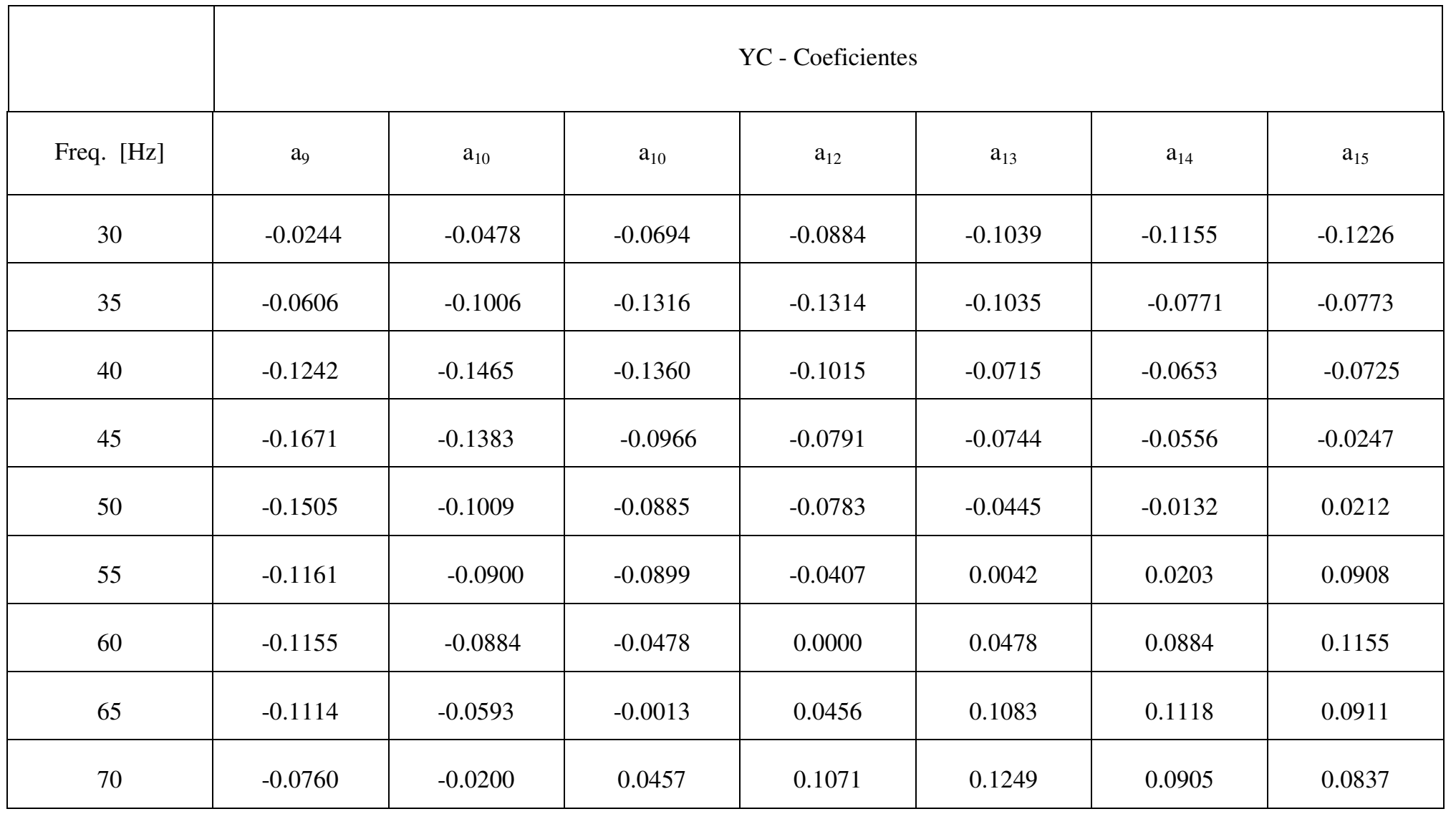




\begin{tabular}{|c|c|c|c|c|c|c|c|c|c|}
\hline & \multicolumn{9}{|c|}{ YS - Coeficientes } \\
\hline Freq. $[\mathrm{Hz}]$ & $\mathrm{b}_{0}$ & $b_{1}$ & $\mathrm{~b}_{2}$ & $\mathrm{~b}_{3}$ & $\mathrm{~b}_{4}$ & $\mathrm{~b}_{5}$ & $\mathrm{~b}_{6}$ & $\mathrm{~b}_{7}$ & $\mathrm{~b}_{8}$ \\
\hline 30 & -0.0000 & -0.0244 & -0.0478 & -0.0694 & -0.0884 & -0.1039 & -0.1155 & -0.1226 & -0.1250 \\
\hline 35 & 0.0060 & -0.0211 & -0.0533 & -0.0881 & -0.1177 & -0.1358 & -0.1427 & -0.1433 & -0.1402 \\
\hline 40 & -0.0011 & -0.0208 & -0.0359 & -0.0710 & -0.1239 & -0.1651 & -0.1732 & -0.1580 & -0.1400 \\
\hline 45 & $0.0072-$ & -0.0332 & -0.0545 & -0.0632 & -0.0903 & -0.1431 & -0.1835 & 0.1758 & -0.1308 \\
\hline 50 & -0.0016 & -0.0313 & -0.0624 & -0.0917 & -0.0951 & -0.1020 & -0.1414 & -0.1625 & -0.1121 \\
\hline 55 & 0.0073 & -0.0480 & -0.0714 & -0.1001 & -0.1189 & -0.1051 & -0.0972 & -0.1010 & -0.0613 \\
\hline 60 & 0.0000 & -0.0478 & -0.0884 & -0.1155 & -0.1250 & -0.1155 & -0.0884 & -0.0478 & 0.0000 \\
\hline 65 & 0.0018 & -0.0537 & -0.1025 & -0.1295 & -0.1339 & -0.1157 & -0.0744 & -0.0226 & 0.0322 \\
\hline 70 & -0.0004 & -0.0400 & -0.1050 & -0.1484 & -0.1370 & -0.1128 & -0.0532 & 0.0067 & 0.0473 \\
\hline
\end{tabular}




\begin{tabular}{|c|c|c|c|c|c|c|c|}
\hline & \multicolumn{7}{|c|}{ YS - Coeficientes } \\
\hline 30 & -0.1226 & -0.1155 & -0.1039 & -0.0884 & -0.0694 & -0.0478 & -0.0244 \\
\hline 35 & -0.1308 & -0.1113 & -0.0831 & -0.0522 & -0.0243 & 0.0014 & 0.0297 \\
\hline 40 & -0.1208 & -0.0870 & -0.0393 & 0.0011 & 0.0208 & 0.0359 & 0.0710 \\
\hline 45 & -0.0812 & -0.0370 & 0.0074 & 0.0429 & 0.0574 & 0.0688 & 0.1062 \\
\hline 60 & 0.0478 & 0.0884 & 0.1155 & 0.1250 & 0.1155 & 0.0884 & 0.0478 \\
\hline 65 & 0.0857 & 0.1221 & 0.1347 & 0.1257 & 0.0923 & 0.0429 & -0.0108 \\
\hline 70 & 0.1148 & 0.1490 & 0.1342 & 0.1069 & 0.0428 & -0.0123 & -0.0554 \\
\hline
\end{tabular}




\begin{tabular}{|c|c|c|c|c|c|}
\hline \multirow{5}{*}{} & \multicolumn{5}{|c|}{ Filtro para a componente exponencial amortecida } \\
\hline Freq. [Hz] & $\mathrm{a}_{0}$ & $\mathrm{a}_{1}$ & $\mathrm{a}_{2}$ & $\mathrm{a}_{3}$ & $\mathrm{a}_{4}$ \\
\hline 30 & 1.3638 & 0 & 0 & 0 & -1.2289 \\
\hline 35 & 1.1827 & 0 & 0 & 0 & -1.0657 \\
\hline 40 & 1.0478 & 0 & 0 & 0 & -0.9441 \\
\hline 45 & 0.9439 & 0 & 0 & 0 & -0.8506 \\
\hline 50 & 0.8621 & 0 & 0 & 0 & -0.7768 \\
\hline 55 & 0.7964 & 0 & 0 & 0 & -0.7176 \\
\hline 60 & 0.7429 & 0 & 0 & 0 & -0.5970 \\
\hline
\end{tabular}




\section{REFERÊNCIAS BIBLIOGRÁFICAS}

[1] 7UM62 Multifunction Generator, Motor and Transformer Relay - Manual, C53000-G1176-C149-3 - SIEMENS;

[2] DGP - Digital Generator Protection Relay ${ }^{\mathrm{TM}}$ - Instruction Manual, V210.32000P - GE INDUSTRIAL SYSTEMS;

[3] SEL-300G Instruction Manual, Date Code 20030225, SCHWEITZER ENGINEERING LABORATORIES, INC;

[4] LGPG111 Integrated Protection Relay - Service Manual, R5942B, ALSTOM;

[5] G. Benmouyal, "An Adaptative Sampling-Interval Generator for Digital Relaying," IEEE Transactions on Power Delivery, Vol. 4, Nº 3, July 1989;

[6] T. Sezi, “A New Method for Measuring Power System Frequency," 0-7803-5515-6/99 - IEEE;

[7] P. Crossley, S. Haslam, N. Jenkins, "Evaluation of a New Type of Protection Relay for Wind Farms;"

[8] P. V. Indiresan, S. S. Murthy, "Generating Electrical Power form Wave Energy," CH2781-3/89/0000-2121 - 1989 IEEE;

[9] R. M. G. Castro, A. E. Gomes, J. M. F. de Jesus, "Transient Behaviour of an Induction Generator in Small Hydro Plants;" 
[10] IEEE Std. C62.92.1-2000, "IEEE Guide for the Application of Neutral Grounding in Electrical Utility Systems - Part I: Introduction;”

[11] IEEE C62.92-1989, "IEEE Guide for the Application of Neutral Grounding in Electrical Utility Systems - Part II: Grounding of Synchronous Generator Systems;"

[12] Siemens, "Application Notes on Generator Protection Schemes," 11/2002, www. siprotec.com;

[13] IEEE C37.102-1995, "IEEE Guide for AC Generator Protection;"

[14] R. H. Regan, K. Wakeley, "Rotor Monitoring and Protection for Large Generators," Electrica Machines and Drives 11-13 September 1995, Conference Publication No. 412, IEE;

[15] IEEE C37.106-1987, "IEEE Guide for Abnormal Frequency Protection for Power Generating Plants;"

[16] L. B. Jackson, "Digital Filters and Signal Processing," Kluwer Academic Publishers, 4a. Edição 1990;

[17] T. S. Sidhu, M. S. Sachdev, "An Iterative Technique for Fast and Accurate Measurement of Power System Frequency," IEEE Transactions on Power Delivery, Vol. 13, No. 1, January 1998;

[18] T. S. Sidhu, "Accurate Measurement of Power System Frequency Using a Digital Signal Processing Technique," IEEE Transactions on Instrumentation and Measurement, Vol. 48, No. 1, February 1999;

[19] D. Hart, D. Novosel, Y. Hu, B. Smith, M. Egolf, “A New Frequency Tracking and Phasor Estimation Algorithm for Generator," IEEE Trans. on Power Delivery, Vol. 12, N. 3, July 1997; 
[20] A. G. Phadke, J. S. Thorp, “Computer Relaying for Power Systems,” Research Studies Press Ltd., 1990;

[21] E. C. Senger, "Análise do registrador de longa duração Reason - RP-IV," Relatório 1, versão 0;

[22] J.-L. Lescourret, "Method and means for measuring the frequency of a periodic signal," US patent No 4.866.260, September 12, 1989;

[23] M. M. Giray, M. S. Sachdev, "Off-nominal frequency measurements in electric power system," IEEE Trans. on Power Delivery, Vol. 4, No. 3, July, 1989;

[24] A. G. Phadke, J. Thorp, and M. Adamiak, "A new measurement technique for tracking voltage phasors, local system frequency and rate of change of frequency," IEEE Trans. Power Apparat. Syst., vol. 102, No 5, pp. 1025-1038, 1983;

[25] N. N. de Santana, E. C. Senger, "Pré-filtragem da componente aperiódica exponencial para os algoritmos utilizados em relés de distância”. 